\title{
The Construction of Memory in the Present City of Mississauga
}

\author{
by
}

Michael Duric

A thesis submitted to the Faculty of Graduate and Postdoctoral Affairs in partial fulfillment of the requirements for the degree of

\author{
Master of Architecture
}

Carleton University

Ottawa, Ontario

(C) 2018, Michael Duric 


\section{A B S T R A C T}

This thesis explores how memory plays an important part in the identity of cities, and questions how do our collective memories define a sense of place over time? Focusing on the founding villages within the city of Mississauga, Ontario, this thesis looks at the forgotten identities of its early settlements. Working alongside existing site conditions, and through the design of architectural installations, I intend to design "memory triggers" that activate the presence of surviving elements, such as building fragments, photographic materials, concealed remains, and transmedia stories that can engage the residents and the visitors with a memory of the past that is constructed in the present, providing unique experiences that inform a meaningful present. Eventually, my aim is to construct images of the past into the future based on the few remnants of these lost towns, embodied in various physical forms, in various sites, in a way that will establish their place within the city as a whole. 


\section{A C K N O W L E D G M E N T S}

I would like to express my gratitude to my advisor, Federica Goffi, for the guidance provided throughout the past year, this has truly been a wonderful experience.

To my sister, who has always supported me along the way, and to my parents who have provided me with the opportunity to better myself, I thank you.

To the friendships I have established over the years, I thank you for the encouragement and laughter along the way.

Michael Duric 


\section{T A B L E OF C O N T E N T S}

$\begin{array}{lc}\text { ABSTRACT } & \text { II } \\ \text { ACKNOWLEDGMENTS } & \text { III } \\ \text { TABLE OF CONTENTS } & \text { IV } \\ \text { LIST OF ILLUSTRATIONS } & \text { V I } \\ \text { INTRODUCTION } & 10\end{array}$

PART I

HISTORY OF MISSISSAUGA 16

$\begin{array}{ll}\text { SENSE OF PLACE } & 20\end{array}$

HISTORY OF DIXIE

PART II

MEMORY 29

RESTORATION 31

PROCESS OF COLLECTING 37 


\section{T A B L E OF C O N T E N T S}

\section{PART III}

$\begin{array}{lc}\text { POSTCARDS } & 44 \\ \text { INSTALLATIONS } & 70 \\ \text { ROOM } & 90 \\ \text { CONCLUSION } & 95 \\ \text { REFERENCES } & 97 \\ \text { ENDNOTES } & 100\end{array}$




\section{I S T O F I L L U S T R A T I O N S}

Figure 1: Photo courtesy of The Corporation of the City of Mississauga C. www.mississauga.ca

Figure 2: Photo courtesy of The Corporation of the City of Mississauga C. Www. mississauga.ca

Figure 3: Photo courtesy of The Corporation of the City of Mississauga $\mathbb{C}$. www. mississauga.ca

Figure 4: Photo courtesy of The Corporation of the City of Mississauga C. Www. mississauga.ca

Figure 5: Photo courtesy of The Corporation of the City of Mississauga $\mathbb{C}$. Www.mississauga.ca

Figure 6: Photo courtesy of The Corporation of the City of Mississauga C. Www. mississauga.ca

Figure 7: Photo courtesy of The Corporation of the City of Mississauga $\mathbb{C}$. www. mississauga.ca

Figure 8: Illustration by Author, Original Photo courtesy of The Corporation of the City of Mississauga C. www.mississauga.ca

Figure 9: Illustration by Author, Original Photo courtesy of The Corporation of the City of Mississauga (C). www.mississauga.ca

Figure 10: Illustration by Author, Original Photo courtesy of The Corporation of the City of Mississauga(C. www.mississauga.ca

Figure 11: Illustration by Author, Original Photo courtesy of The Corporation of the City of Mississauga $($. www.mississauga.ca

Figure 12: Illustration by Author, Original Photo courtesy of The Corporation of the City of Mississauga (C). www.mississauga.ca 


\section{I S T O F I L L U S T R A T I O N S}

Figure 13: Illustration by Author, Original Photo courtesy of The Corporation of the City of Mississauga C. www.mississauga.ca

Figure 14: Illustration by Author, Original Photo courtesy of The Corporation of the City of Mississauga(C. www.mississauga.ca

Figure 15: Photo by Author Figure 16: Illustration by Author Figure 17: Photo by Author, Original Photo courtesy of The Corporation of the City of Mississauga (C) www. mississauga.ca

Figure 18: Illustration by Author, Original Photo courtesy of The Corporation of the City of Mississauga ( . www.mississauga.ca

Figure 19: Photo by Author

Figure 20: Photo by Author

Figure 21: Illustration by Author, Original Photo courtesy of The Corporation of the City of Mississauga(C. www.mississauga.ca

Figure 22: Illustration by Author, Original Photo courtesy of The Corporation of the City of Mississauga ( . www.mississauga.ca

Figure 23: Illustration by Author, Original Photo courtesy of The Corporation of the City of Mississauga (C). www.mississauga.ca

Figure 24: Illustration by Author, Original Photo courtesy of The Corporation of the City of Mississauga (C). www.mississauga.ca 


\section{I S T O F I L L U S T R A T I O N S}

Figure 25: Illustration by Author, Original Photo courtesy of The Corporation of the City of Mississauga (C). www.mississauga.ca

Figure 26: Illustration by Author, Original Photo courtesy of The Corporation of the City of Mississauga(C. www.mississauga.ca

Figure 27: Illustration by Author, Original Photo courtesy of The Corporation of the City of Mississauga C. Www.mississauga.ca

Figure 28: Illustration by Author, Original Photo courtesy of The Corporation of the City of Mississauga (C). www.mississauga.ca

Figure 29: Illustration by Author, Original Photo courtesy of The Corporation of the City of Mississauga (C). www.mississauga.ca

Figure 30: Illustration by Author, Original Photo courtesy of The Corporation of the City of Mississauga (C) www.mississauga.ca

Figure 31: Illustration by Author, Original Photo courtesy of The Corporation of the City of Mississauga (C). www.mississauga.ca

Figure 32: Illustration by Author, Original Photo courtesy of The Corporation of the City of

Mississauga (C). www.mississauga.ca

Figure 33: Illustration by Author

Figure 34: Illustration by Author

Figure 35: Photo by Author

Figure 36: Photo by Author

Figure 37: Illustration by Author 


\section{I S T O F I L L U S T R A T I O N S}

Figure 38: Illustration by Author Figure 39: Illustration by Author Figure 40: Photo by Author Figure 41: Illustration by Author Figure 42: Illustration by Author Figure 43: Illustration by Author Figure 44: Photo by Author Figure 45: Illustration by Author Figure 46: Illustration by Author Figure 47: Illustration by Author Figure 48: Illustration by Author Figure 49: Illustration by Author Figure 50: Illustration by Author, Original Photo found at; bearded-architect.tumblr.com, Author unknown

Figure 51: Photo by Author Figure 52: Photo by Author Figure 53: Photo by Author 


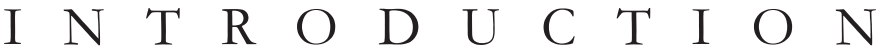

A memory is something that is remembered from the past; a personal memory is something that a person can recall from a period in their own life. Individual memories can offer a glimpse into a person's earlier life, they can remind one about a moment when they felt joy, sadness, fear, or anger. While the memory itself, cannot be accessed through any physical means, they can however be associated with a physical location in the world. Villages and Cities provide their own unique memories, which are constructed over time, creating their own multicultural identities. As people live and die in these settlements, they ultimately pass on their own memories onto the sites they inhabited. As time goes on, additional memories could be associated with individual sites and locations, but through the destruction of buildings and new site expansion these memories seem to have instead fallen out of touch with the current setting, and eventually became almost entirely forgotten.

Focusing my gaze towards the future of the city of Mississauga, my intention is to construct over and with the fragments of the memories 
and identities of the towns that helped create the city as we know it, even when they were almost completely effaced and at times erased. As Mississauga grew from the amalgamation of several villages and towns, the city rapidly grew as a post-war suburb. Lying west of Toronto, the newly formed city provided abundant farm land ready for new development. While new development and infrastructure helped with the expansion of the city, it also risked losing the existing towns and their identities. Many of the founding towns and villages have lost a great deal of what could have become their heritage, through the loss of historic buildings, and with the new developments these once small villages have lost the characters and the elements that define their past present identities, which failed to become a memory to the degree in which many of these buildings are no longer existent. They have neither been altered, nor adapted to a new use, but have been simply done away with.

Since much of the villages have lost the elements that help form their own heritage, I choose to define heritage as what the individual deems of value or importance. The standard definition defines heritage through; its character-defining elements, elements like materials, forms, location or even cultural associations all help create a sense of heritage ${ }^{1}$. While the standard definition provides an overarching 
description, it does not take individual experiences or histories into account. As the project would not deal with typical existing conditions, it would rely heavily on the memories of the early inhabitants.

Guided by the loss of memory, I find myself closely attached to the topic of my thesis. As someone who grew up in Mississauga, many of my fondest memories occurred while living and growing up in the city. While I can still be reminded of individual memories that occurred in my lifetime, I question what is the legacy of those who came before me? What were the memories of the original inhabitants of these towns? Did they not also wish to leave a legacy as well? I cannot answer these questions as the past is not accessible, much like the memories themselves. I can however shed some light upon the memories and retrace the spaces and locations they used to inhabit. Perhaps this question can only be answered from a present condition, relying on archival research, and the remapping of lost structures against the current layer of built form in the city. I intend to provide memory triggers that help engage the residents and visitors, with a memory of the past. Eventually, my aim is to construct the memories of these lost towns in a way that will help establish their place within the city as a whole. One of the major approaches involved 
the technique of transmedia storytelling; which combines multiple elements and media formats to construct a collective narrative. The technique is commonly interpreted through branding, or marketing, but it has the potential to provide an architectural approach to represent content across multiple platforms. ${ }^{2}$ In this way, I used the approach to allow my thesis to be understood through various designed elements, much like the memories of the founding villages, which appeared in parts, the thesis is displayed in the same manner. 
$I$

PART I

HISTORY OF MISSISSAUGA

SENSE OF PLACE

PROCESS OF COLLECTING 


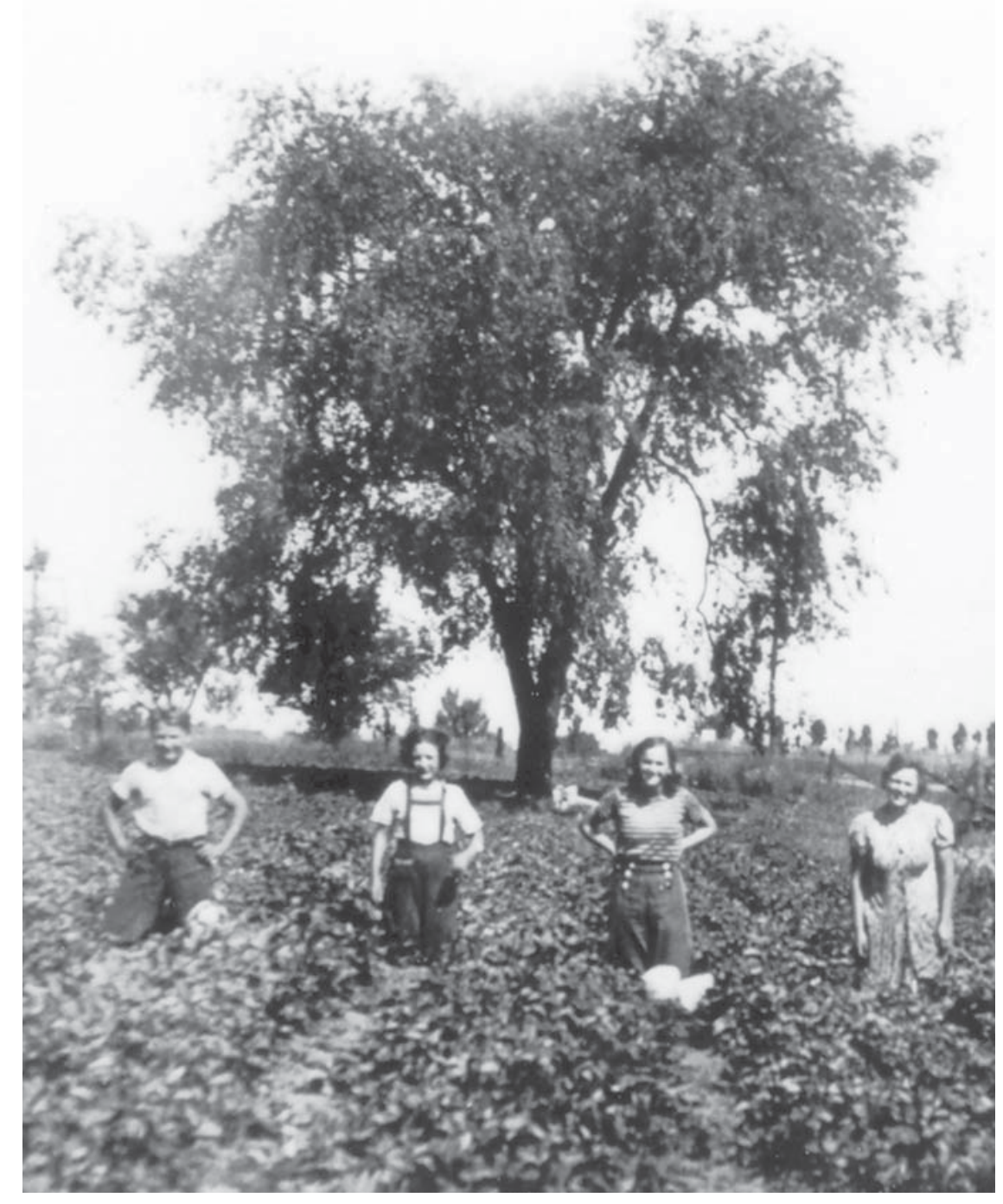

Figure 1: Kennedy Farm, Dixie, c.1915 


\section{H I S T O R Y O F M I S I S S A G A}

In the last 50 years, the city of Mississauga, Ontario has undergone significant change to its landscape through its rapid development of

abundant farm land into the bustling suburb it is today. Lying just west of Toronto and sharing the shoreline along Lake Ontario, Mississauga evolved from the amalgamation of several small towns and villages to form Canada's sixth largest city. While the age of the city is still relatively young, the villages that helped create the city have a richer history amongst them. Officially declaring itself a city in 1976, Mississauga joined the towns of Clarkson, Cooksville, Dixie, Erindale, Lakeview, Lorne Park, Malton, Meadowvale Village, Port Credit, and Streetsville.

Mississauga itself traces back to before European settlement, where The Mississaugas were an Ojibwa band of aboriginal people living in and around the many rivers along Lake Ontario. Even the city's name is of aboriginal origin, where "Mississauga" translates to: River of the North of Many Mouths. Between 1805 and 1820 many treaties were signed between the British crown and the Mississauga people, which 
surrendered much of the land that now encompasses the region and its neighboring counties. As time went on, settlements began to develop throughout the new surveys and eventually the Mississauga people relocated in 1847. Aside from the ten villages that now define the city, Mississauga used to house many different villages within its borders. While certain villages grew and evolved over time, others declined into disappearance altogether. ${ }^{3}$

Focusing on the founding villages that have remained, the aim of this project is to construct the identities of the towns seeding the memories that helped create the city as we know it. Many of the founding villages have lost great portions of their heritage, through the loss of historic buildings, and due to new developments, these once small villages have lost the characteristics and elements that defined their identities, and would have sediment their memories. Looking forward, the thesis aims to inspire a more critical approach to the heritage of our historical centers. 


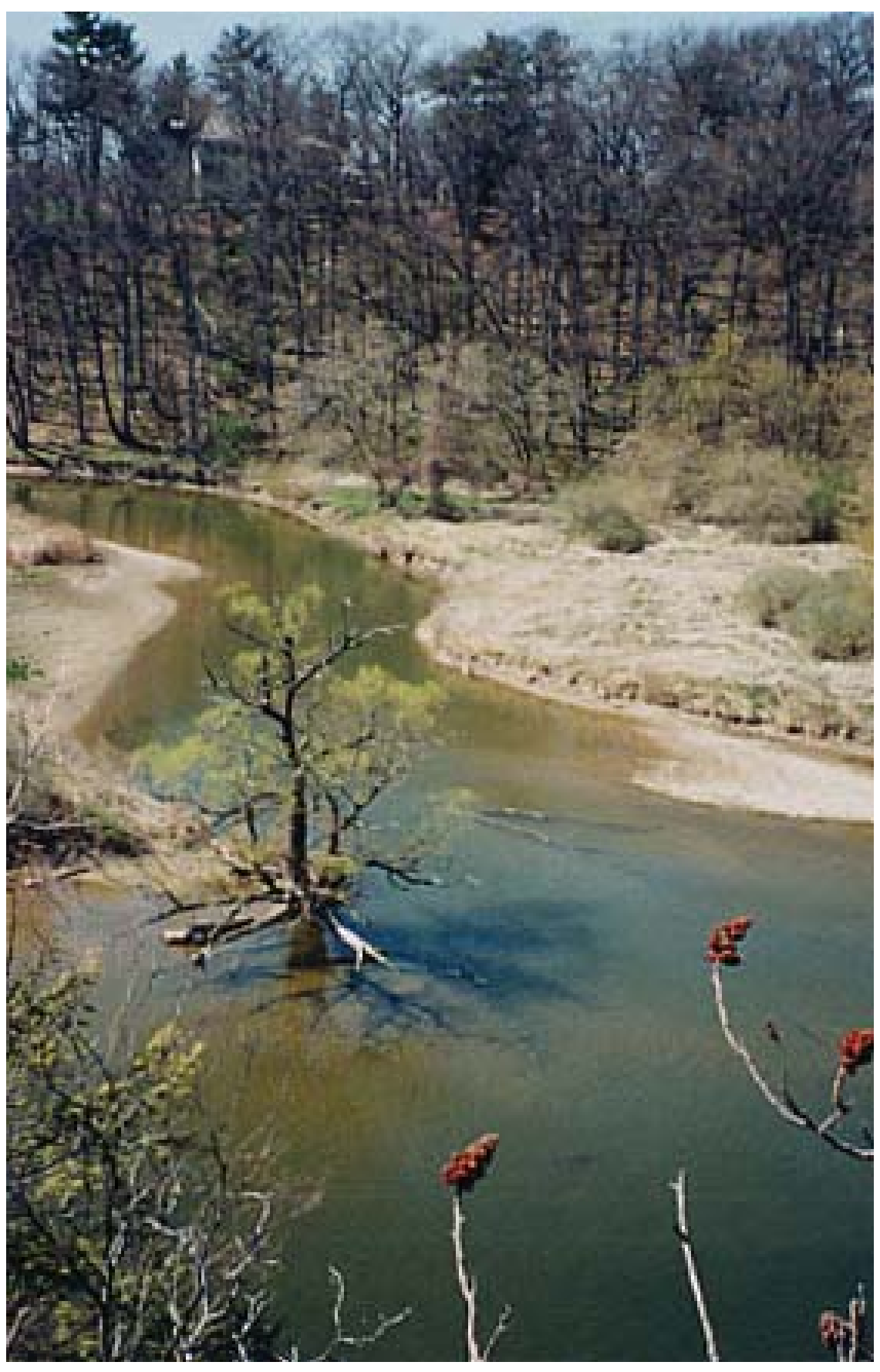

Figure 2: Credit River Flats, 1999 


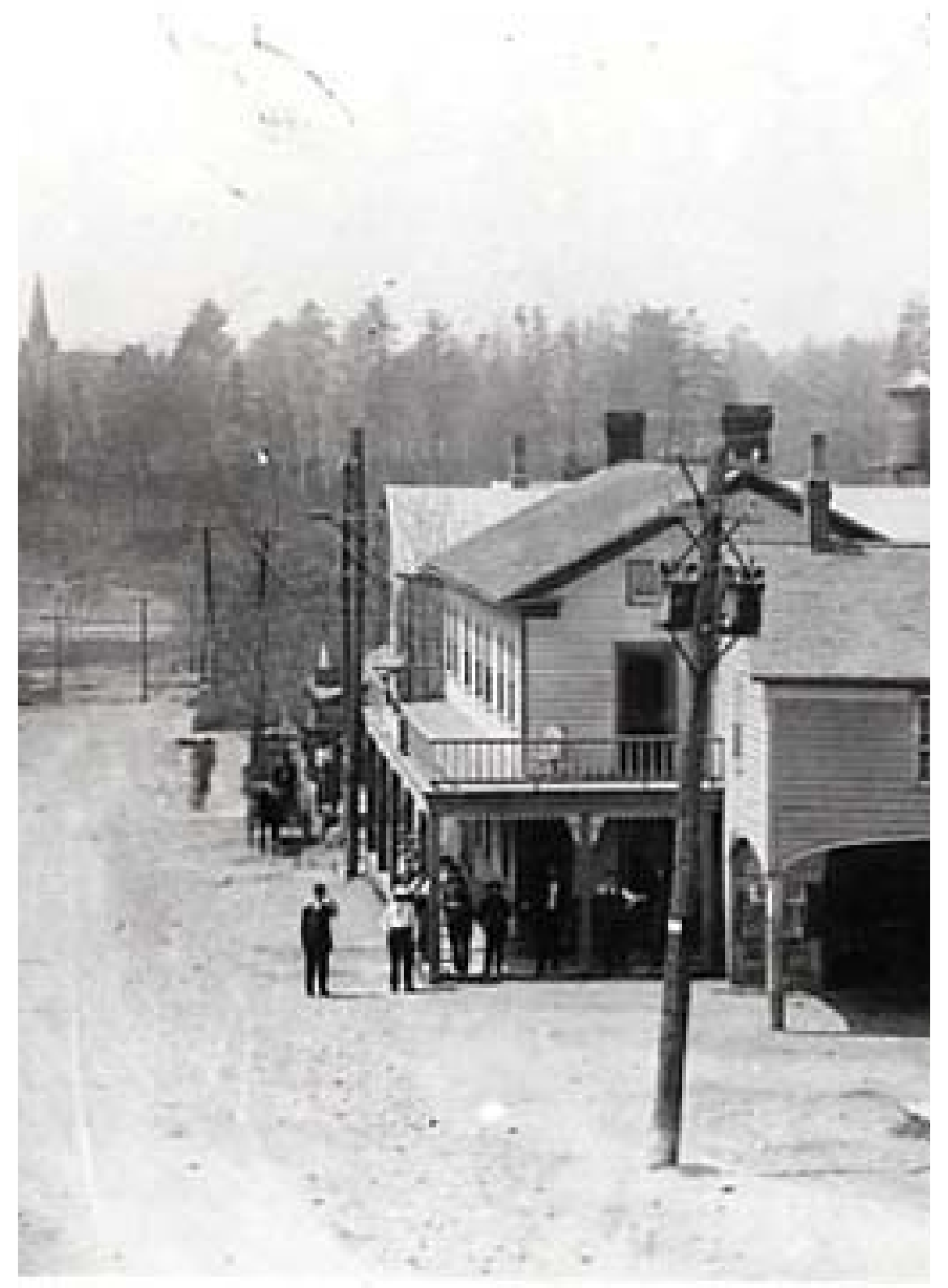

Figure 3: Erindale, c.1910 


\section{S E N S E O F P L A C E}

How does one define a place? Is it the buildings that make up the cities we inhabit? Can we even separate the buildings from the history that precedes them on this land? Or the activities and memories held within buildings and in a place? Place is both made of the tangible and intangible elements, which define our cities. A sense of place is informed by not just the built form that we inhabit, it is also the experiences and memories held within them. Ideas about place can often be associated with the term genius loci, usually referring to a location's distinctive atmosphere, or a "spirit of place". ${ }^{4}$ The concept refers to the Roman belief that each being, or place has a spirit, which gives it life. In this way, a sense of place forms an identity in a location, but also provides us with an attachment to the places where we reside. Norberg-Schulz describes place as a space where humans know their

presence..$^{5}$ Place can then be seen as our awareness of our identity and the relationship we hold between the tangible and intangible environment. While place forms an identity, that identity is also at risk of being lost. Many of the places we inhabit are in a state of constant 
change. Mississauga, which evolved from an area of lush opens spaces and farmland, now represents one of Canada's largest cities. While still relatively young, it is at risk of disconnecting from the identities that defined its founding villages. Norberg-Schulz wrote that when man loses the world around him, he also loses his identity.

"The loss of things and places makes up a loss of "world". Modern man becomes "worldless", and thus loses his own identity, as well as the sense of community and participation. Existence is experienced as "meaningless", and man becomes "bomeless" because he does not any longer belong to a meaningful totality. ${ }^{6}$

As Mississauga is still in a state of change, it is important to be reminded of what defines the identities of its founding villages and respect the spirit of place within them. 


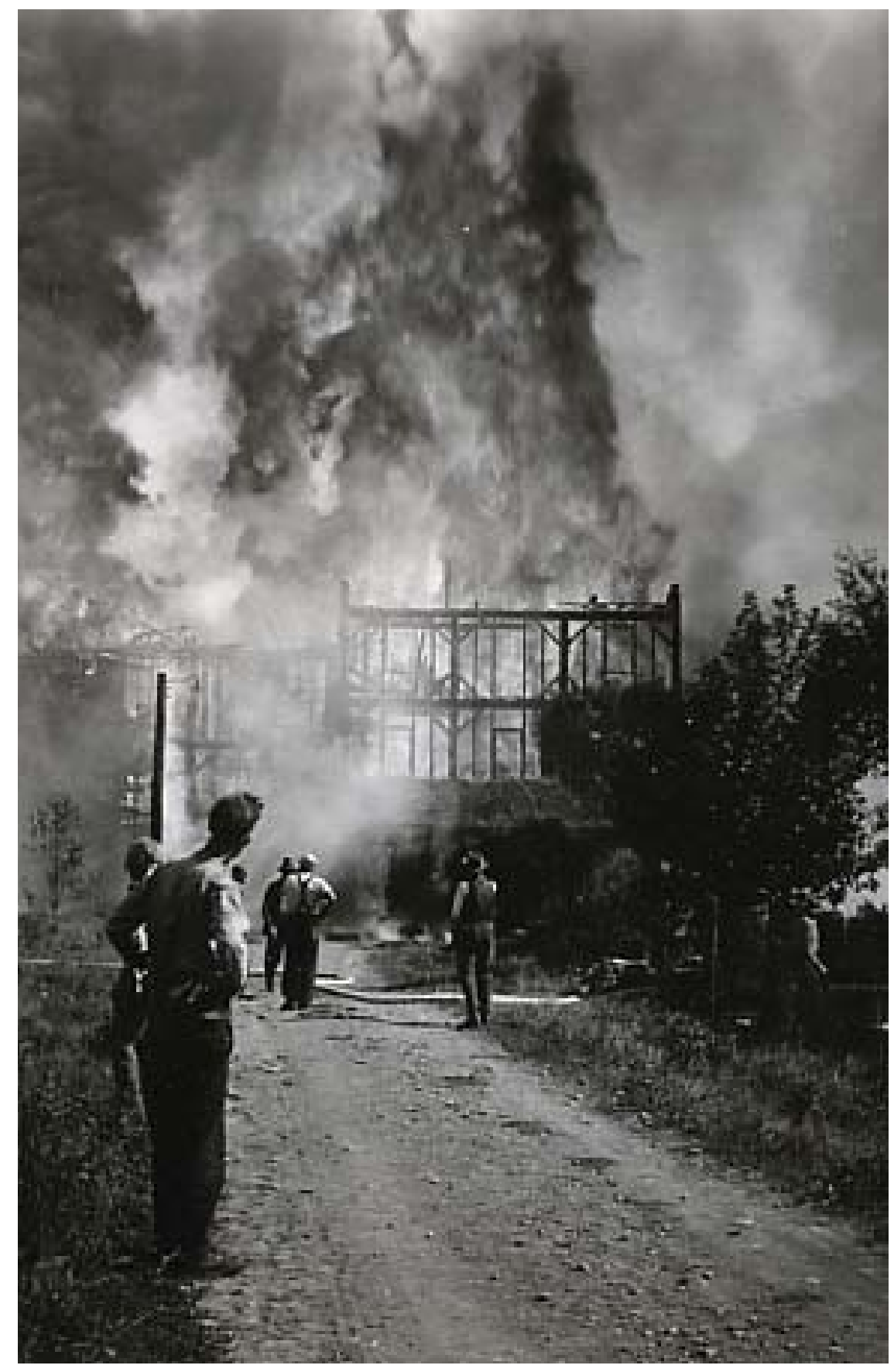

Figure 4: Mill Fire, Streetsville, 1929 

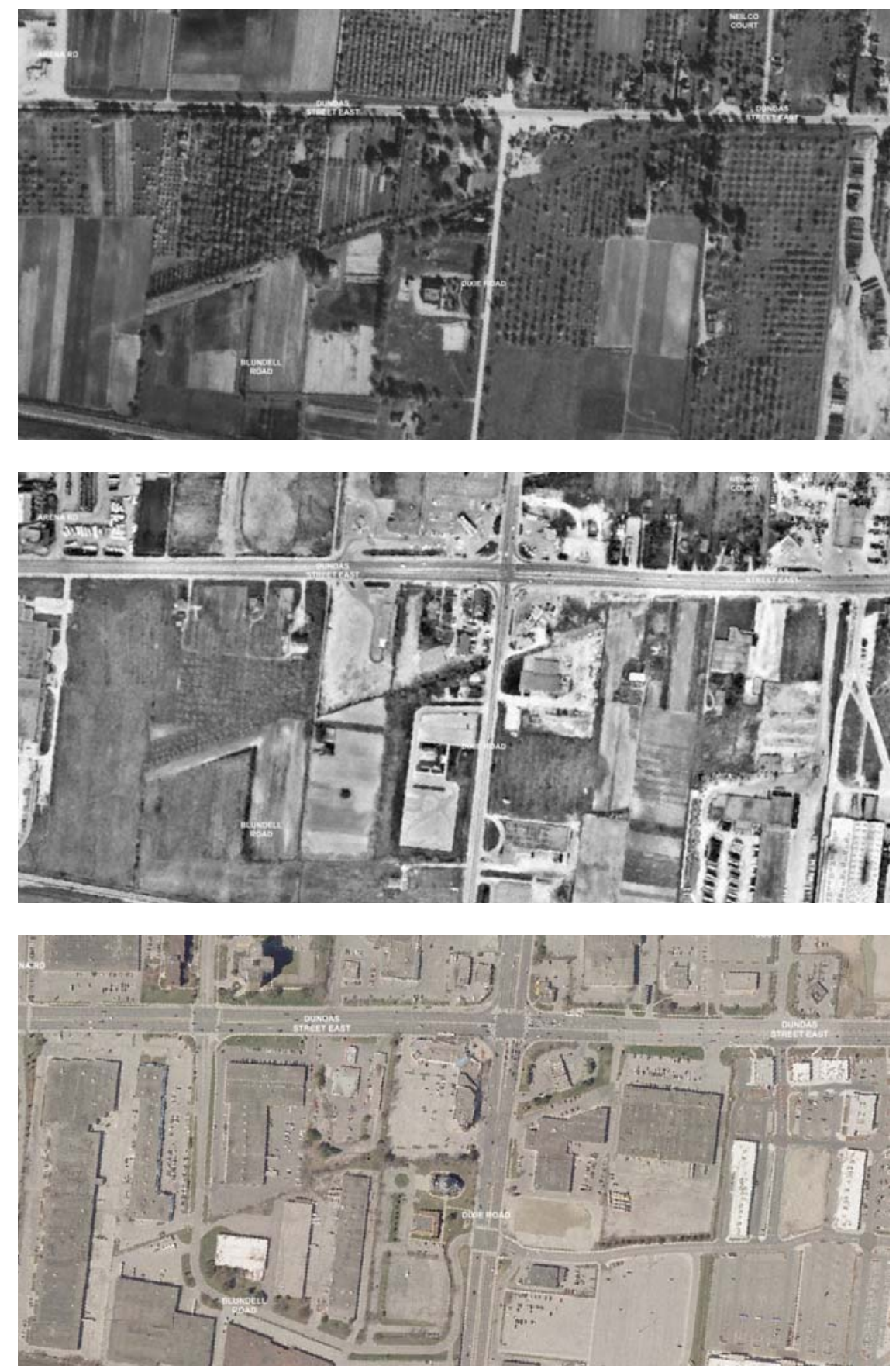

Figure 5: Aerial Images, Dixie, 1955, 1966,2017 


\section{H I S T O R Y O F D I X I E}

Changing its name throughout its history, Dixie would share a group of names that defined its borders. Fountain Hill, Sydenham, Onion Town, Fronthill, and Corn Town, would all describe this small village along its main corridor; Dundas street. Around 1806, the town would eventually spring up along this major route, and early settlers would see the construction of a tavern, hotel, and carpentry shop. One of these major stopping points, the Atlantic Hotel, would be located at the present day Tomken and Dundas road intersection. By 1865, the town would eventually adopt the name Dixie, in honor of Dr. Beaumont Wilson Bowen Dixie, who had given a large donation to the Union Chapel. Lying just east of the town of Cooksville, which would see large commercial success, Dixie would struggle to attain the same achievements. However, where Dixie lacked in commerce, it prospered as both a religious and agricultural center. The Union Chapel and St. Patrick's Roman Catholic Church would provide residents ample space to socialize. By the early 20th century, Dixie would largely become known for its farming communities 
and markets. ${ }^{7}$ Looking at Dixie today however, you no longer see such strong ties to its religious and agriculture identities. As the suburban boom swept the city, Dixie now resembles strip malls and parking lots, where few if any of its original characters remain. ${ }^{8}$ 


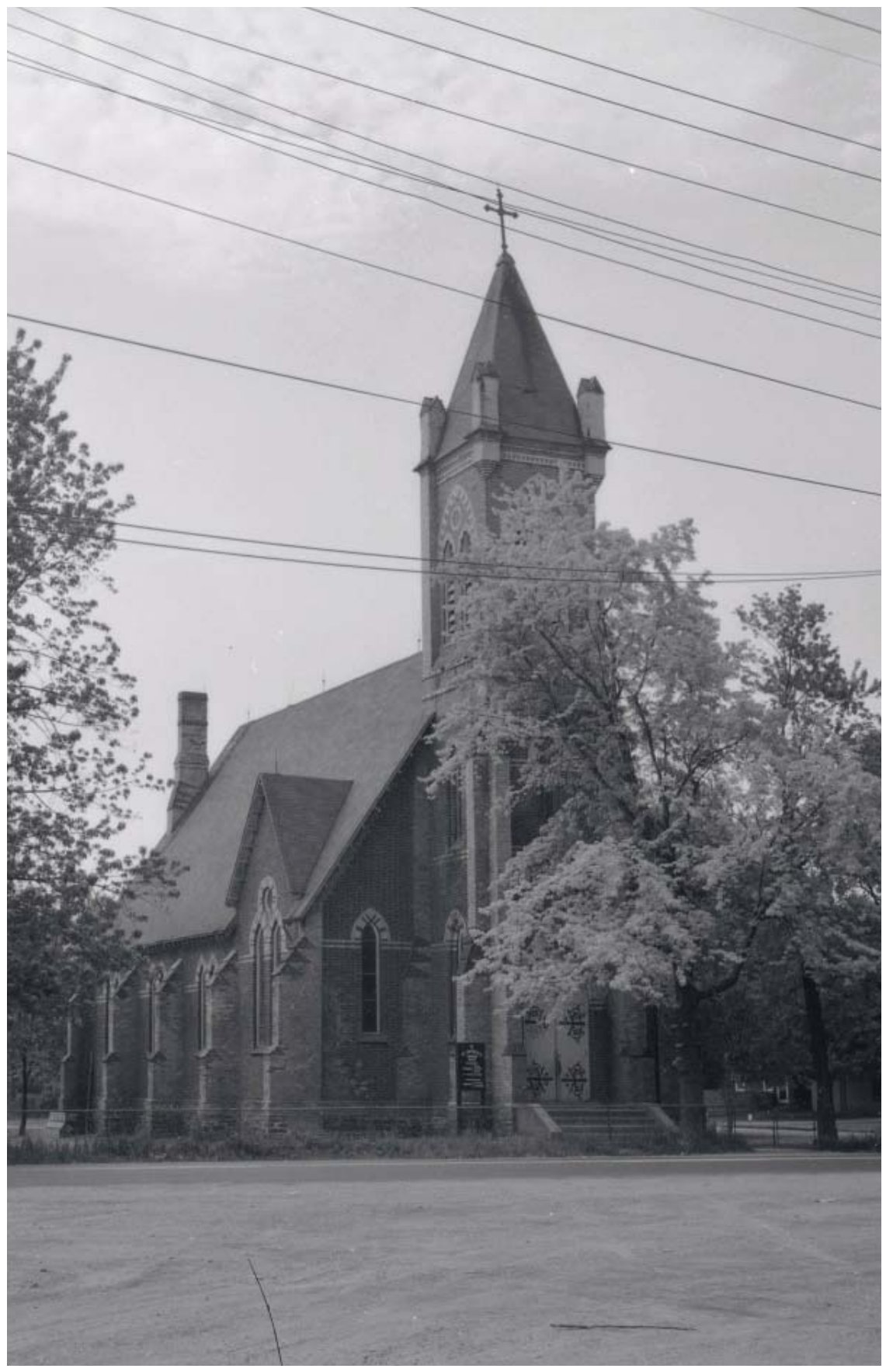

Figure 6: St.Patrick's Roman Catholic Church, Dixie,1955 


\section{II}

M ISS ISS A U G A

MEMOR Y

RESTORATION

PROCESS OF COLLECTING 


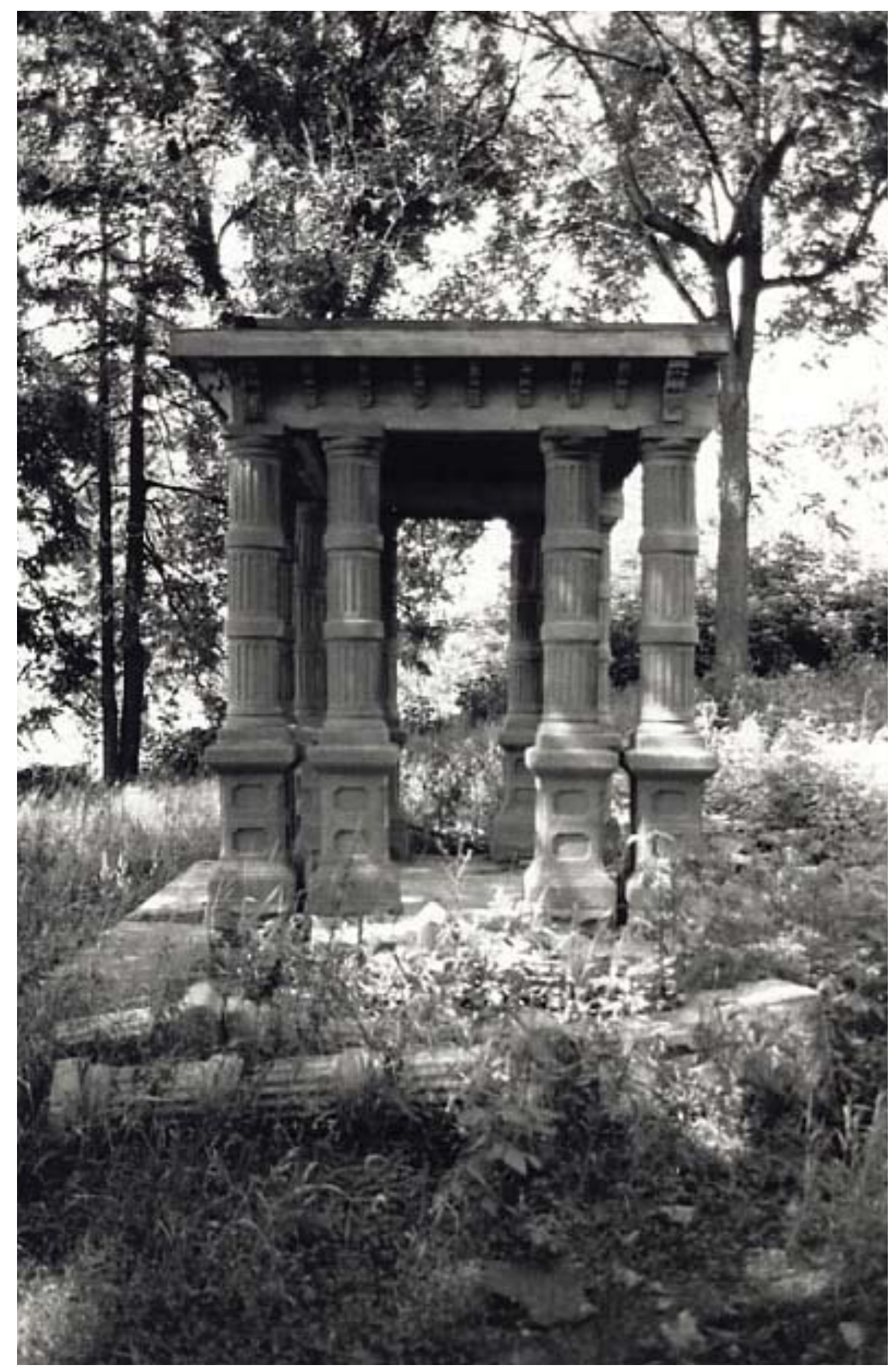

Figure 7: Gravelle Residence, Stone Pillars, 2010 


\section{E M O R Y}

What does memory mean? Is our mind forcing us to think back to a time where we felt a specific emotion? Or are we reminding ourselves of a memory we experienced when we are in a certain location? A more scientific definition of memory affirms that it is a faculty by which the mind stores and remembers information. ${ }^{9}$ Memory is something that comes from the past, it is something we can recall. Memories allow us to exist and function in the world, they allow us to reminisce past events in such a way that we may function in society. Some memories allow us to retain information on skills needed to write, read, or engage in conversation. Yet these memories attributed to these skills are taken for granted. We do not stop to think about how to speak, or write something down, we simply just do it. Why then do we so easily forget what we did last week, or an event in our childhood? Are the memories of our past there to serve as a reminder? Or do they serve a larger role in our daily lives? The mind is not easily understood, and our knowledge on the human brain can only extend so far, and yet we are capable of remembering our past at a blink of an eye. 
Cormac McCarthy describes that; "Scars have the strange power to remind us that our past is real". ${ }^{10}$ A scar on your forehead may remind you of the time your sister hit you with a shovel, but also has the capacity of providing a trigger to that specific memory. Much like the scars on our bodies, our cities provide us with the triggers to remember. Society remembers with many aids, but our built form may be the most important. Where we live, work, and engage with others all provide the means to create memories. Many people will be able to describe their first home, where they can use their senses to explain what the space was like. Being able to describe a specific color, material, or smell has a powerful effect on our mind, since these senses can be used to trigger those memories once more.

Our senses allow us to perceive our surroundings and translate that data, into a visual memory. This visual memory allows to create a specific image in our mind, which can then provide us the tool to remember. Whether it is a visual, auditory, or other sensorial stimulation, our mind can be reminded of that memory. If we can trigger memories in ourselves, can we also provide the tools to trigger the collective memories of others? Memory is obviously personal and cannot be easily explained to another without some context. Memory is also 
incomplete, as we cannot truly recall every detail of past experiences, and in some instances in the process to reconstruct lost memories, the effort becomes a confabulation, or even a falsehood. This is also why it is important to realize that we do not re-construct our memories, rather we actively construct them in the present. A memory shared by two people may differ slightly, providing a different description of the time, or the visuals experienced. While memory may be false, it does paint a picture of our history.

\section{R E S T O R A T I O N}

The memories of the early settlers of Mississauga's villages are not accessible, however, we have some elements in the forms of existing buildings, photographs, and shared transmedia stories. These forms allow us to understand but a glimpse of what life could have been like at that time. As memory is involved with remembering something from the past, it is also a concept embedded in the conservation movement. As conservation deals with the buildings of past, so too, do they deal with memories associated with them. In the book On Altering Architecture, Fred Scott, provides a discussion around the unaltered and altered state of buildings and the role that the 
architect plays in relations to it. The themes and discussions around conservation in the book greatly influenced my opinions on how we deal with heritage buildings. As someone who does not come from a traditional background in conservation, I have always maintained a high interest in how we deal with our historical past and its built form. When I began thinking about these issues, I believed that all heritage buildings no matter how great their importance, or cultural value, should be restored to a time that best reflected their original condition. However, my position changed when confronted with this question posed by Scott: "in planned restoration, to what previous condition is the restoration intended? ${ }^{11}$ Having the understanding that restoration was a process dealt with bringing an item back to a perceived original condition. I began to uncover the history and philosophies behind the term. In Scott's book, he details the arguments surrounding restoration and two of the major players involved. Comparing the concept in the works of both Viollet-le-Duc and John Ruskin, I began to understand the implications restoration has on buildings.

"To restore a building, it isn't to maintain it, to repair, or rebuild it, it is to recover a perfection that may have never existed at any given time." 
'Restaurer un edifice, ce n'est pas l'entretenir, le reparer ou le refaire, c'est retablir dans un etat complet qui peut n'avoir jamais existe, a un moment donne 12

Viollet-le-Duc sees restoration as a way in which the architect can attempt to bring a building's pure form into reality, a form which might not have existed in its history. Addressing restoration through his way of thinking, would ultimately see buildings restored to a condition that best represented their original buildings style, but never existed before. For example, if a building was built during the 12th century, but featured multiple additions throughout the 13th, 14th, or 15th centuries, the building would be re-finished in the most significant style in which it was originally conceived. Whereas Ruskin dismisses the role of restoration altogether.

"Neither by the public nor by those who care of public monuments, is the true meaning of the word restoration understood. It means the most total destruction which a building can suffer: A destruction out of which no remnants can be gathered: a destruction accompanied with false description of the thing destroyed. Do not let us deceive ourselves in this important matter; it is impossible, as impossible as to raise the dead, to restore anything that has ever been great or beautiful in architecture." 13 
Ruskin's argument on restoration provides a counter analysis of restoration, as compared with Le Duc creation of a fictional past. As restoration involved dealing with an existing condition, a building or object, it became clear that this process would not be applicable in relation to Mississauga's founding villages. Understanding that much of what I was dealing with no longer existed in the physical form of buildings, but in individual parts, spoils, photographs and in some cases written accounts. If only dealing with parts of the whole, how could one attempt to use restoration as a process? Ruskin discusses his disdain towards restoration and its relation to the dead workman, as an important fact that in further understanding restoration leads to the creation of a forged past that one cannot restore, he describes:

"That which I have above insisted upon as the life of the whole, that spirit which is given only by the hand and eye of the workman, can never be recalled. Another spirit may be given, and it is then a new building; but the spirit of the dead workman cannot be summoned up, and commanded to direct other hands, and other thoughts. And as for direct and simple copying, it is palpably impossible. What copying can there be of surfaces that have been worn half an inch down? The whole finish of the work was in the half inch that is gone; if you attempt to restore that finish, you 
do it conjecturally; if you copy what is left, granting fidelity to be possible, how is the new work better than the old? There was yet some life, some mysterious suggestion of what it had been, and of what it had lost; some sweetness in the gentle lines which rain and sun had wrought. There can be none in the brute hardness of the new carving... Do not let us talk then of restoration. The thing is a Lie from beginning to end. You may make a model of a building as you may of a corpse. ${ }^{14}$

Understanding that I could not restore the founding villages to their previous conditions, I decided I would focus on constructing the memories that still linger in the towns. As I would not have access to any physical buildings, and only a few objects, I would focus on using the various parts found through my research and collection process. Being able to deal with archival photographs, aerial images, and historical maps, I was able to gain insight on the memories that occurred within the towns and villages. As Mississauga featured ten founding villages and a handful of lost villages, my aim was to situate the thesis around the town of Dixie. Using one town for the exploration, the concept could be theoretically used also in relations to the other remaining villages, with the potential to expand this research in the future. 


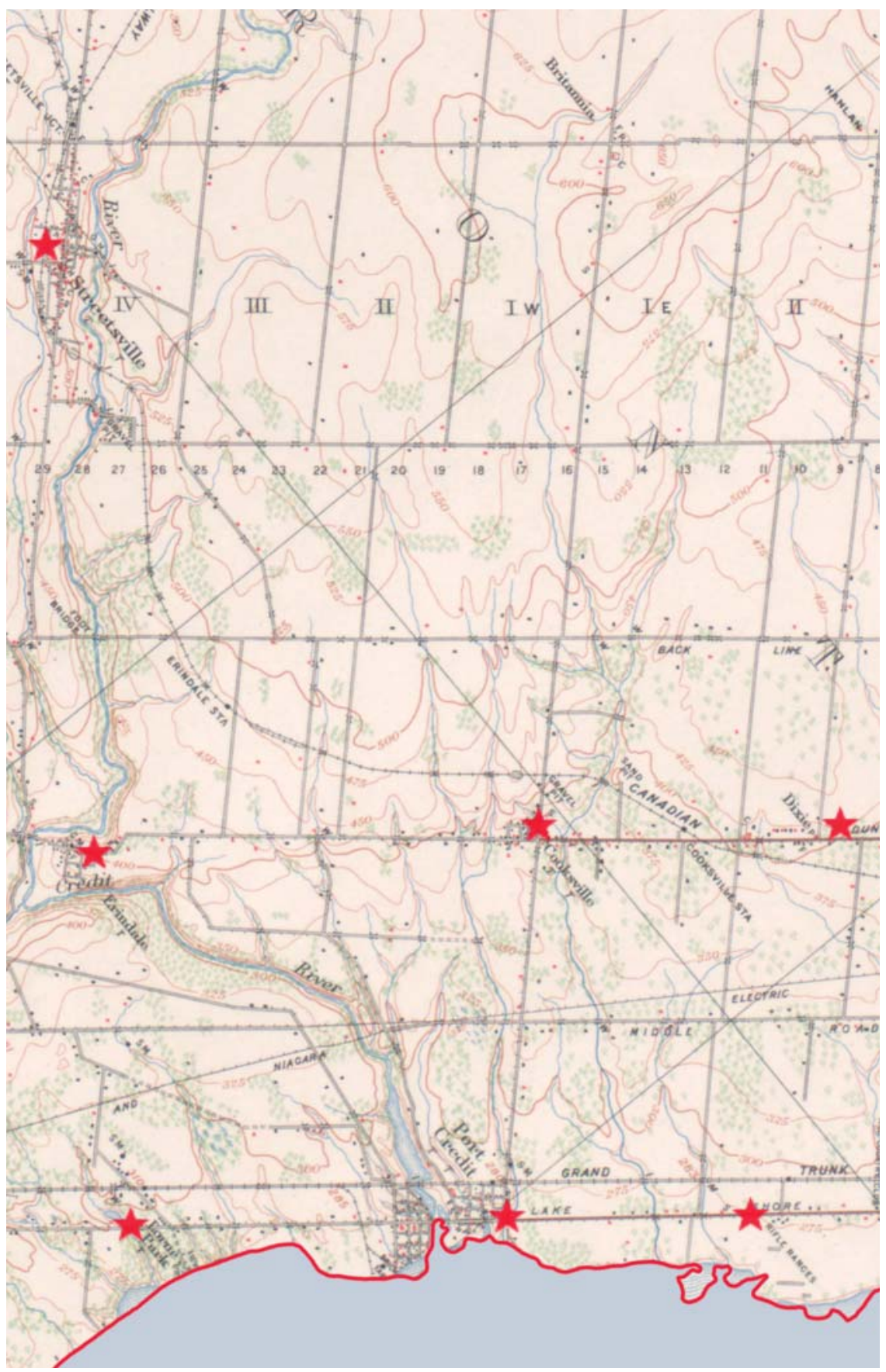

Figure 8: Brampton Sheet, 1909 


\section{P R O C ES S OF C O L L E C T I N G}

My initial research involved devoting time to the collection of historical photographs and maps, along with stories about Mississauga's early days. Early on in my findings I approached the Heritage Mississauga office as a starting point to gain insight knowledge on the work being done by their team. Speaking with their onsite historian, Matthew Wilkinson I was able to start learning about the stories and photographs that influenced my thesis. Wilkinson was able to provide a glimpse of what Mississauga's early villages looked like. He was able to tell the story of how these villages used to exist and function. Wilkinson stressed that buildings have their own voice and that voice has an impact on its community. While our city has grown and changed, our historical structures have witnessed time passing in front of them. Older buildings may not possess the same functionality they had at the time of their construction, but they still contribute to the construction of identity over time. By understanding the stories that extend into the communities I began to research and collect the stories that contributed to a larger collective memory. Originally looking at the lost 
villages, I began to overlay historical maps, aerial, and satellite images to gain a deeper sense of how these villages evolved, functioned and ultimately disappeared. From these findings I narrowed my search to the ten remaining villages defined today.

Looking at the towns of Clarkson, Cooksville, Dixie, Erindale, Lakeview, Lorne Park, Malton, Meadowvale Village, Port Credit, and Streetsville I began to uncover the stories, events and buildings that exist and existed in these places. Moving forward I began to site these memories against the current map of the city, which resulted in constructing a map of traces. This map began to populate as time went on.

Narrowing my focus further I investigated the lingering memories of Dixie, primarily as it was a community that I myself was a part of. Dixie was one of Mississauga's founding villages, but much of what existed has now disappeared. Originally functioning as a prominent religious and agricultural center, many of Dixie's early memories are that of the parishes that developed and built churches along its main corridor. One of the notable ones, the St. Patrick Roman Catholic church stood on the corner of Dixie and Dundas. The beautiful brick building 
stood there until 1976 when the parish sold the land and consequently the building was demolished. What many don't know today however is that the parish also housed a cemetery behind it. Wilkinson had explained that during the parish's departure the decision was made to move the headstones but not the remains of those buried. Thus, some of Dixie's earliest inhabitants remain forgotten underneath what is now a suburban strip malls parking lot. That loss of identity, which I experienced in relations to the lost architecture, expanded to these resting places concealed from sight. This makes one reflect on the parallel existence of the past and present. However, the very fact that a condition like this exists in the first place, reveals our ignorance of our own history. This condition may be viewed as an ethical concern, or even as a complete disregard of morality. Unfortunately, Wilkinson explained that there are at least four known examples of this within the city today. ${ }^{15}$ 


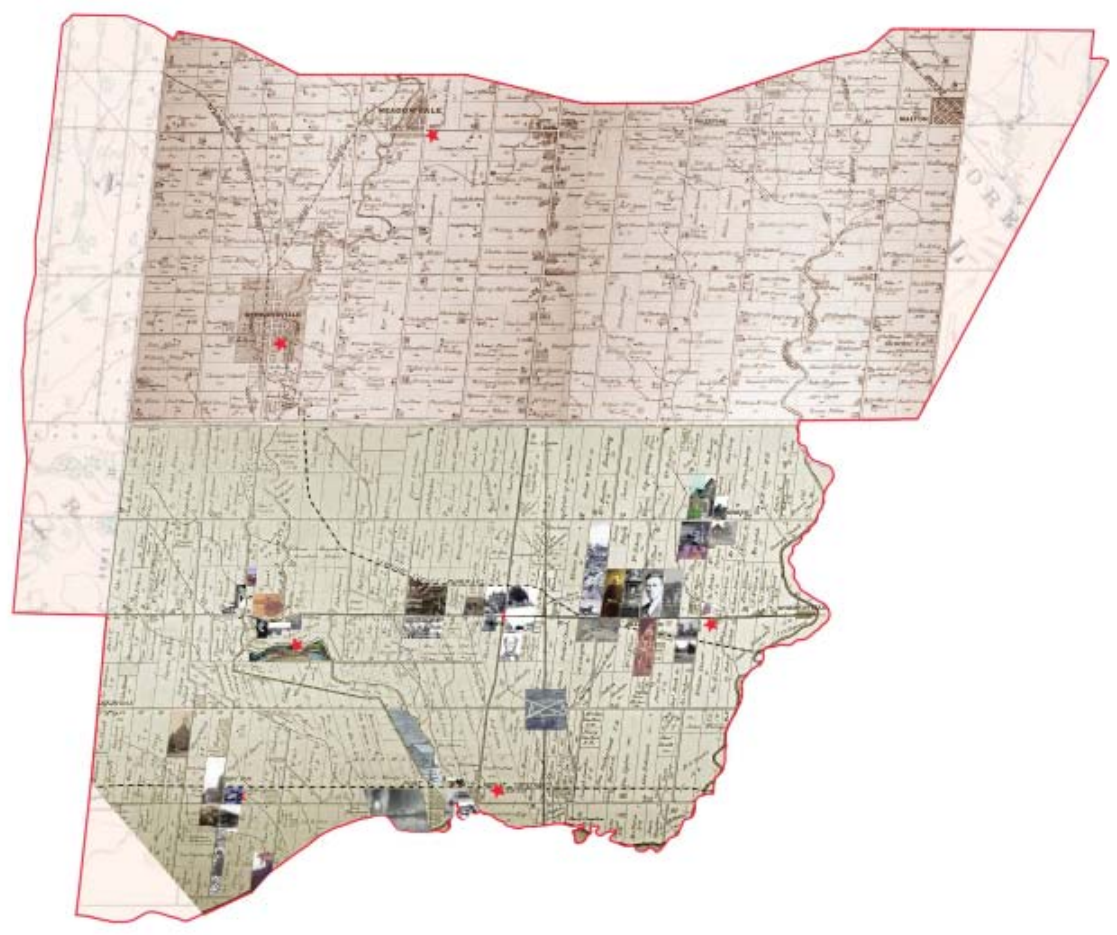

Figure 9: Map of Traces 


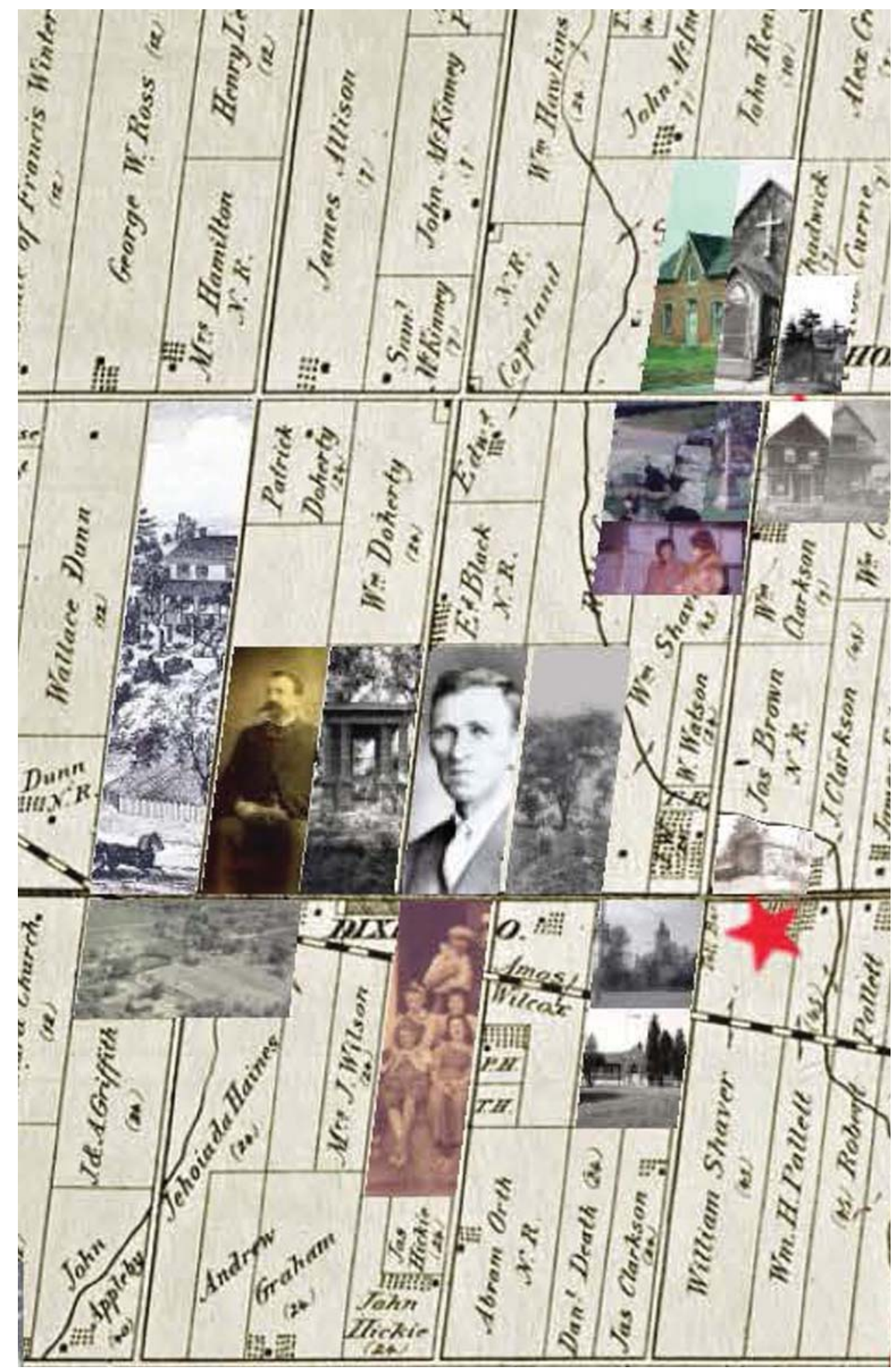

Figure 10: Map of Traces, Zoomed In 


\section{III}

PART III

POSTCARDS

I N S T A L L A T I O N S

$\mathrm{ROOM}$ 

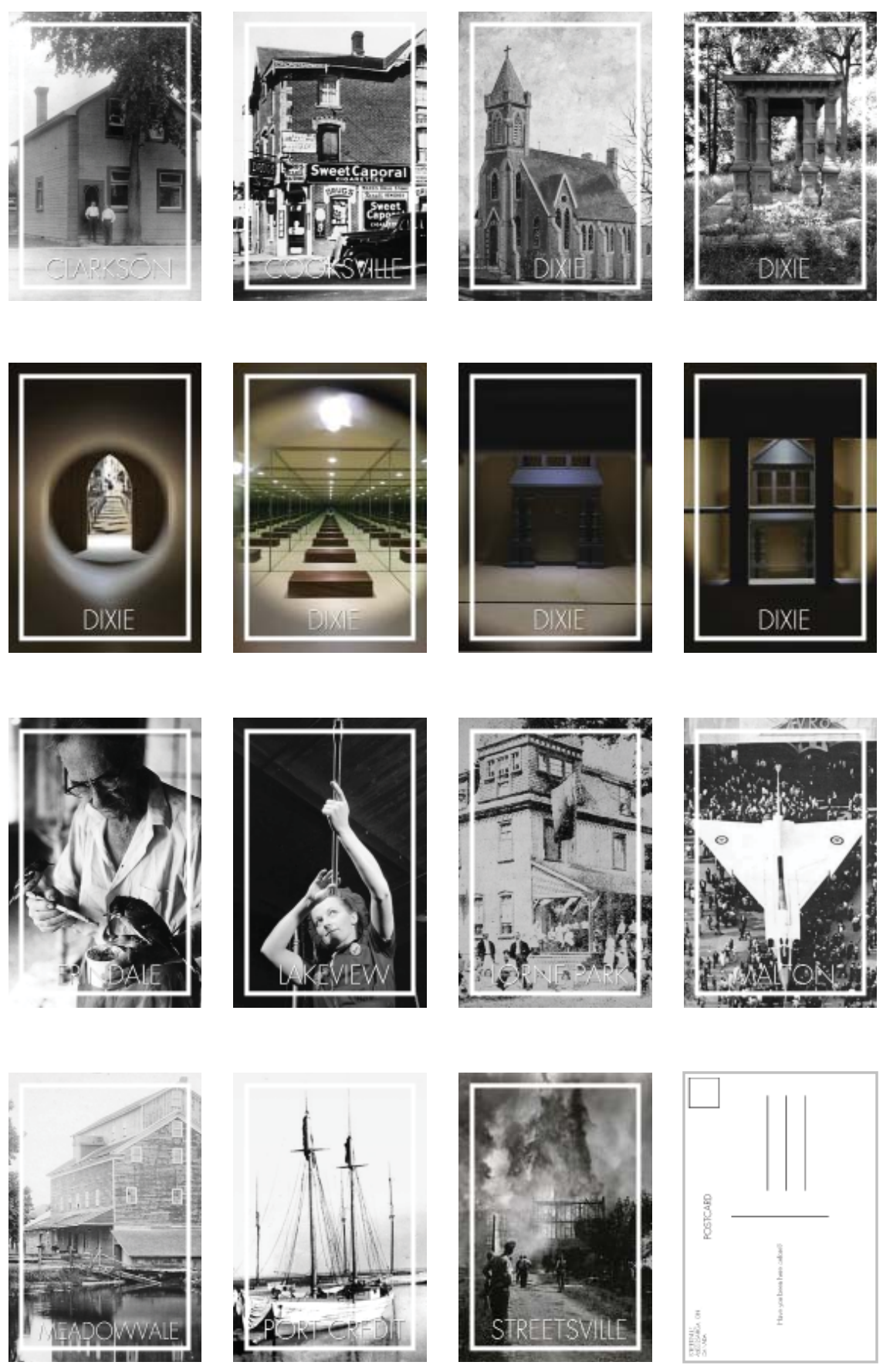

Figure 11: Postcard Designs 


\section{$\mathrm{P} O \mathrm{~S} T \mathrm{CA}$ R D S}

The design on the Postcards stemmed from the hundreds of archival photographs I uncovered throughout my collection process. Being faced with many photographs I needed to find a way in which I could relate to the bulk of the collection. Having an interest in travel and tourism, I looked at vintage tourism posters and the way in which they presented notable locations around the world. Each of these posters depicted a scenario of value, or importance, a way in which to lure the tourist to these magical places of a present that has a past. Whether magical or not, these posters represented activities, or events that occurred in these locations, as such, these events ultimately create the identities of our cities. By understanding that each village has a unique identity, I began to sort the photographs under each corresponding village the event occurred in. While I would ultimately only focus on the town of Dixie, I felt this process was an important step in uncovering the larger collective memories of each of the towns. By focusing on the specific memories, I tried to uncover the memories that truly defined the town. Understanding what each town was known for, I aimed to associate a 
collective memory that held importance within the community. What resulted was an interesting display of memories over the course of the villages own histories. Spanning from Dixies strawberry fields and churches, to Malton's Avro Arrow, I was now able to showcase a series of memory from each of the towns. Focusing on the town of Dixie, I began to select the memories that no longer existed in physical forms within the town. While my own selections are not exhaustive, they hint at a process, where the entire community could be potentially involved in constructing and selecting memories over time. Dixie is known for both an agricultural and religious center. The first memory I focused on is the site of the old St. Patrick's Roman Catholic church.

While the postcards' role served a need to display a large collection of memories, they also served an additional role in describing the narrative of the thesis. As many of the memories uncovered featured buildings lost to time, the memories of these places trans-mediated from a building to a photograph, to a postcard. As such these buildings could no longer be experienced in their physical state, but only perceived and understood from the various images, objects, or stories left behind. The postcards could then be interpreted as just as important as the original building was, since it allowed the viewer 
the tool to remember. By functioning as a tool for remembering, the postcards would also act as a guide to the location where the events occurred. Each of the postcards featured their town name on the cover, while the back would include both its address and a short phrase asking a question to the viewer; "Is this still here? What time is this place? Will you remember this? Have you been here before? Having these questions on the postcard, the viewer would be invited to think back to their own memories and ask themselves that very question. If the viewer could not remember, or did not knowingly have any relation to the site previously, perhaps they would be drawn to the site itself. Upon successfully arriving at the site, the viewer would uncover an answer to the phrase and discover that the memory no longer exists in its original state, yet they could engage with a new memory. 


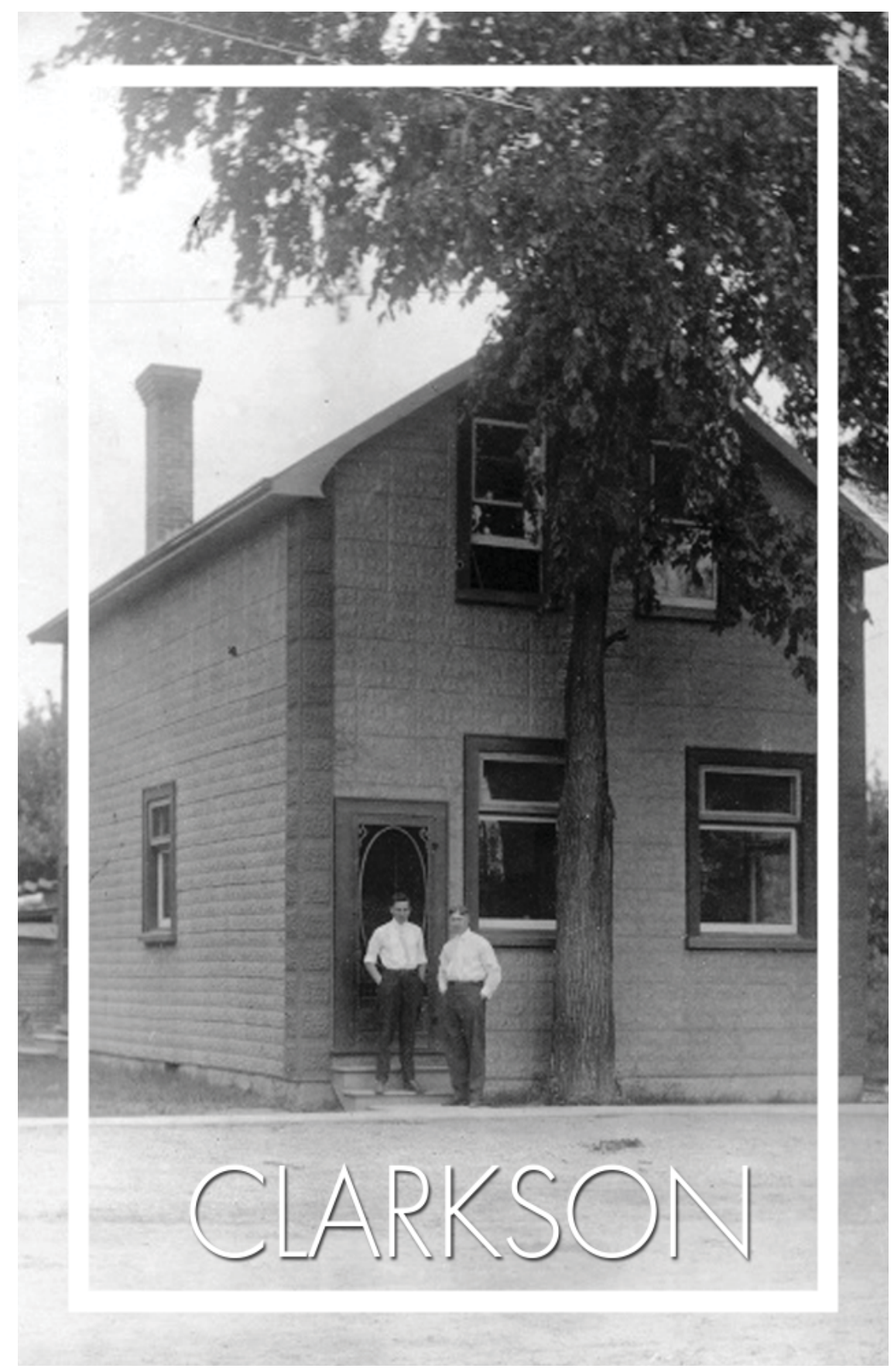

Figure 12: Merchant Bank, c.1914 


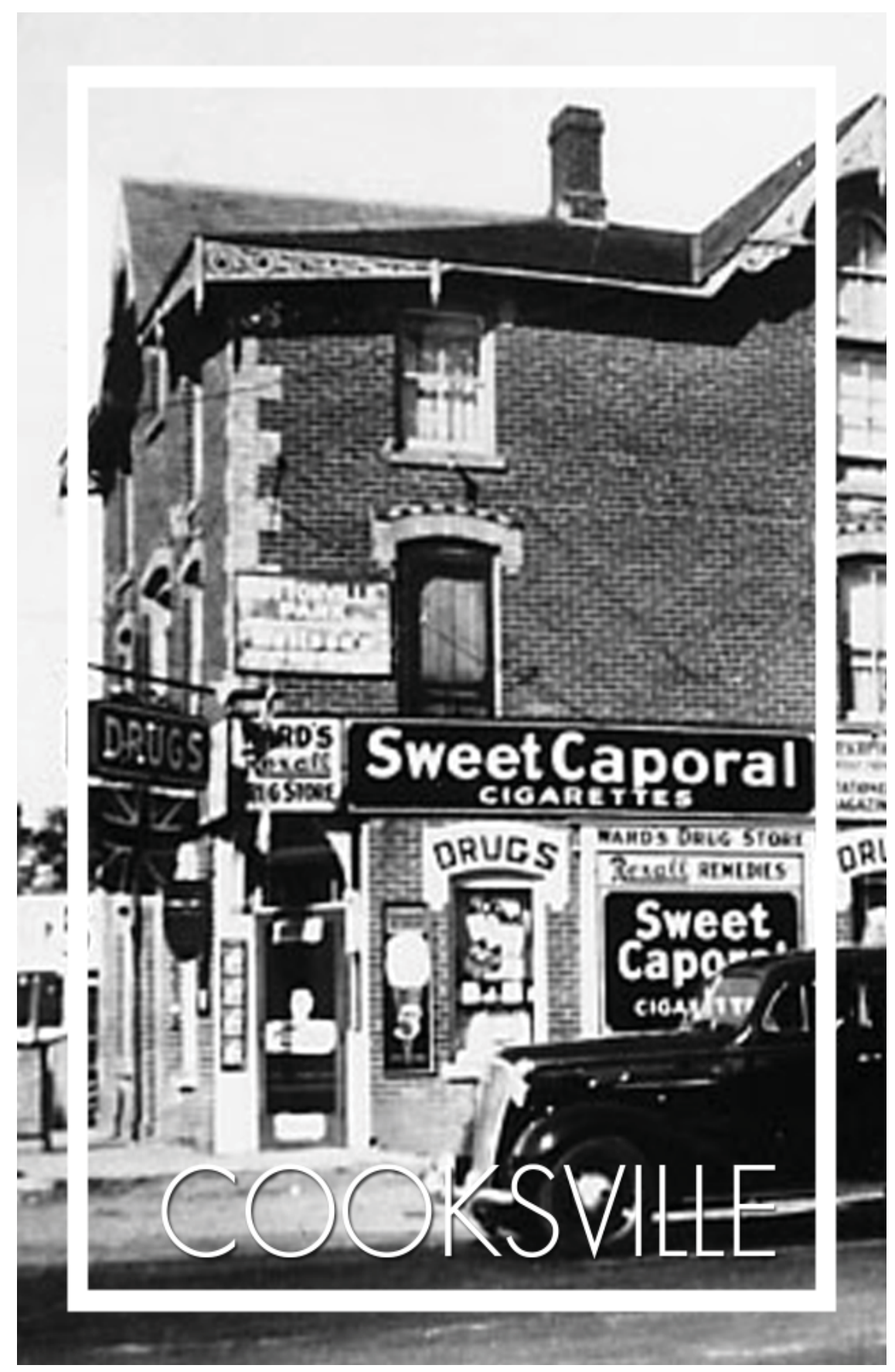

Figure 13: Ward's Drug Store, c.1930 


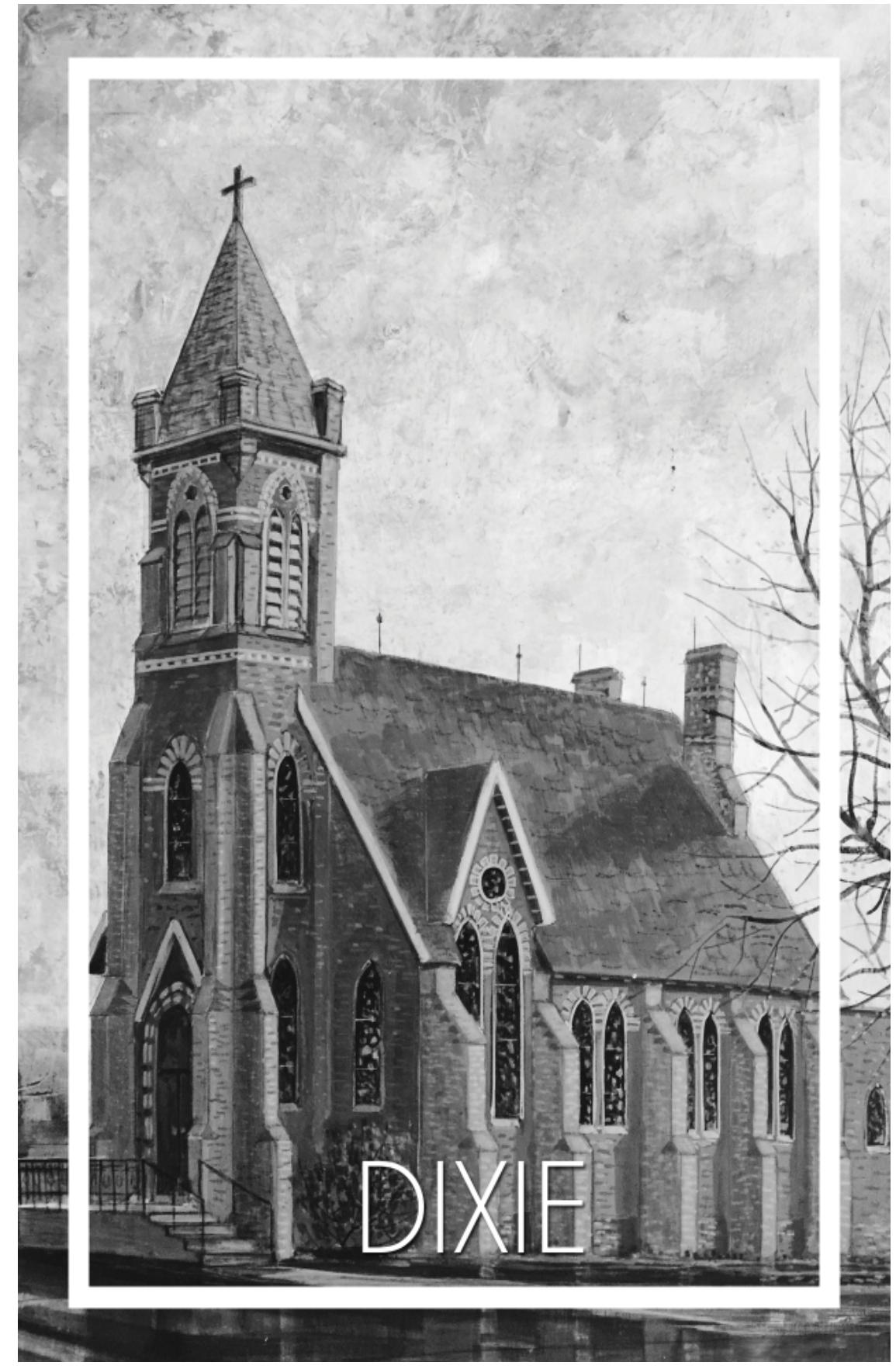

Figure 14: St.Patrick's Roman Catholic Church 


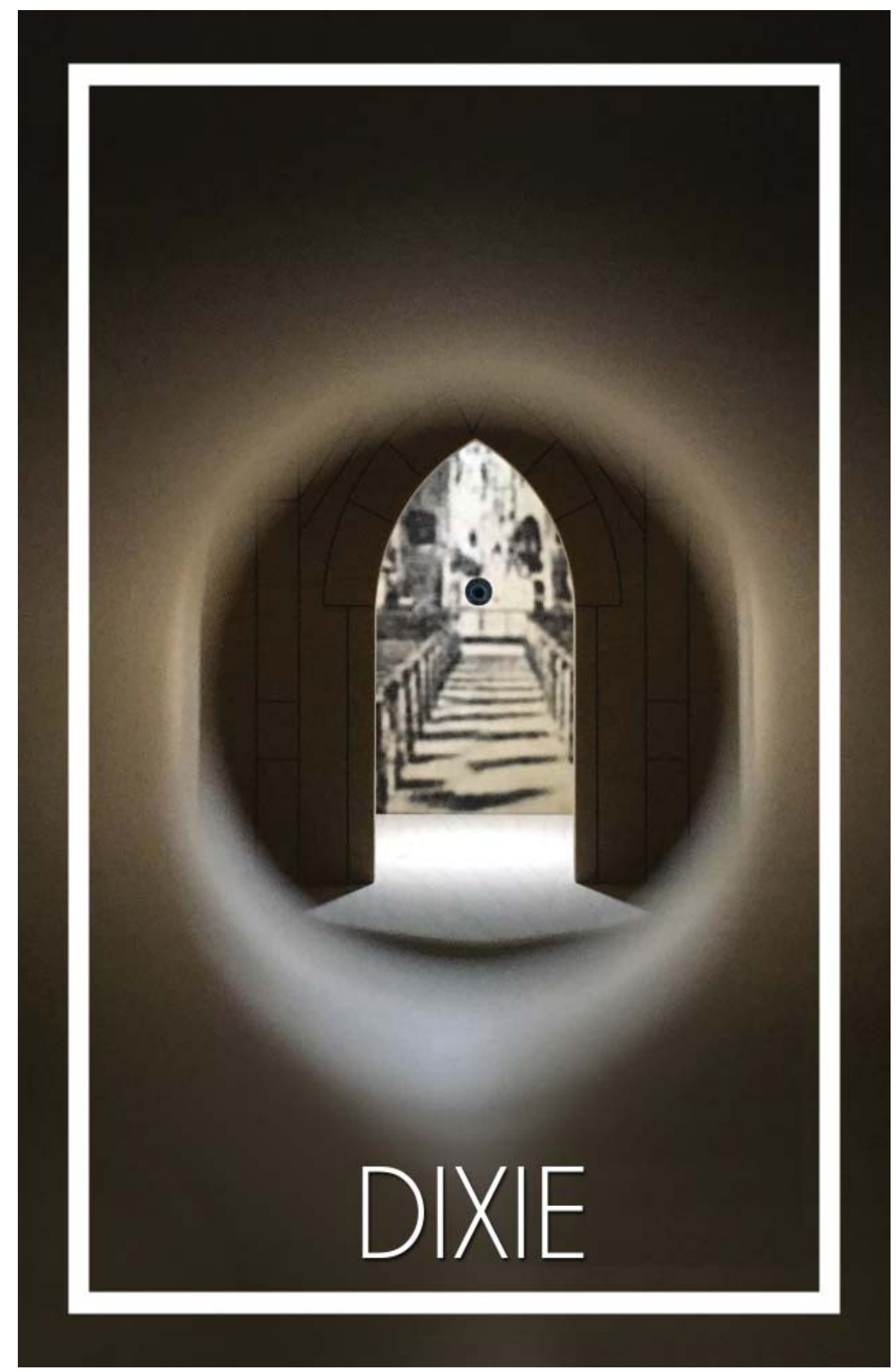

Figure 15: Postcard Installation 1 


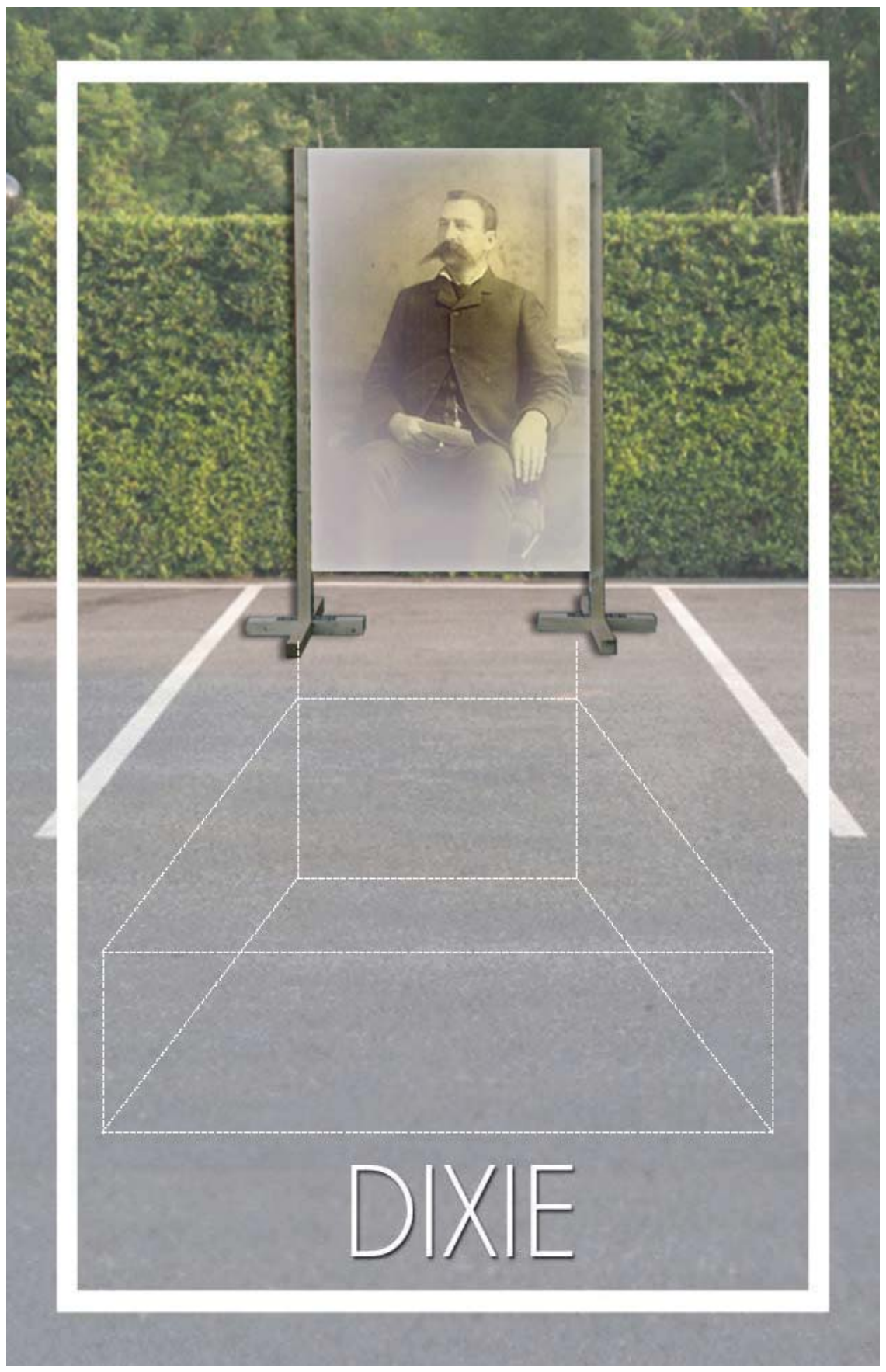

Figure 16: Installation II Concept 


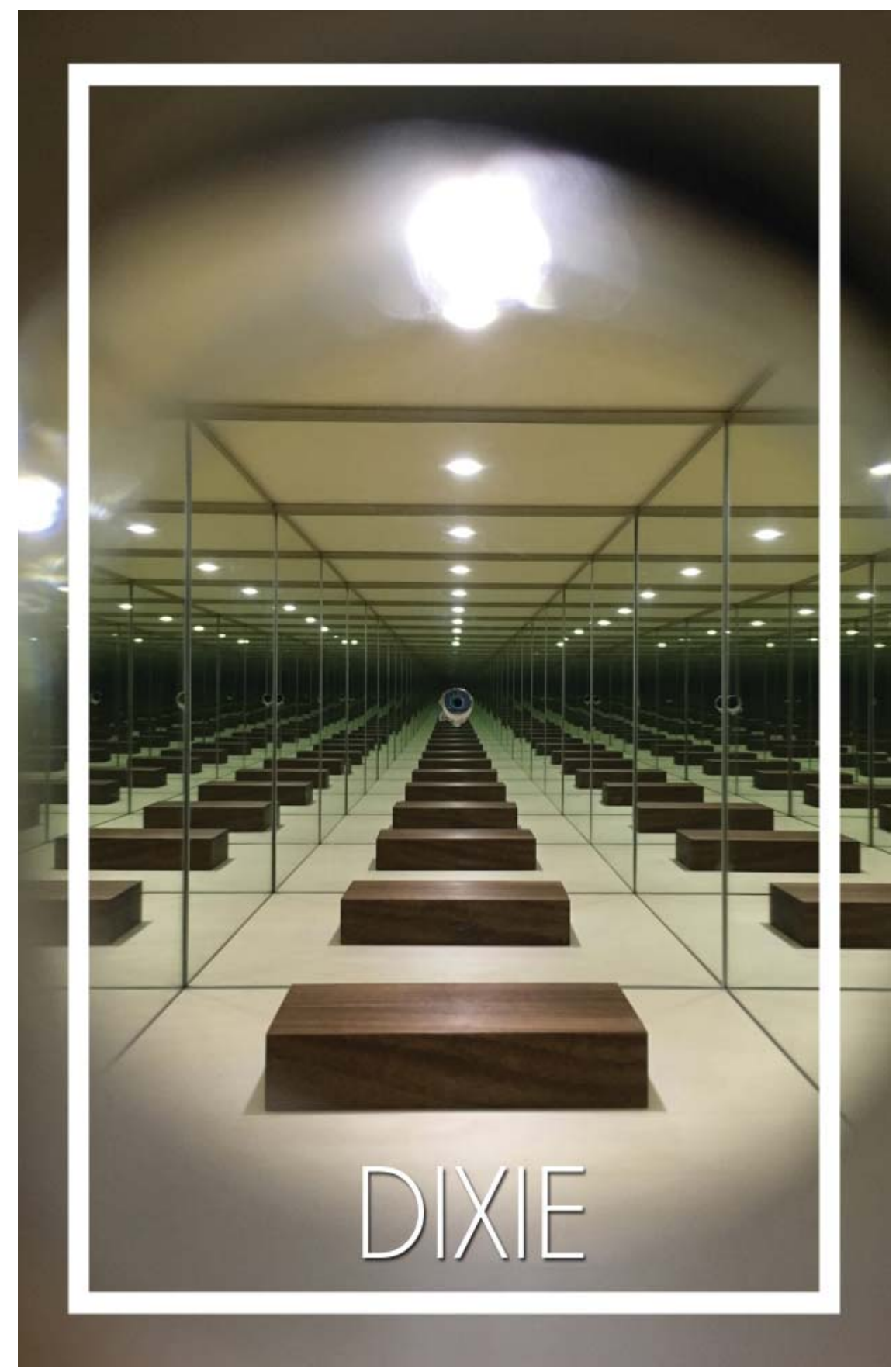

Figure 17: Postcard Installation II 


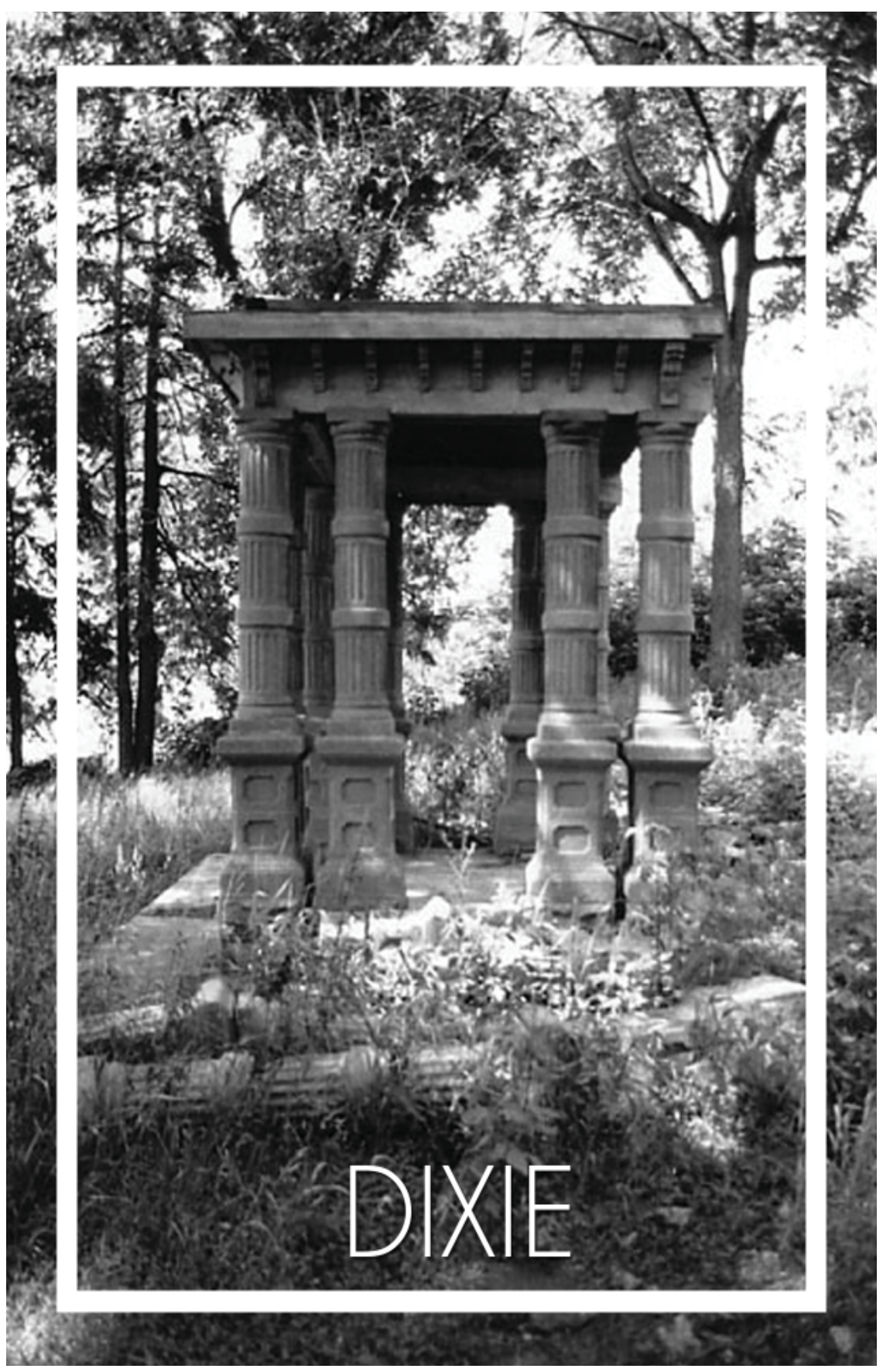

Figure 18: Gravelle Residence, Stone Pillars, 2010 


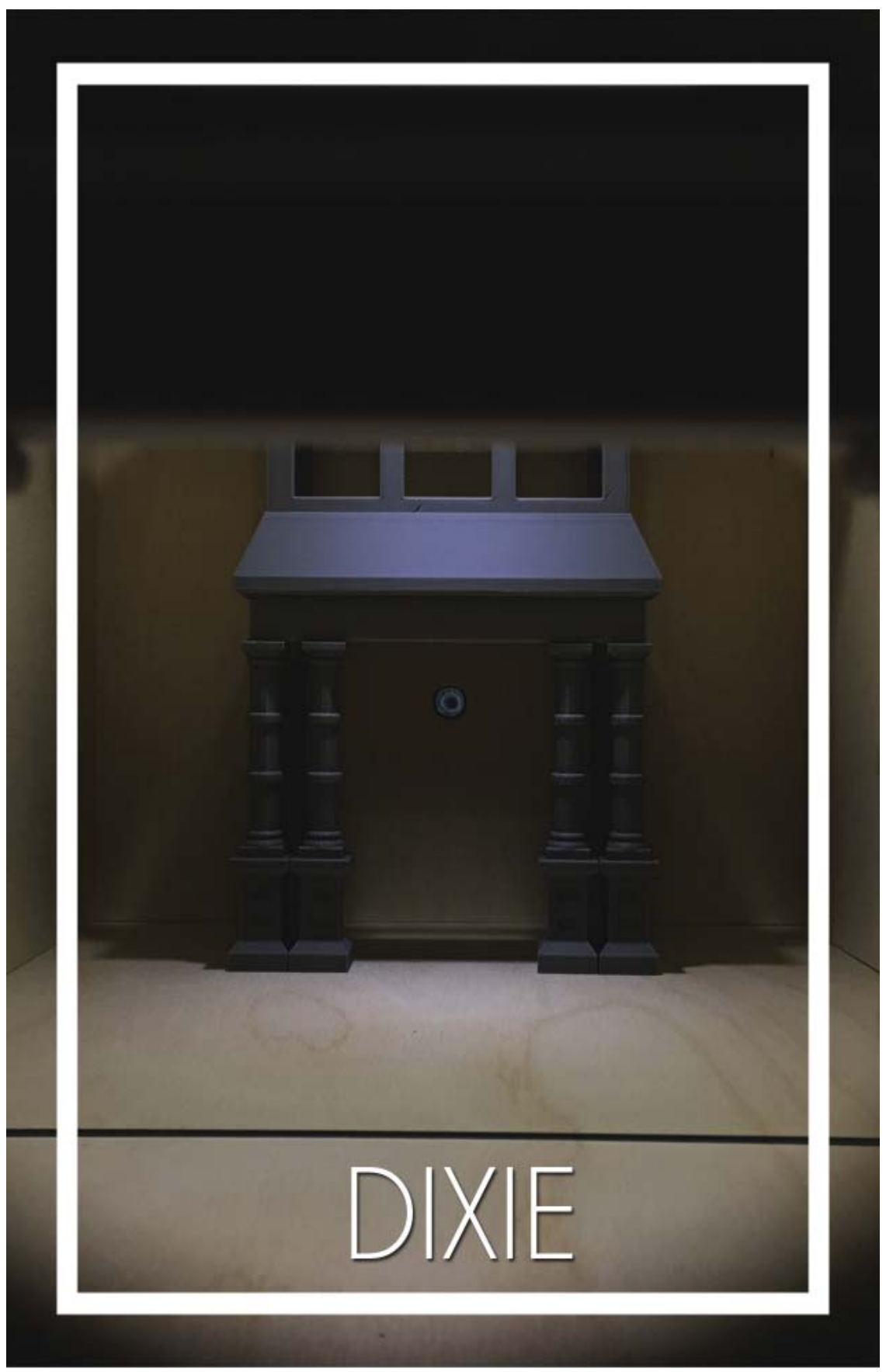

Figure 19: Postcard Installation II 


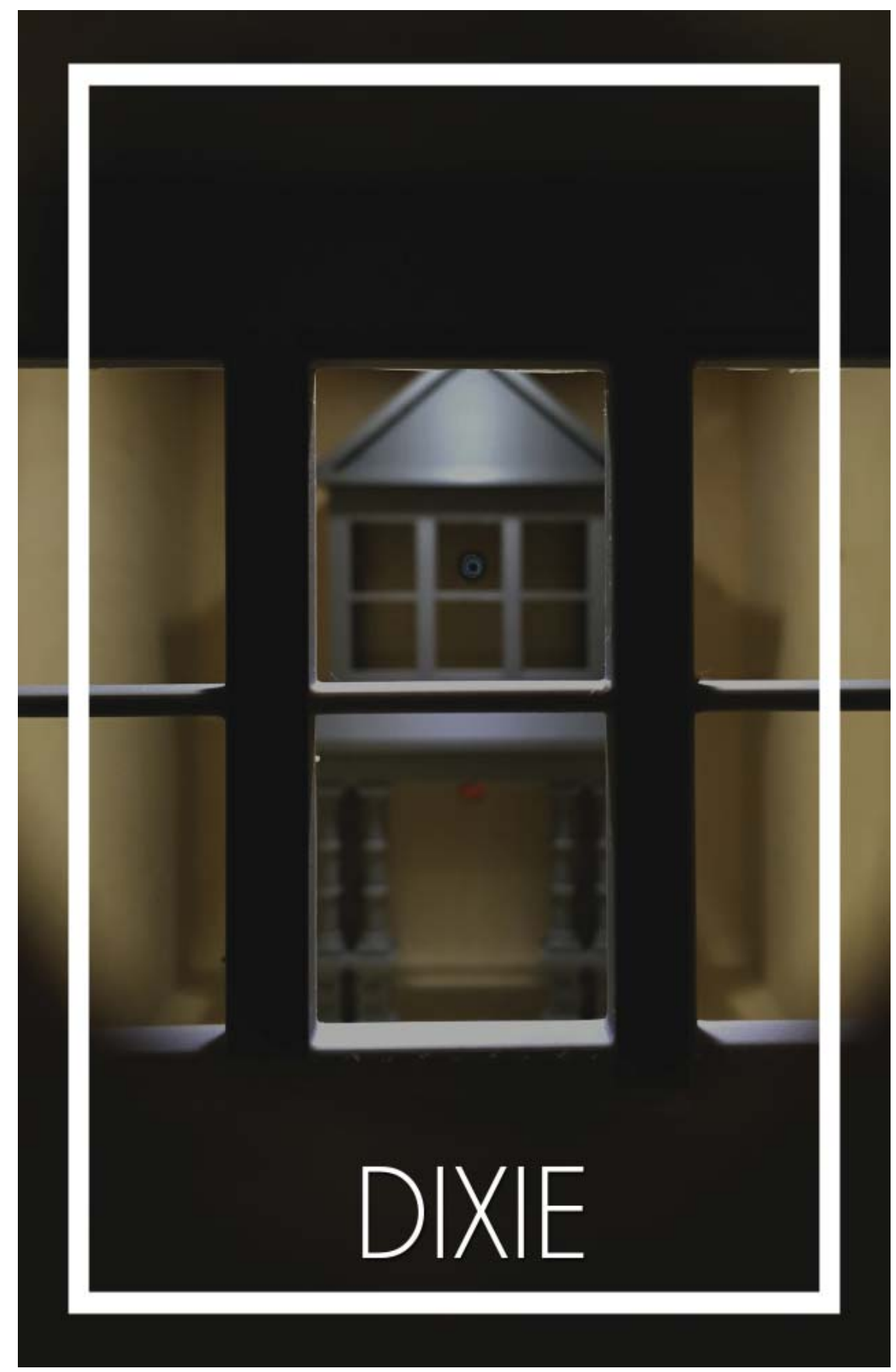

Figure 20: Postcard Installation III 


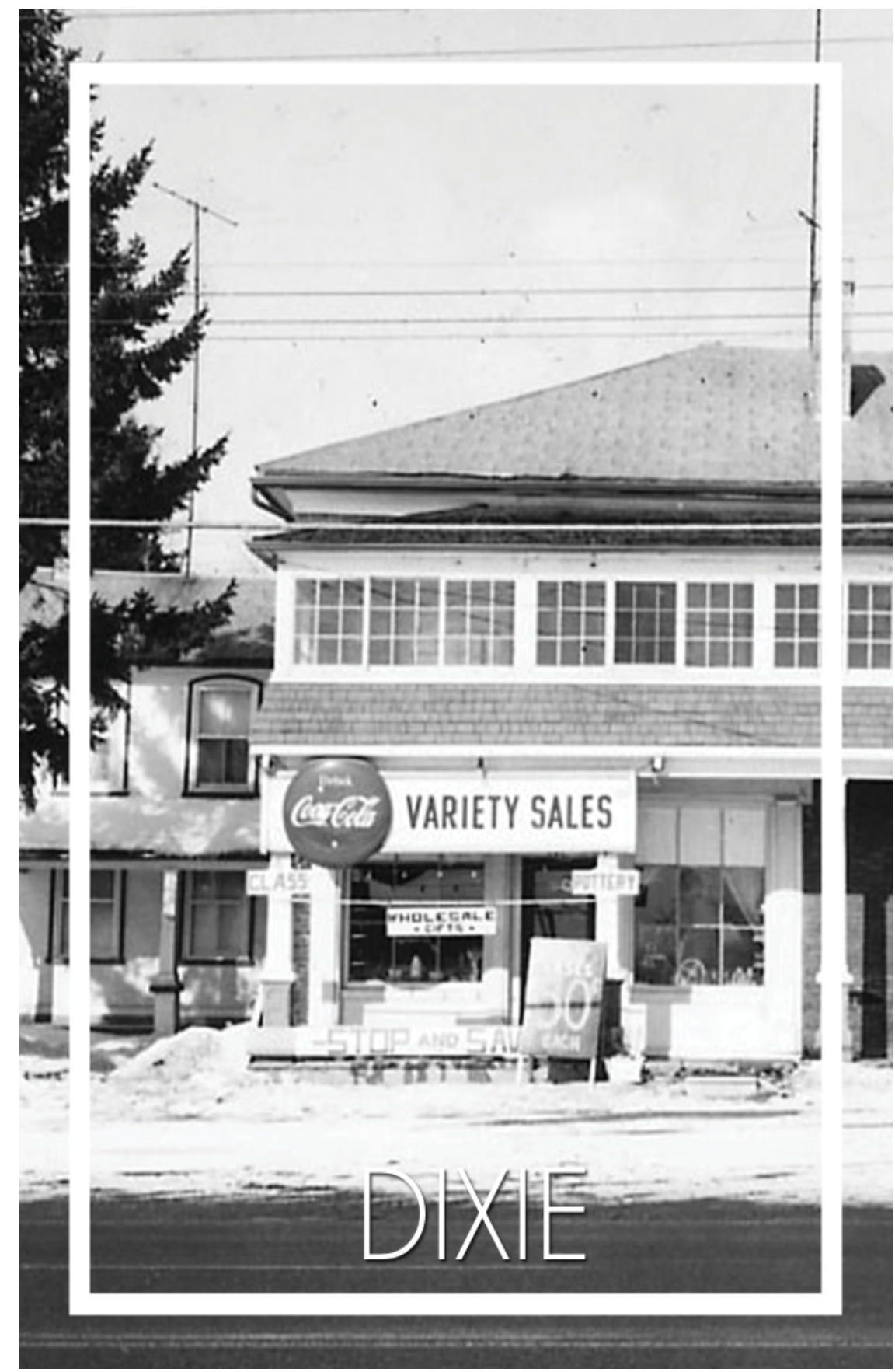

Figure 21: Atlantic Hotel, c.1960 


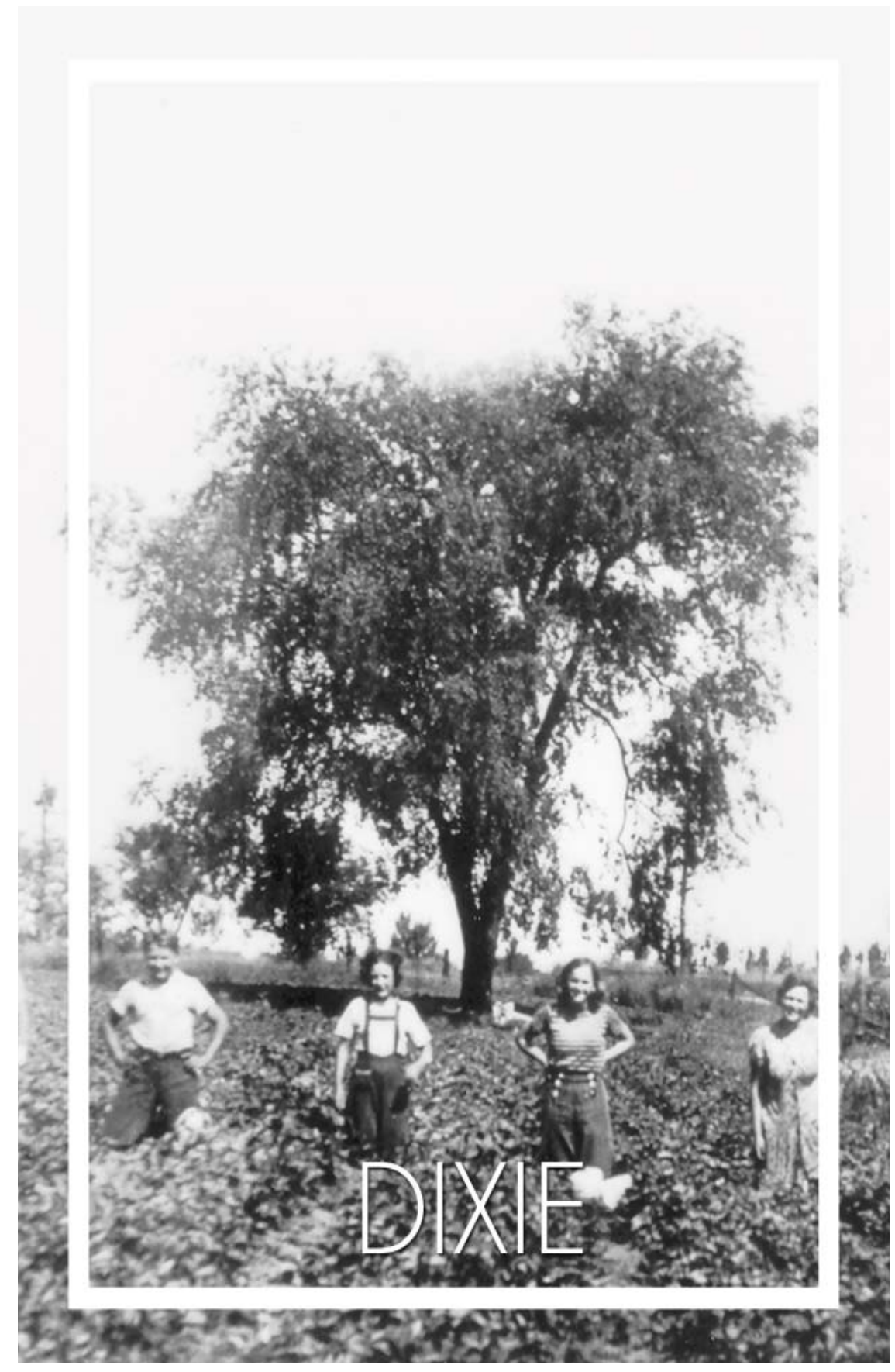

Figure 22: Kennedy Farm, c.1915 


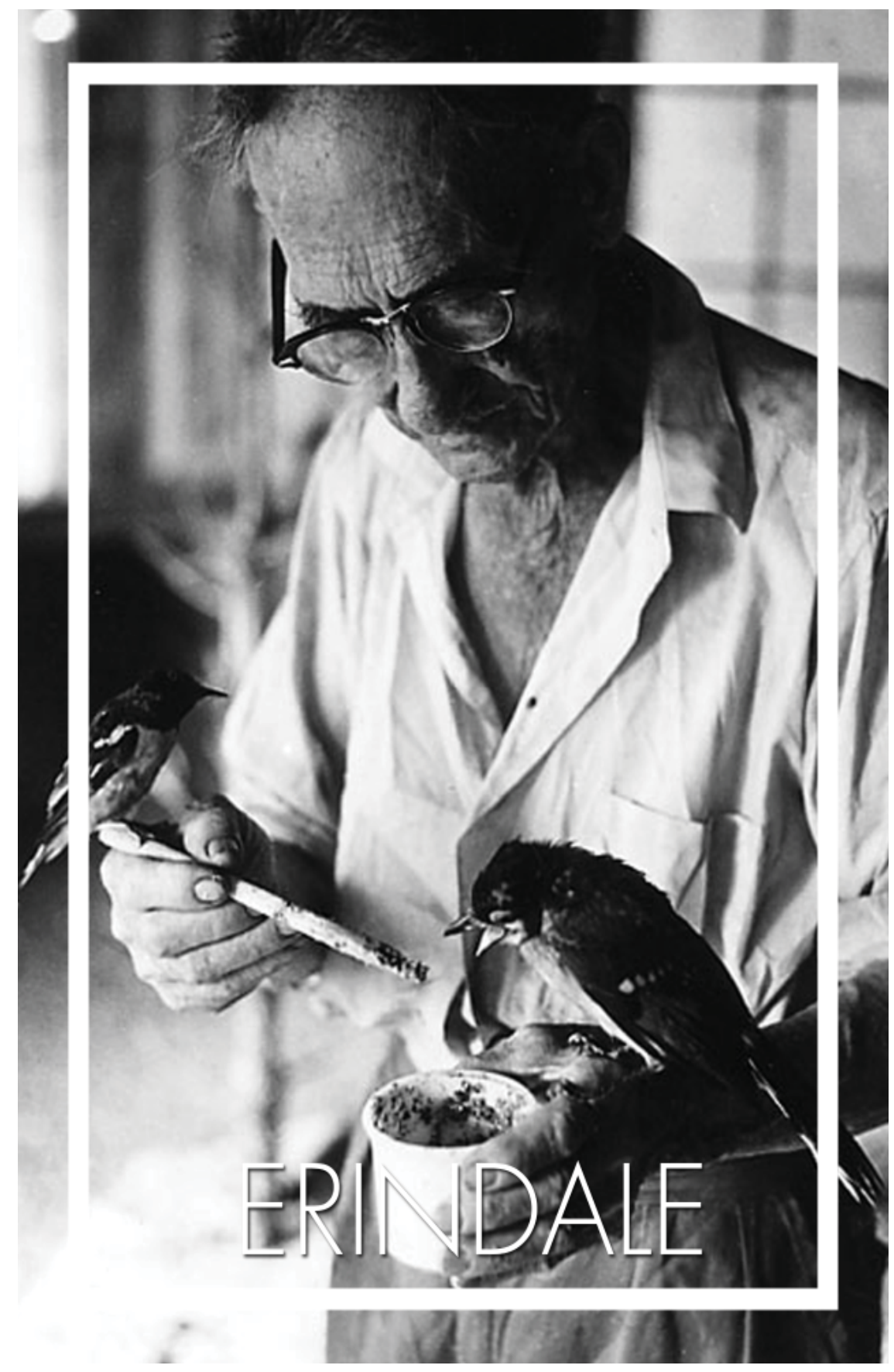

Figure 23: Windinglane Bird Sanctuary, 1970 


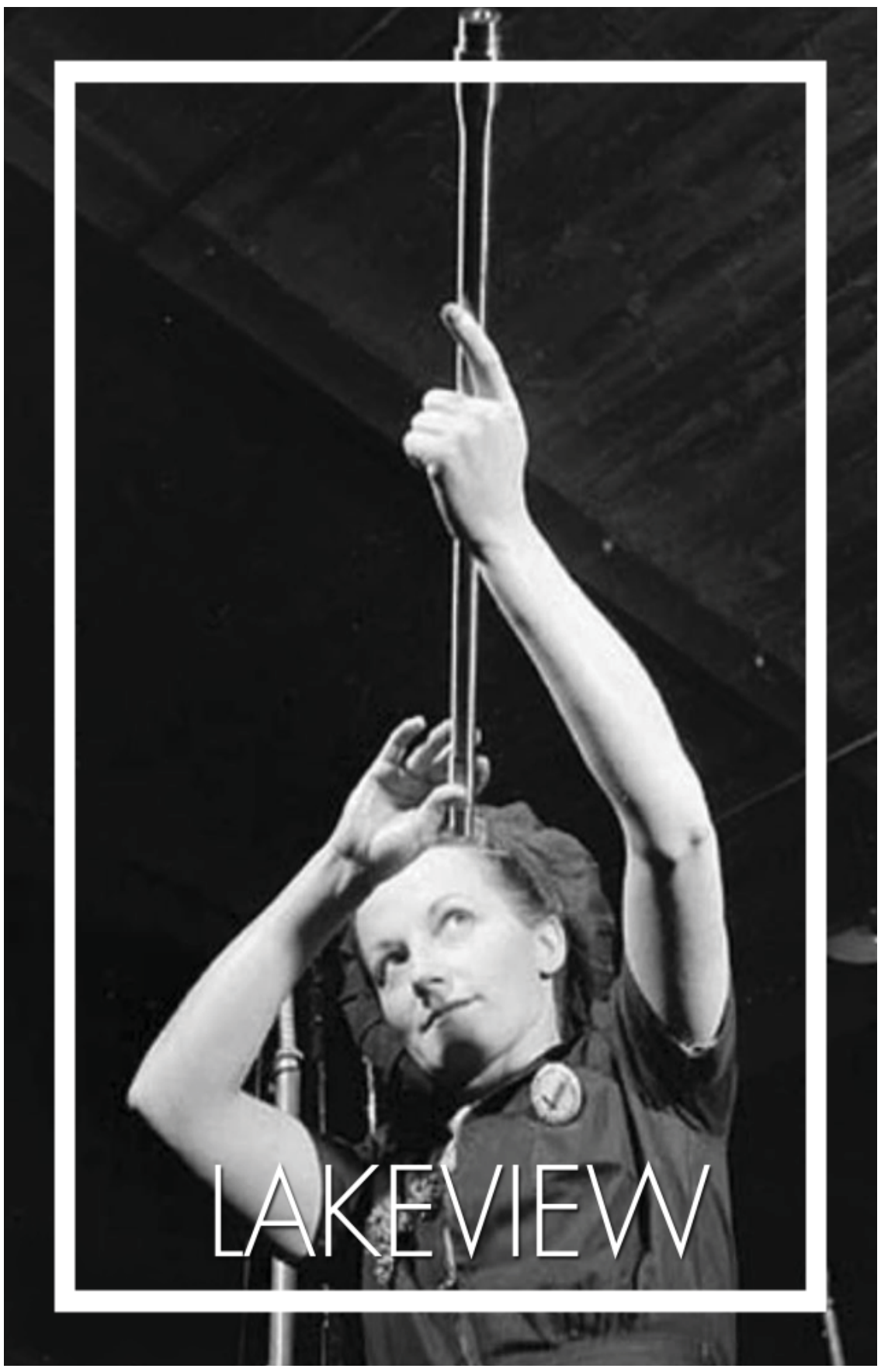

Figure 24: Female Employee Checks Gun Sight, 1942 


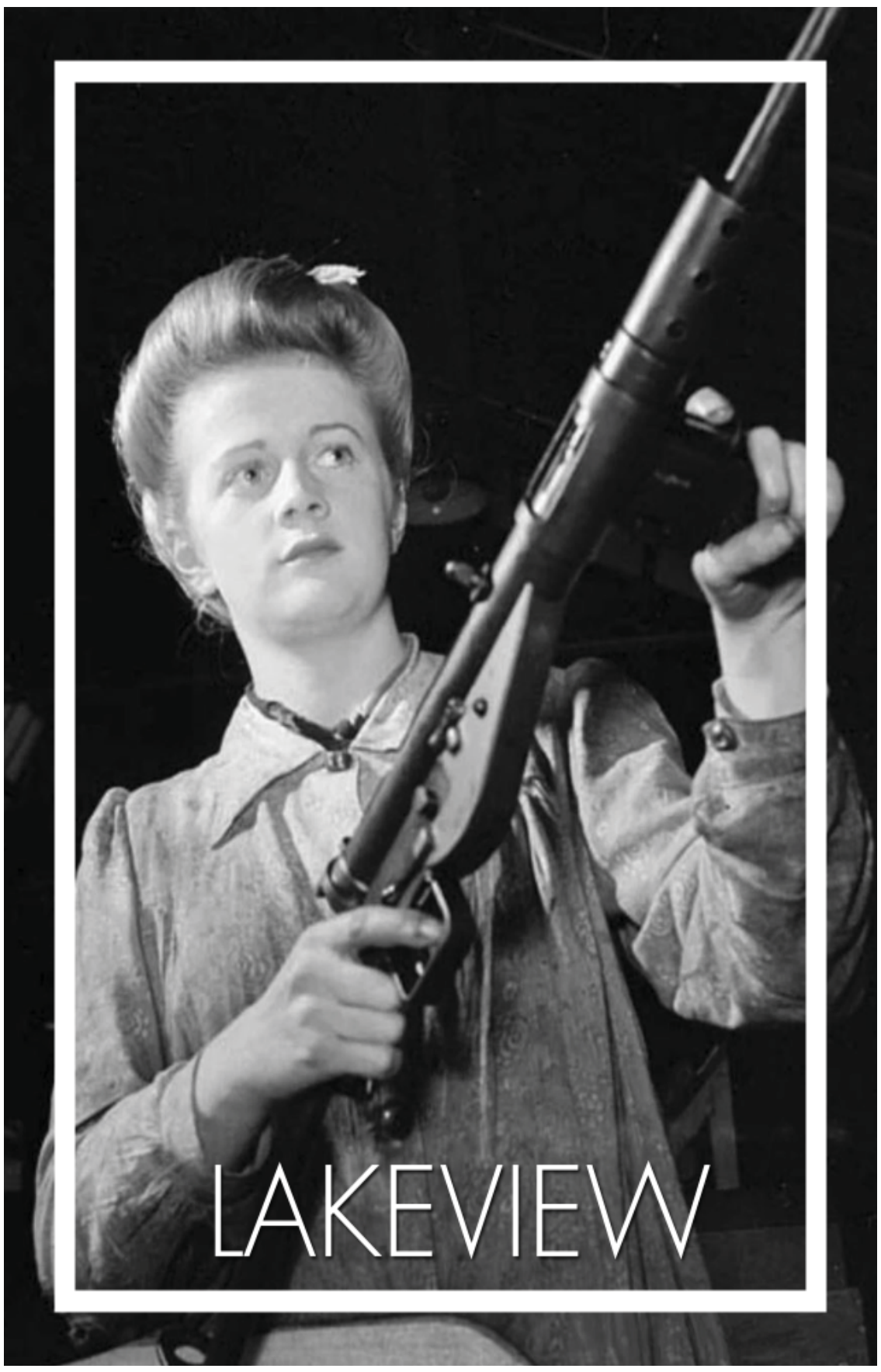

Figure 25: Women Holding Submachine Gun, 1942 


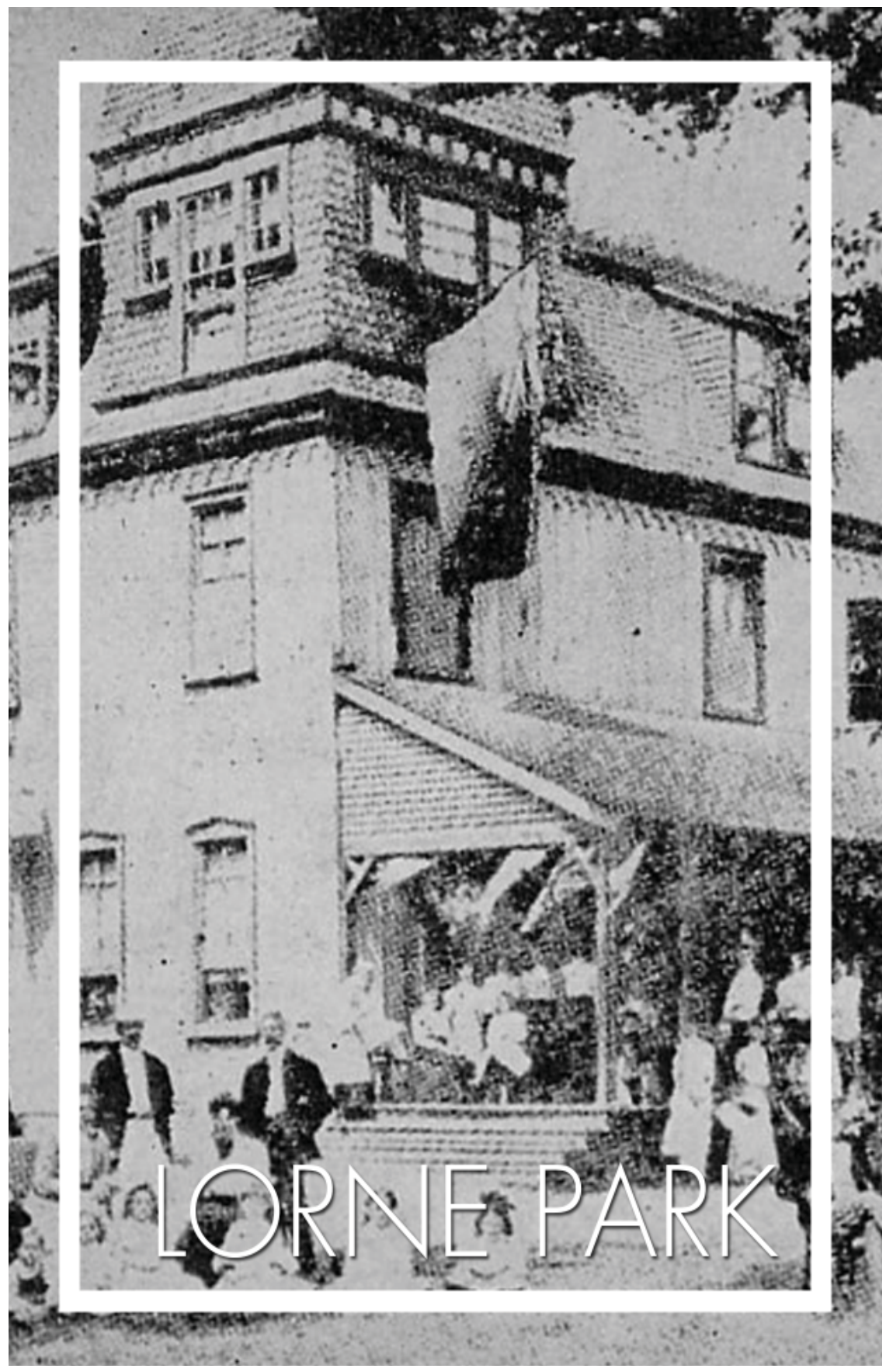

Figure 26: Hotel Louise, b.1879 


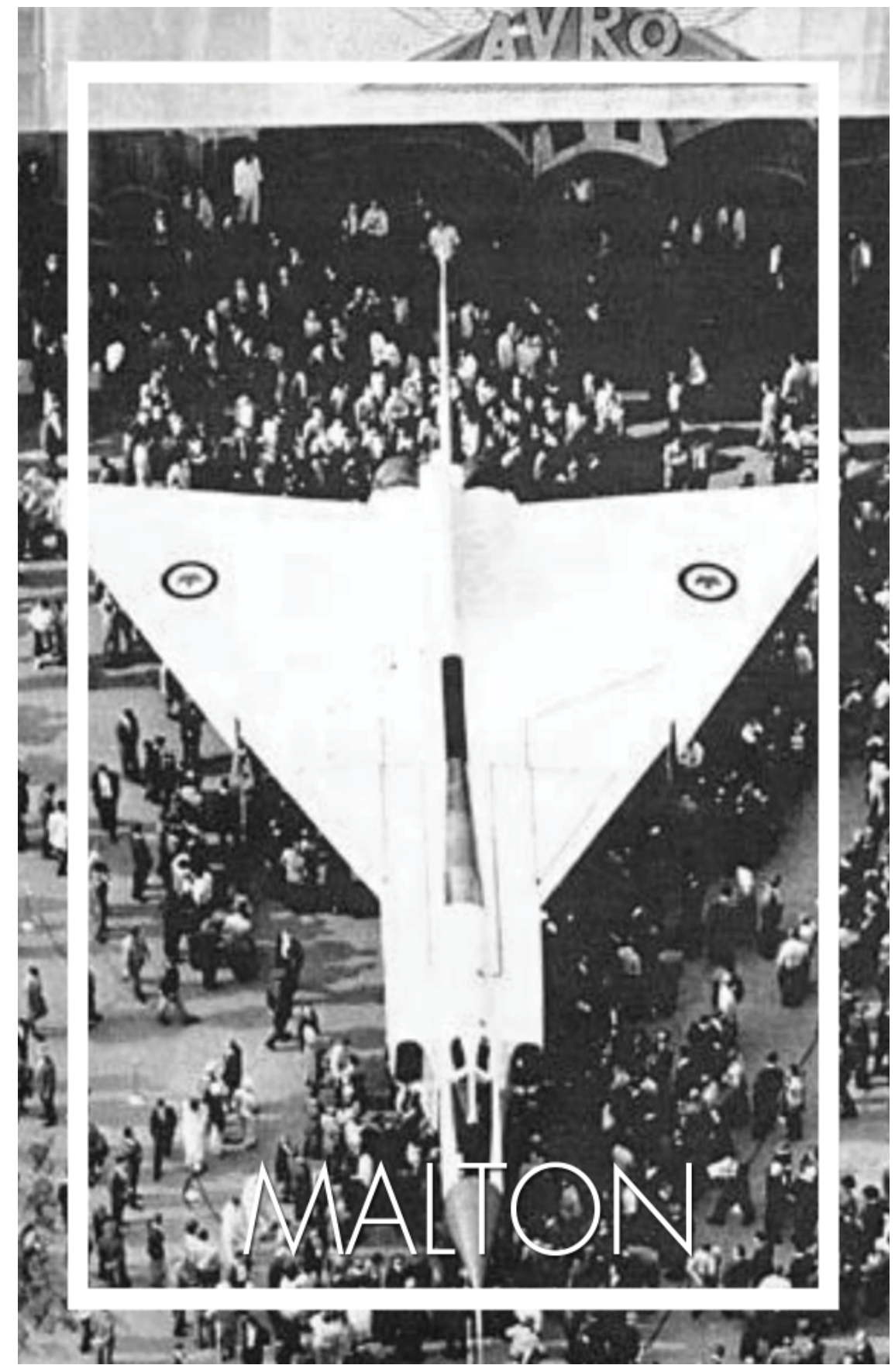

Figure 27: Avro Arrow Roll-out, c.1957 


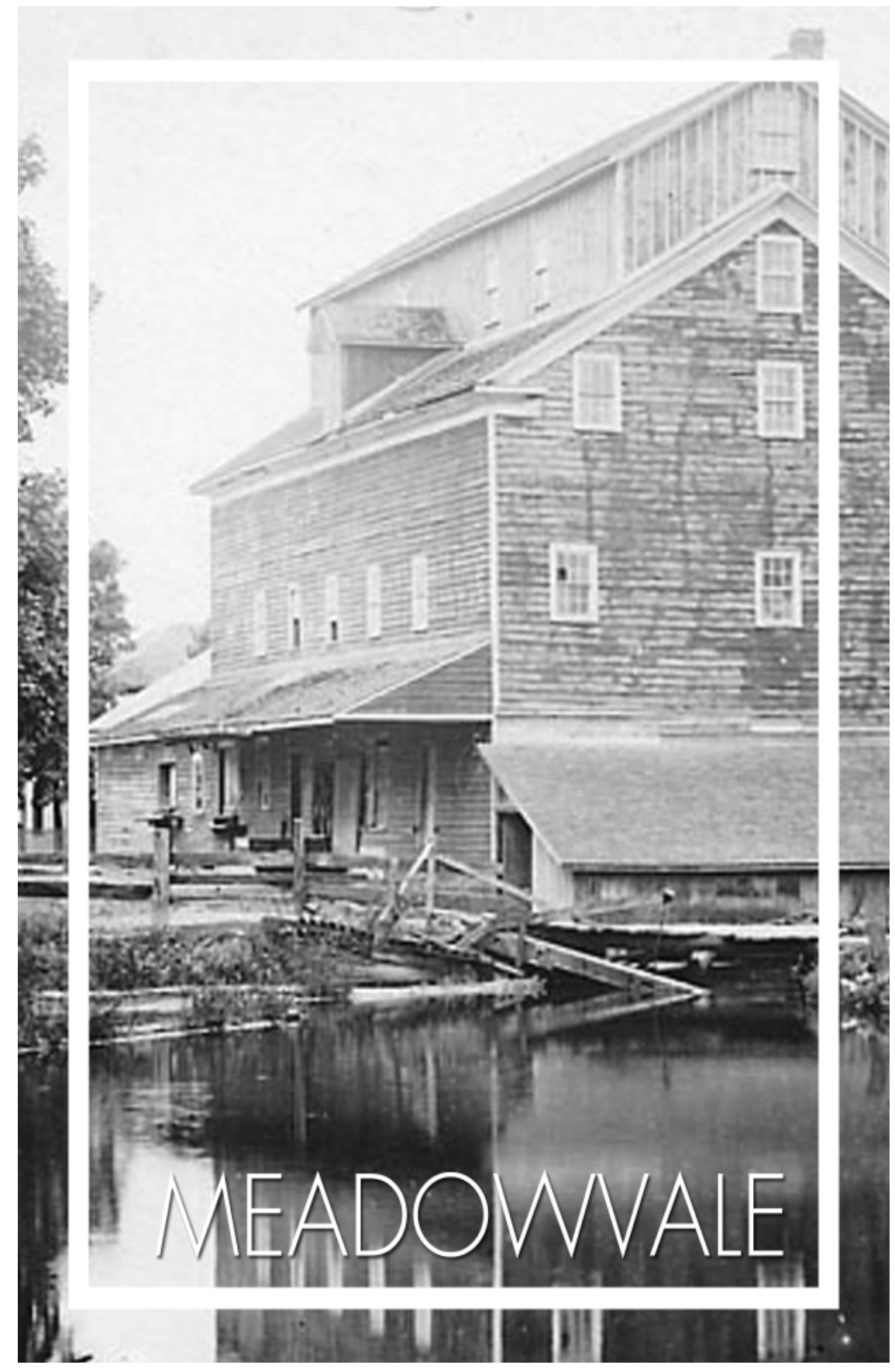

Figure 28: Meadowvale Mill, c.1930s 


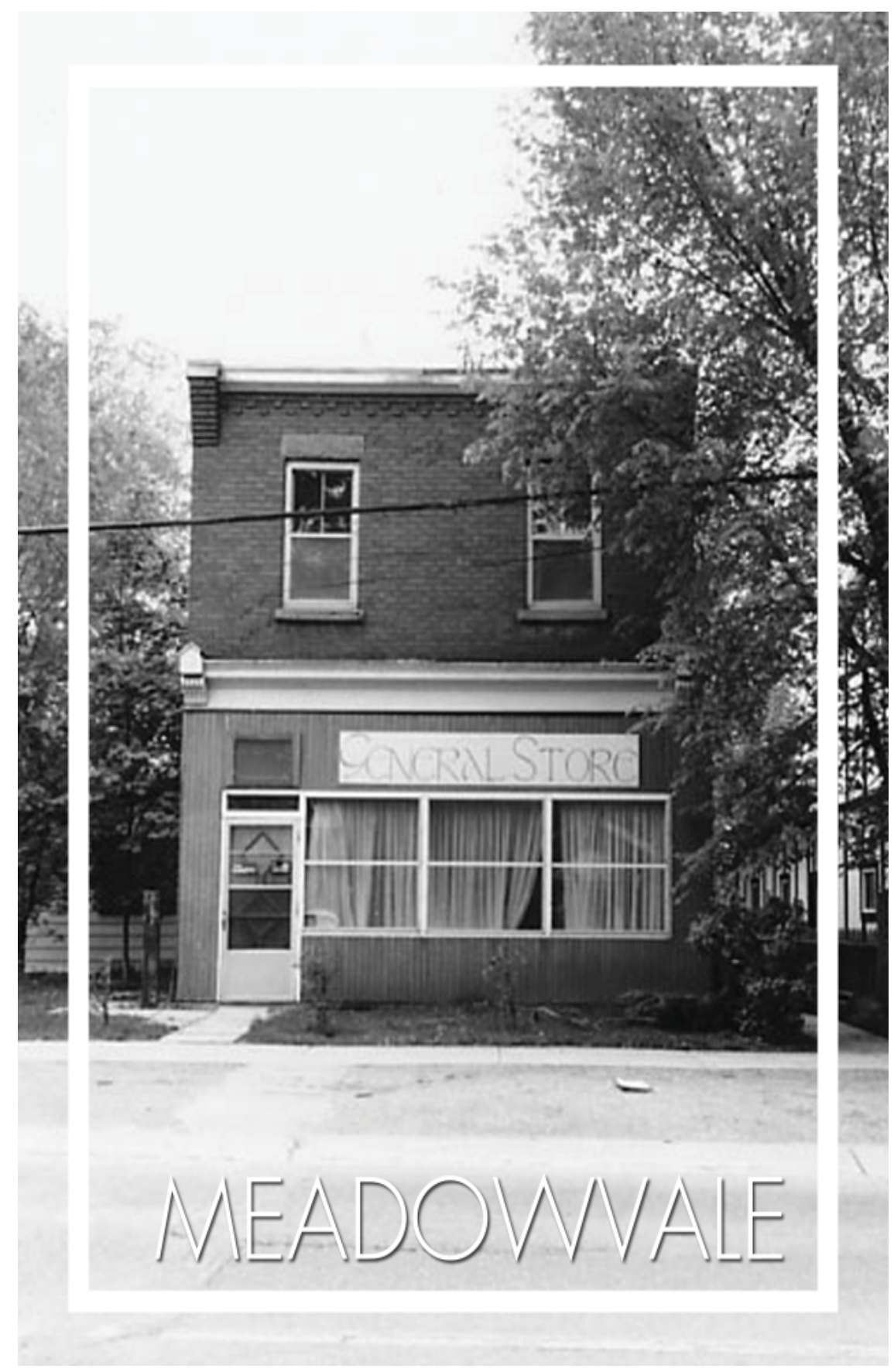

Figure 29: Meadowvale General Store \& Post Office, 1990 


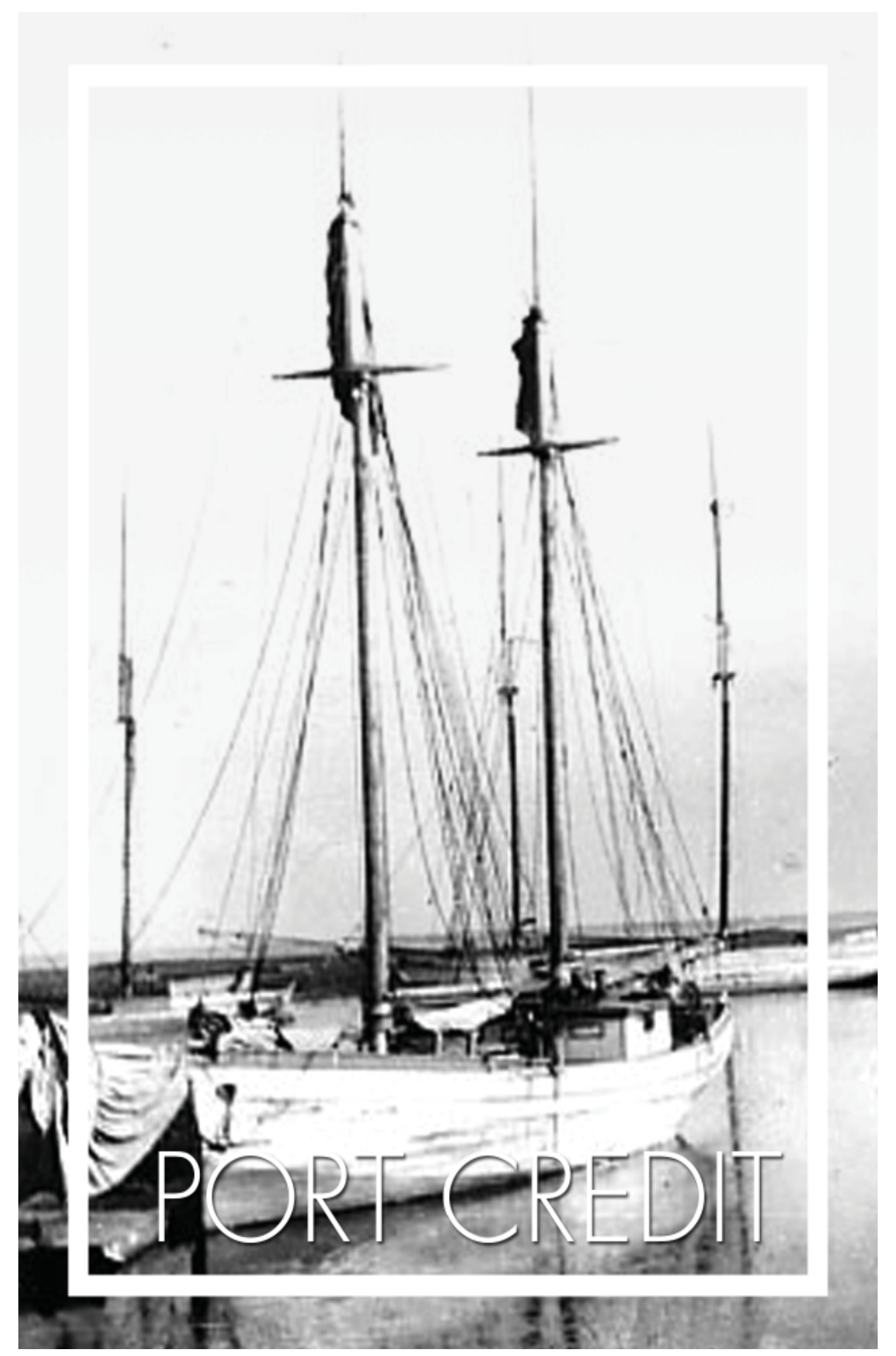

Figure 30: Schooner Arthur Hannah, c.1907 


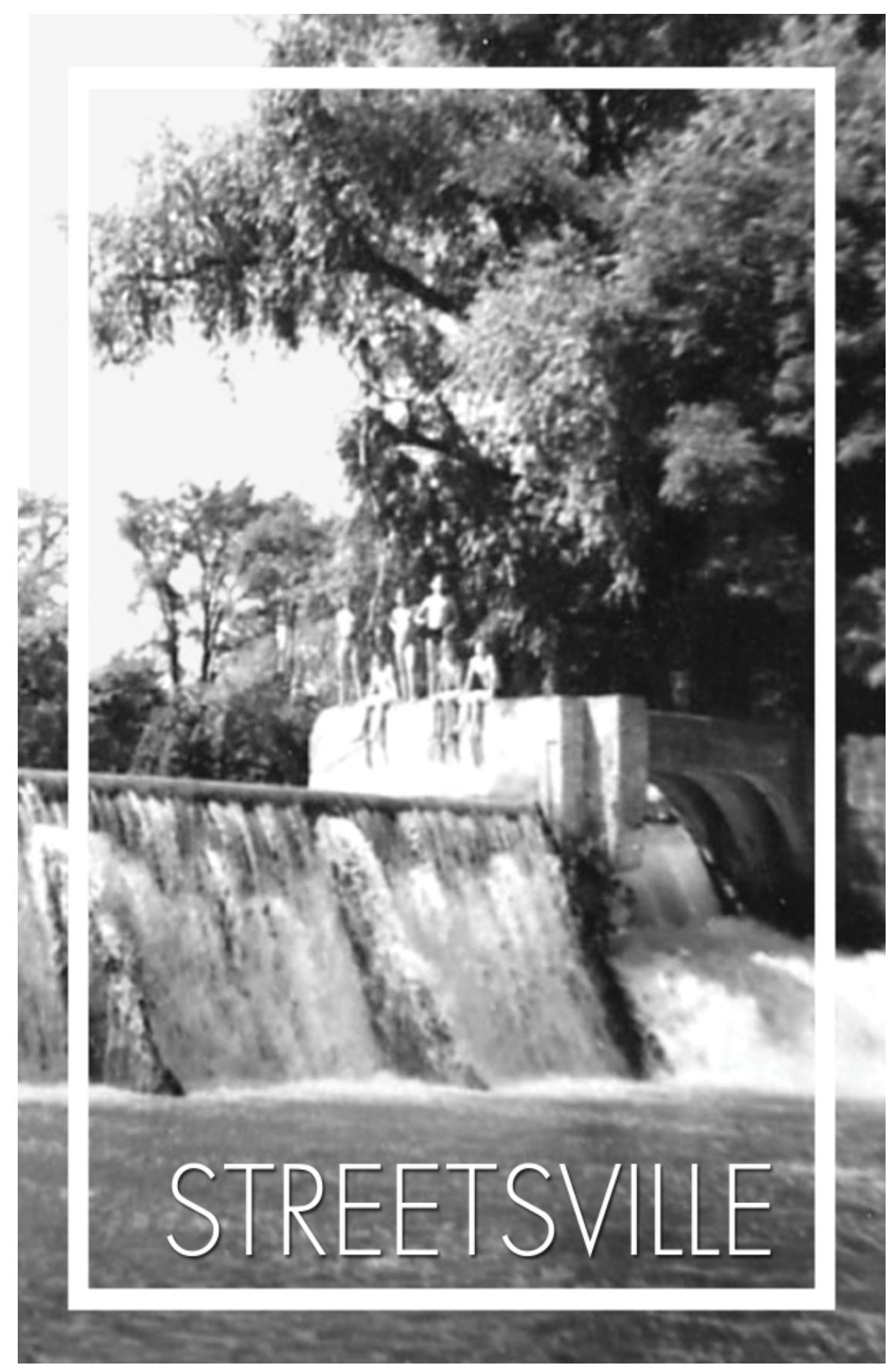

Figure 31: Streetsville P.U.C. Dam, c.1944 


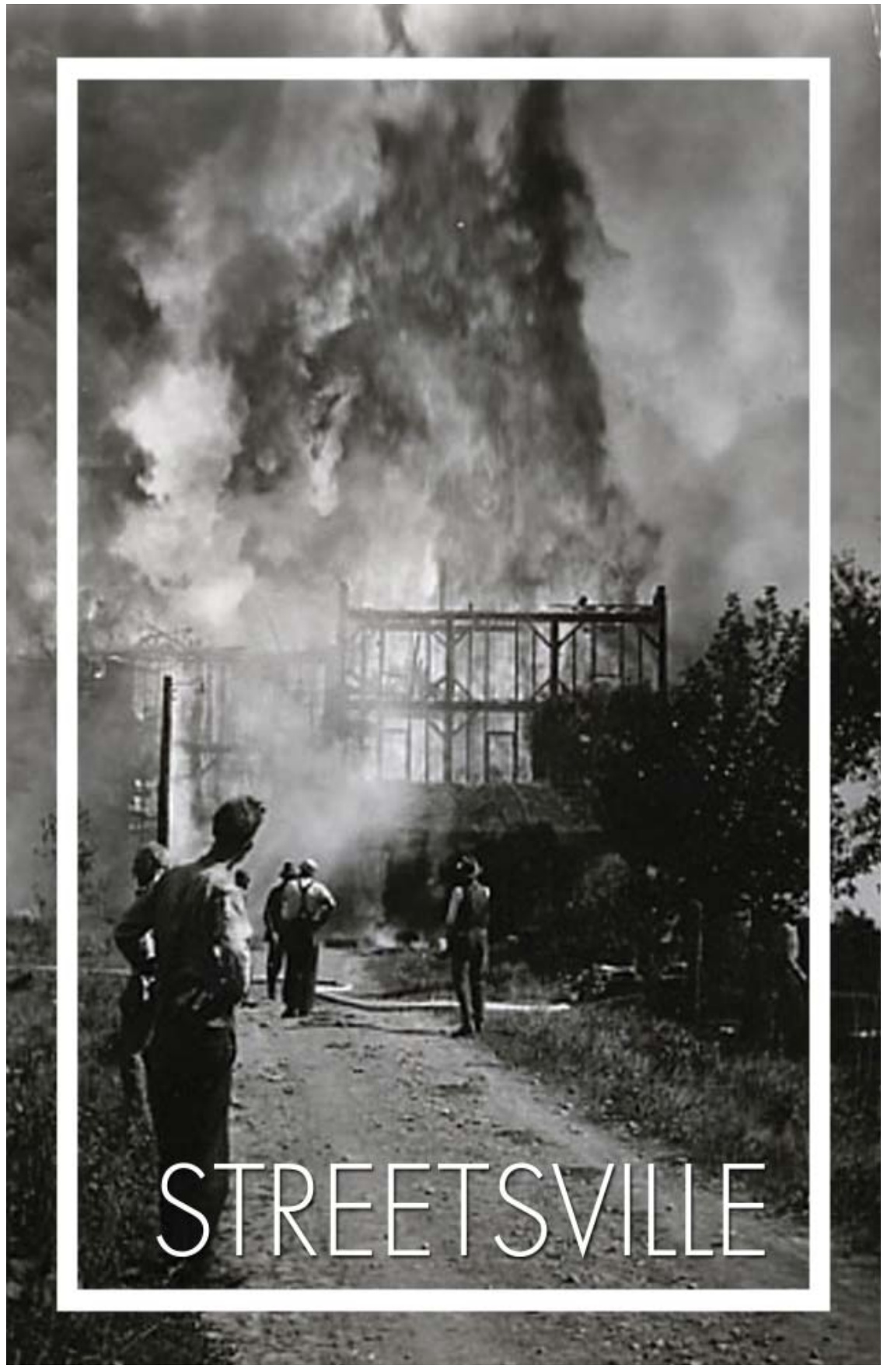

Figure 32: Mill Fire, 1929 


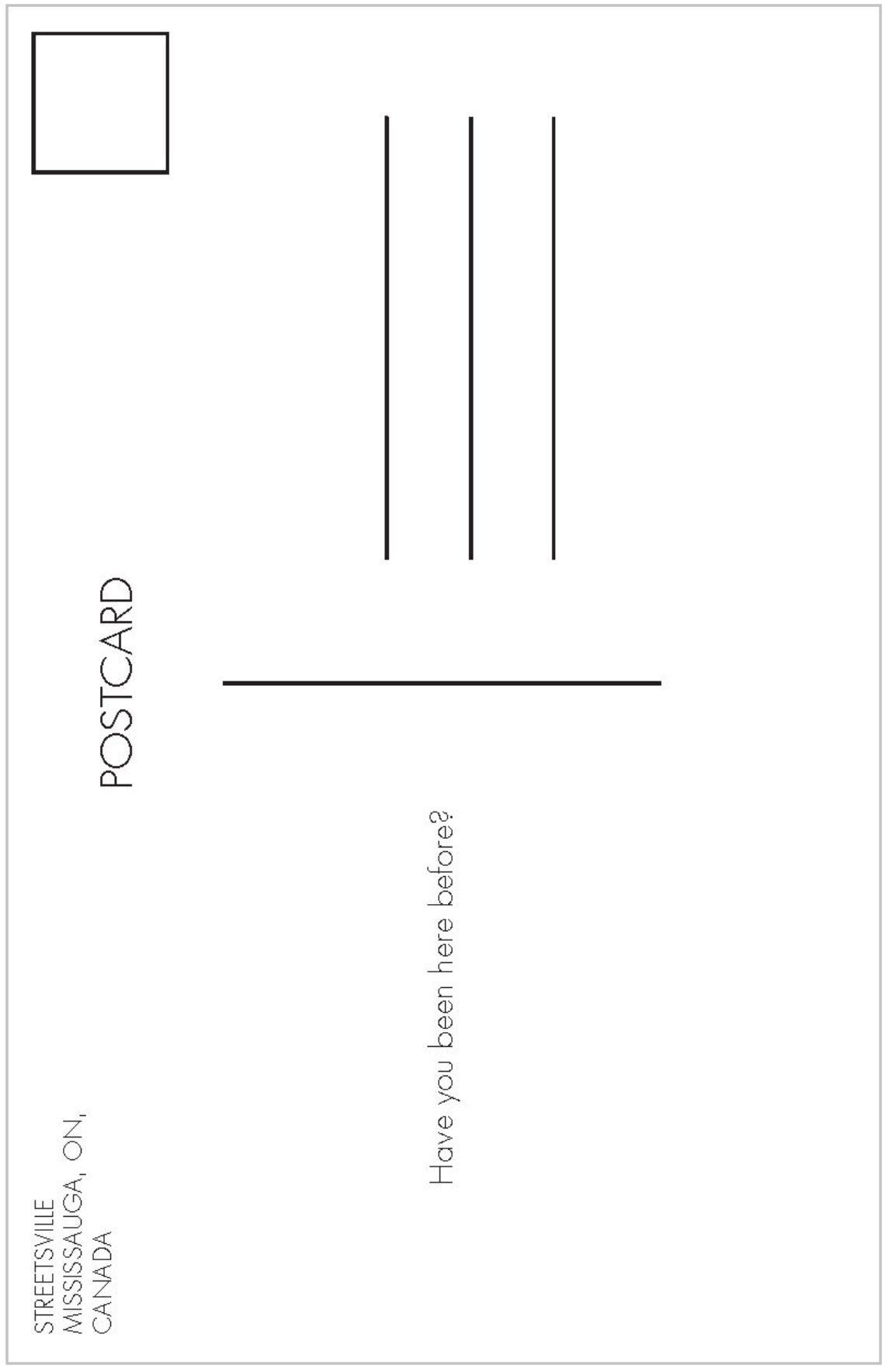

Figure 33: Reverse of Postcard 

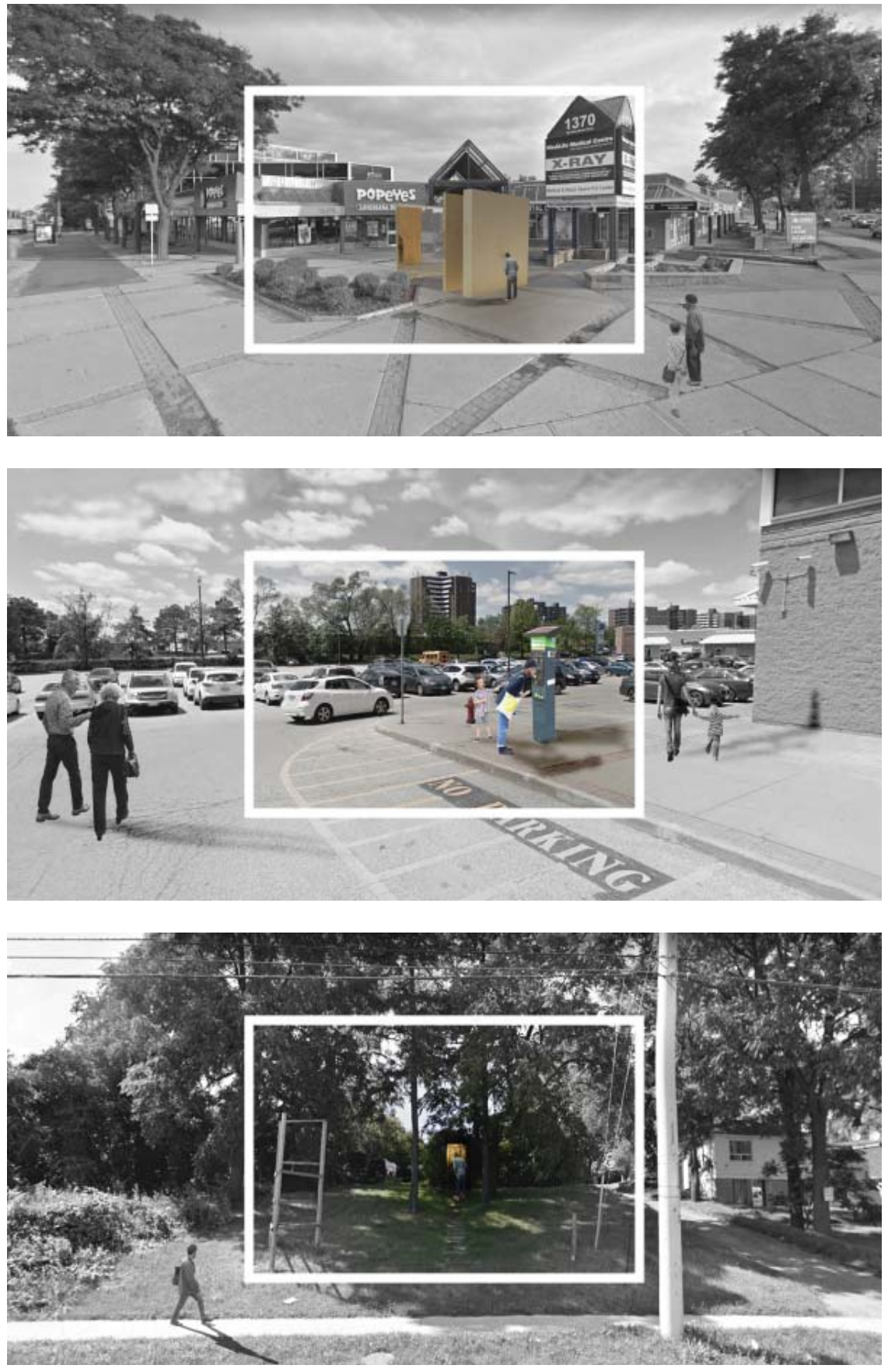

Figure 34: Full Scale Installations 


\section{N S T A L L A T I O N S}

While the postcards guided the viewer to the site, the role of the installations was to engage with them. Dealing with ways in which the senses trigger memories, I began to research approaches where artists dealt with users experiencing and interacting with installation art. Looking at Brunelleschi's tool for discovering linear perspective, I was interested in the way the tool functioned, and engaged the user. Having a system for representing three-dimensional space on a two-dimensional surface intrigued me, as it still allowed the viewer to immerse themselves within that space. This process of reflection greatly influenced the design of the installations as it forced the user to engage with their perception. By inviting the user to decipher the image presented to them, they would be given an opportunity to trigger, or create a memory from the installation itself. As transmedia storytelling involved a narrative to be understood through several mediums, so did the installations presenting themselves. While the project would not permit me to construct the installations on site, they would however be built, allowing me a way to explore this approach. Working 


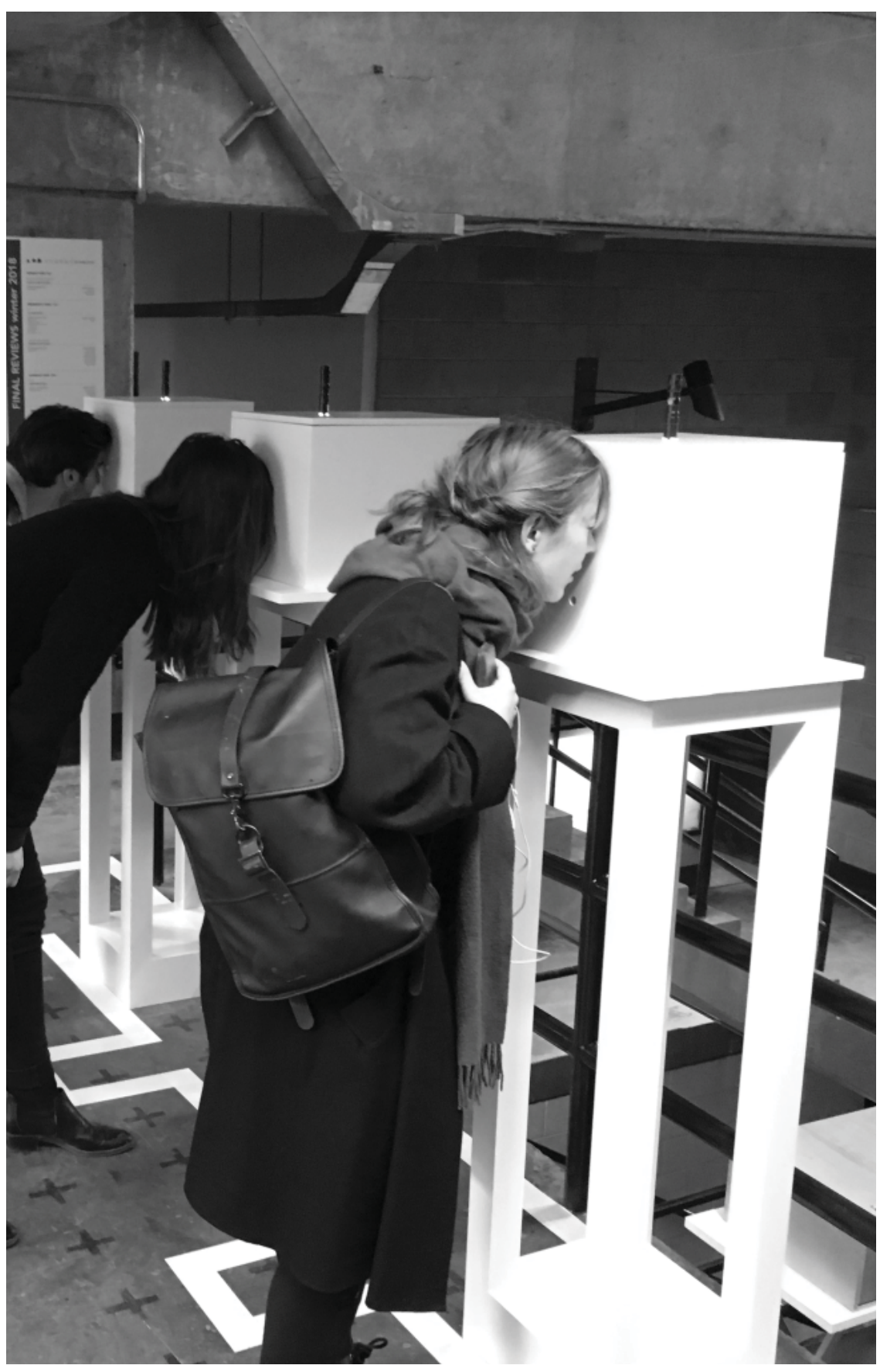

Figure 35: Memory Boxes 
similarly to Brunelleschi's tool, these boxes would function using memory triggers, housed within them a memory of the towns' past. Much like full-scale installations, these boxes would provide users the opportunity to engage with a memory of the past on the site where the past took place. When approaching one of the memory boxes, a small peephole would grant the user access to see what is inside. In a way the box represents the physical manifestation of the mind, where we can only peer into our memories, but not physically access them. The peephole provides a window into the memory, but the box functions as a threshold we cannot cross. Focusing on Dixie, I would end up constructing three boxes to house three memories related to the towns identity. Two memories would involve the St. Patrick's Roman Catholic church and cemetery, while the third would feature the Gravelle Residence. As Dixie was known for its agriculture and religious aspects, I decided to draw attention to these memories since much of these characteristics are no longer there. The first memory box would allow the user to peer into the St. Patrick's church interior. Using a mirror to reflect the images of both the churches exterior and interior, this box provides a glimpse of what the church may have looked like, while standing in front of its doors. Furthering the design of this memory box, the sounds of 
church bells would be included to provide an auditory effect. The reasoning behind this, was to trans-locate the sound of the original church bell that still can be heard in the church's new location, where they are now housed. While this memory box was built in a smaller scale, the intention would have seen this design built in full-scale on the original site of the church. While functioning in the same way, the full- scale installation would allow users to fully immerse themselves in the memory trigger. The actual chiming of the bell would be relayed from a microphone at its current location, while played remotely in the installation. The outcome would see the sights and sounds of the church experienced once more in its original location. The second memory box would expand on the memories around St. Patrick's Roman Catholic church. It is known that the church featured a small cemetery behind the building, which eventually got paved over with a parking lot. As my research did not include a concrete list of those buried, the design would focus on an endless number of dead. Prior to the construction of this memory box, I designed a postcard that depicted an image of a man, displayed as a sign over top a parking spot. The sign would illuminate as someone would park their car, revealing those buried below. The idea behind this was to inform the users of what existed below their feet. Furthering 
this provocation, the design would utilize four mirrors reflecting a wooden block placed at the center of the box. The wooden block is there to signify the casket of those buried underneath the parking lot. As this memory box provides the illusion of infinite space, the suggestion is that there are an infinite number of dead, underneath an infinite number of parking spots. Much like when looking for a parking spot, we will eventually look for a place in the ground. The third memory box would showcase the Gravelle residence, a large two-story building, which was faced with sandstone, concrete columns, and a metal roof. The columns supported a sunroom, which extended from the second floor. This property also featured a barn, and the house included two basements. As not much is known about the family that resided here, the intention for this memory box was to focus on the types of buildings that once were in the town of Dixie. Functioning as an agricultural center, the homes were often surrounded by large expanses of farm land, contrasting the large expanses of parking lots and strip malls that the town features today. This memory box would showcase a model of the Gravelle residence's front portico, and sunroom. As viewers peer through the peepholes, they will be seeing themselves through the model, as if they were standing inside the home itself. 


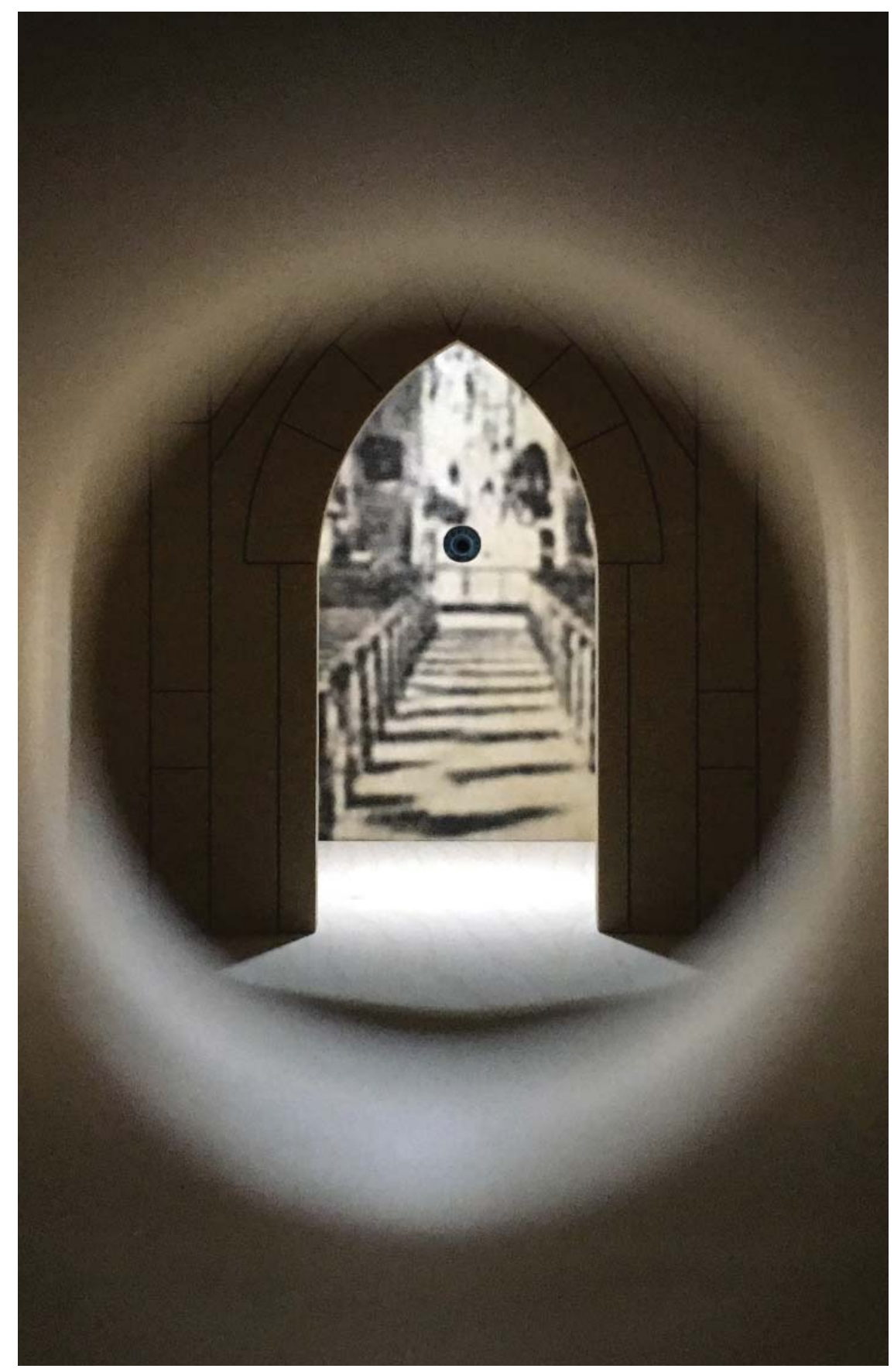

Figure 36: Memory Box 1 


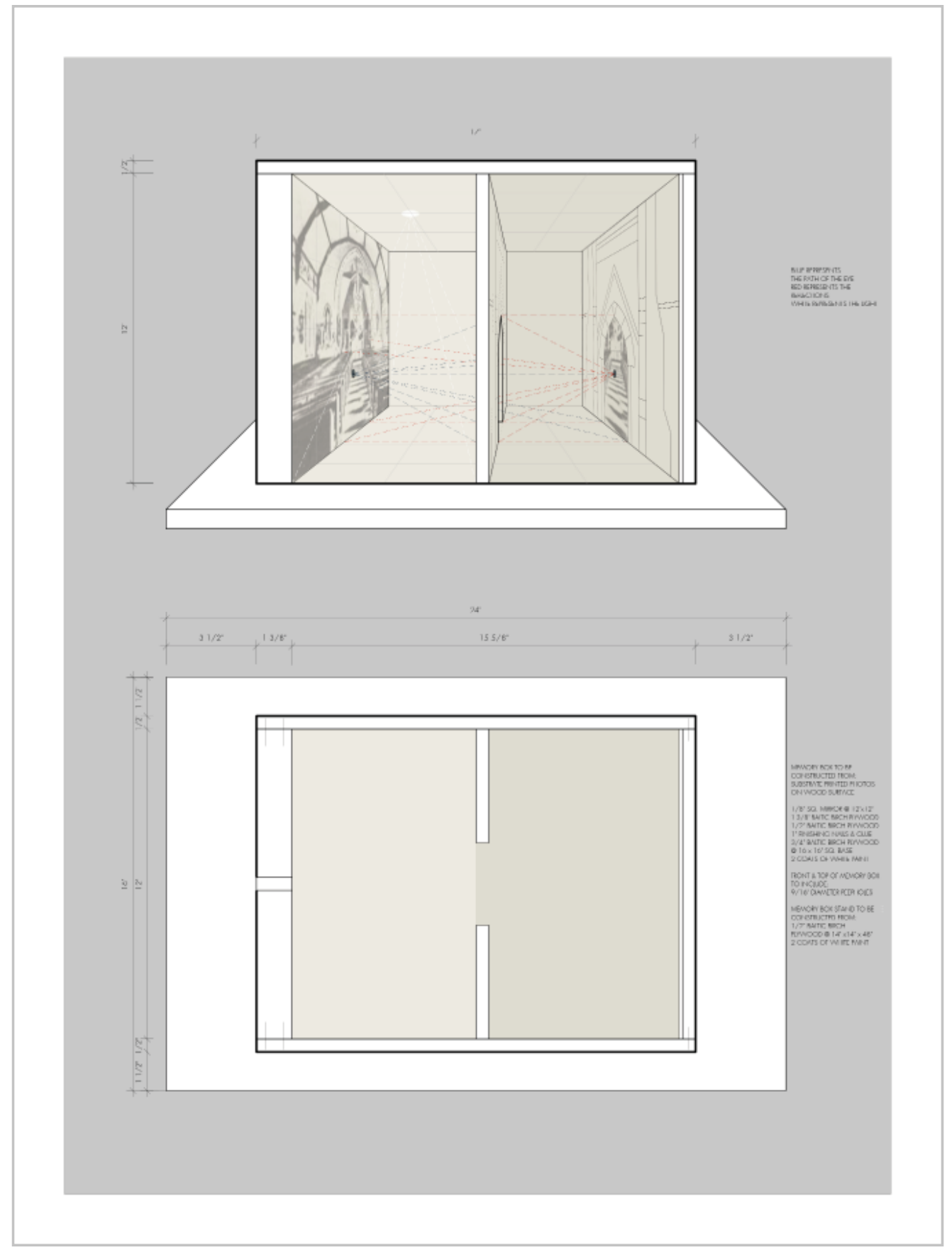

Figure 37: Memory Box 1 Construction 


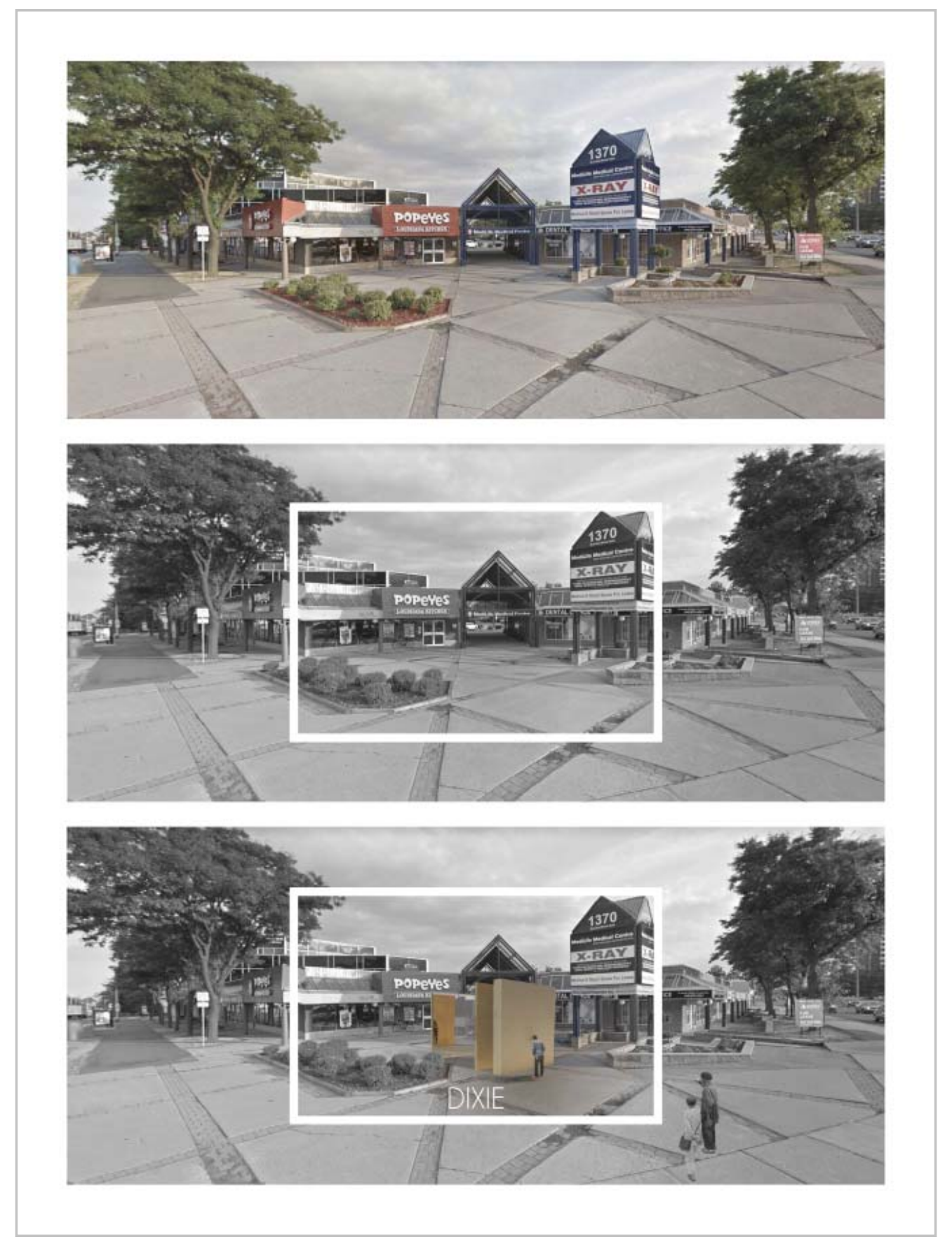

Figure 38: Full Scale Installation 


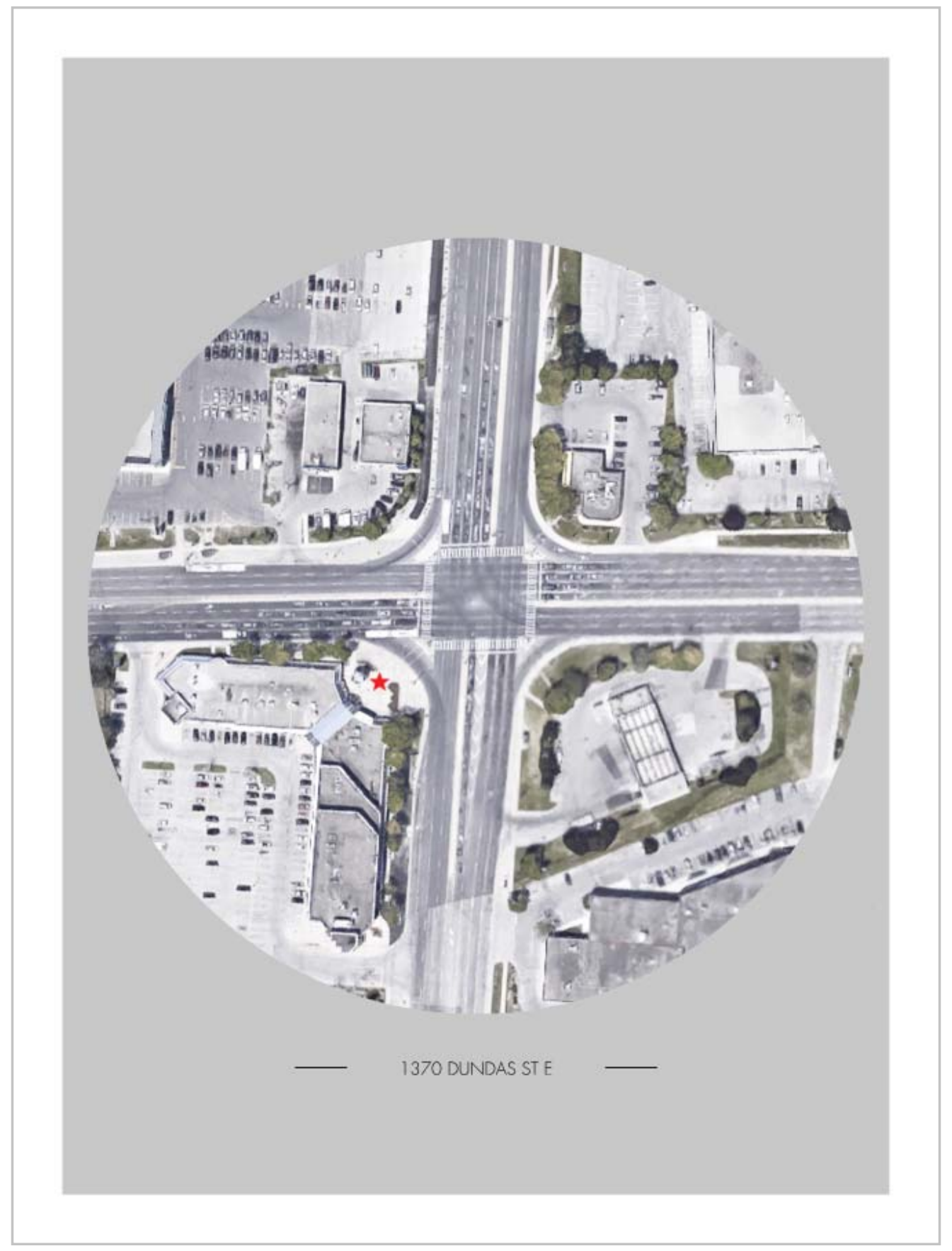

Figure 39: Installation Location 


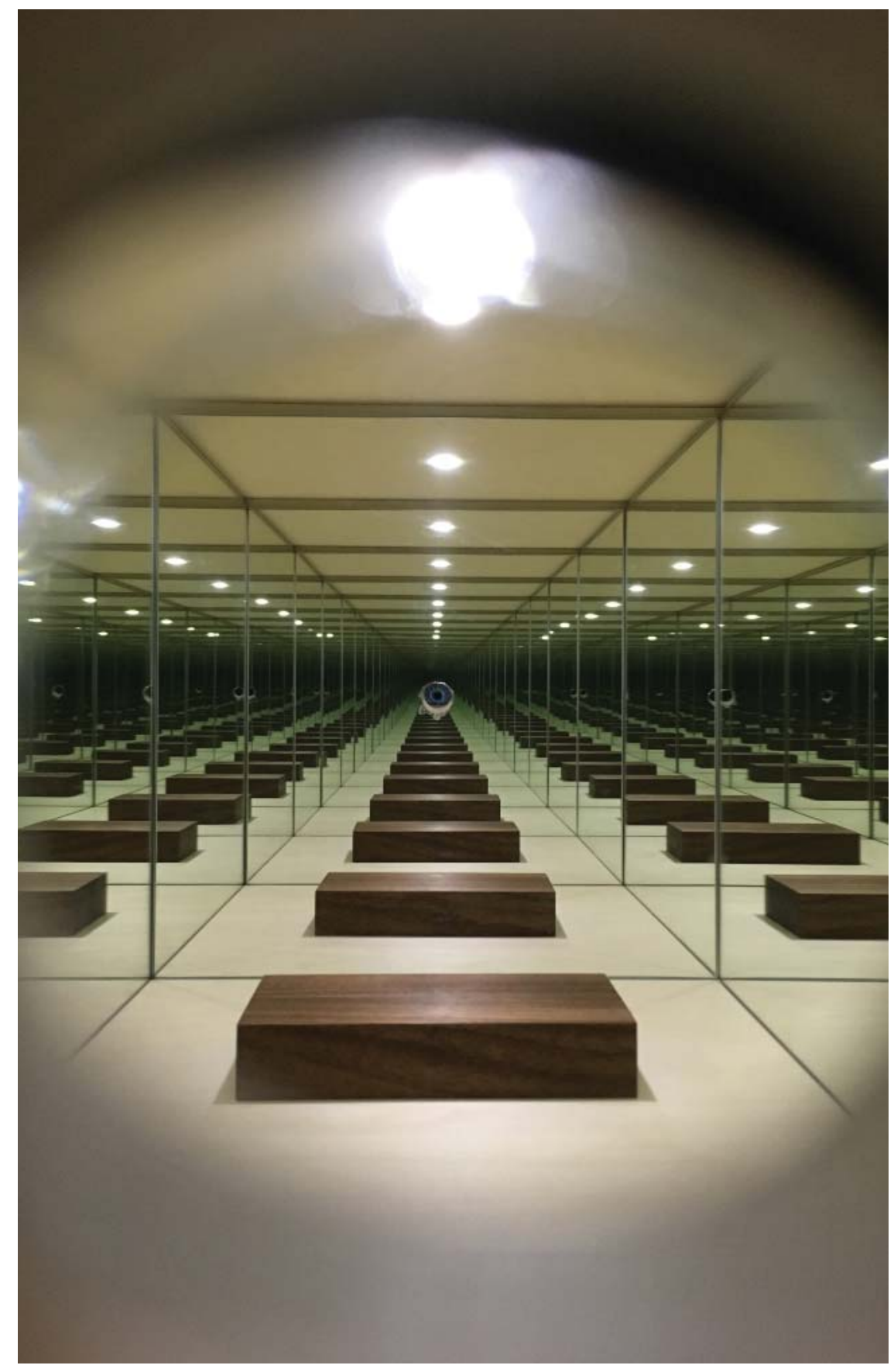

Figure 40: Memory Box 2 


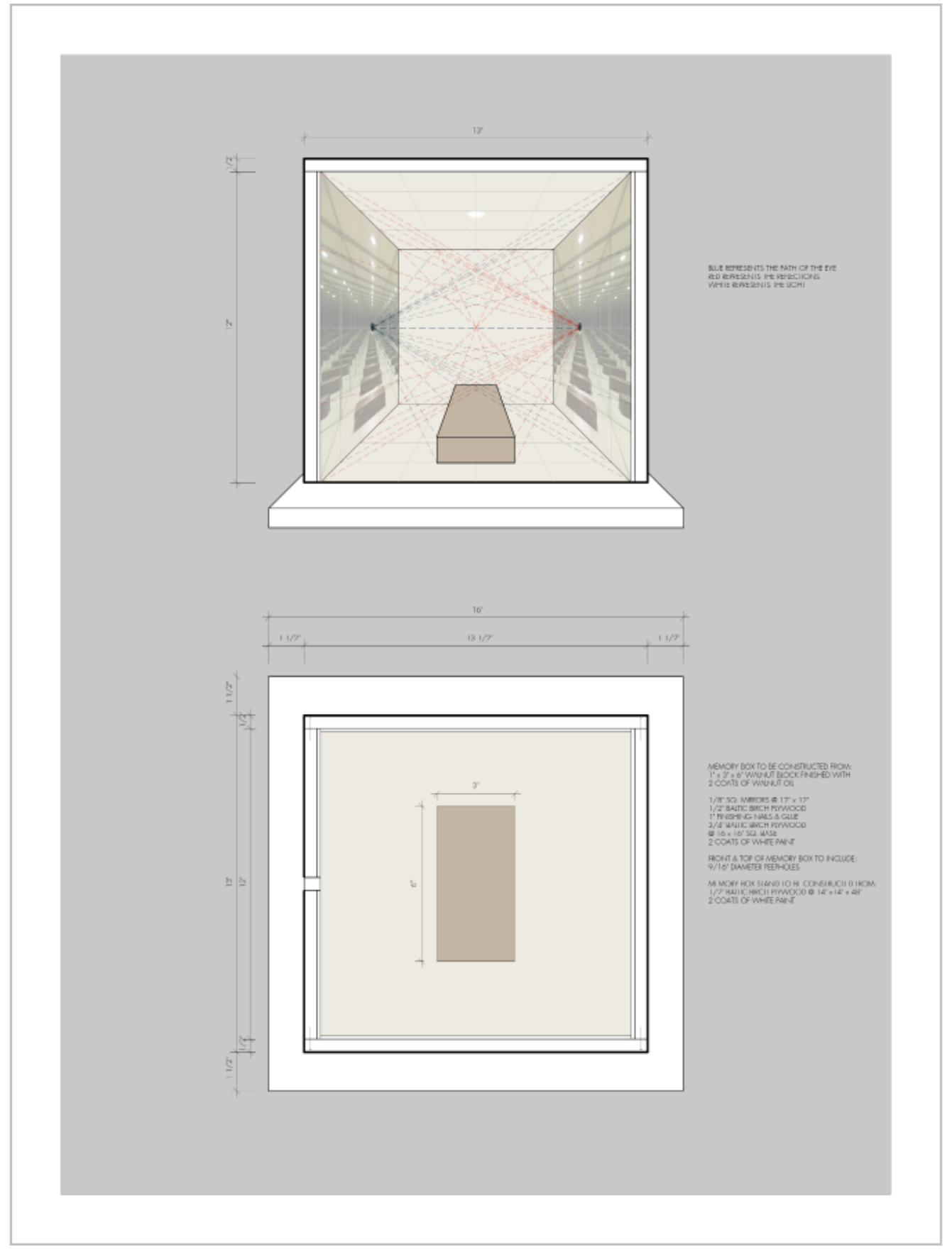

Figure 41: Memory Box 2 Construction 


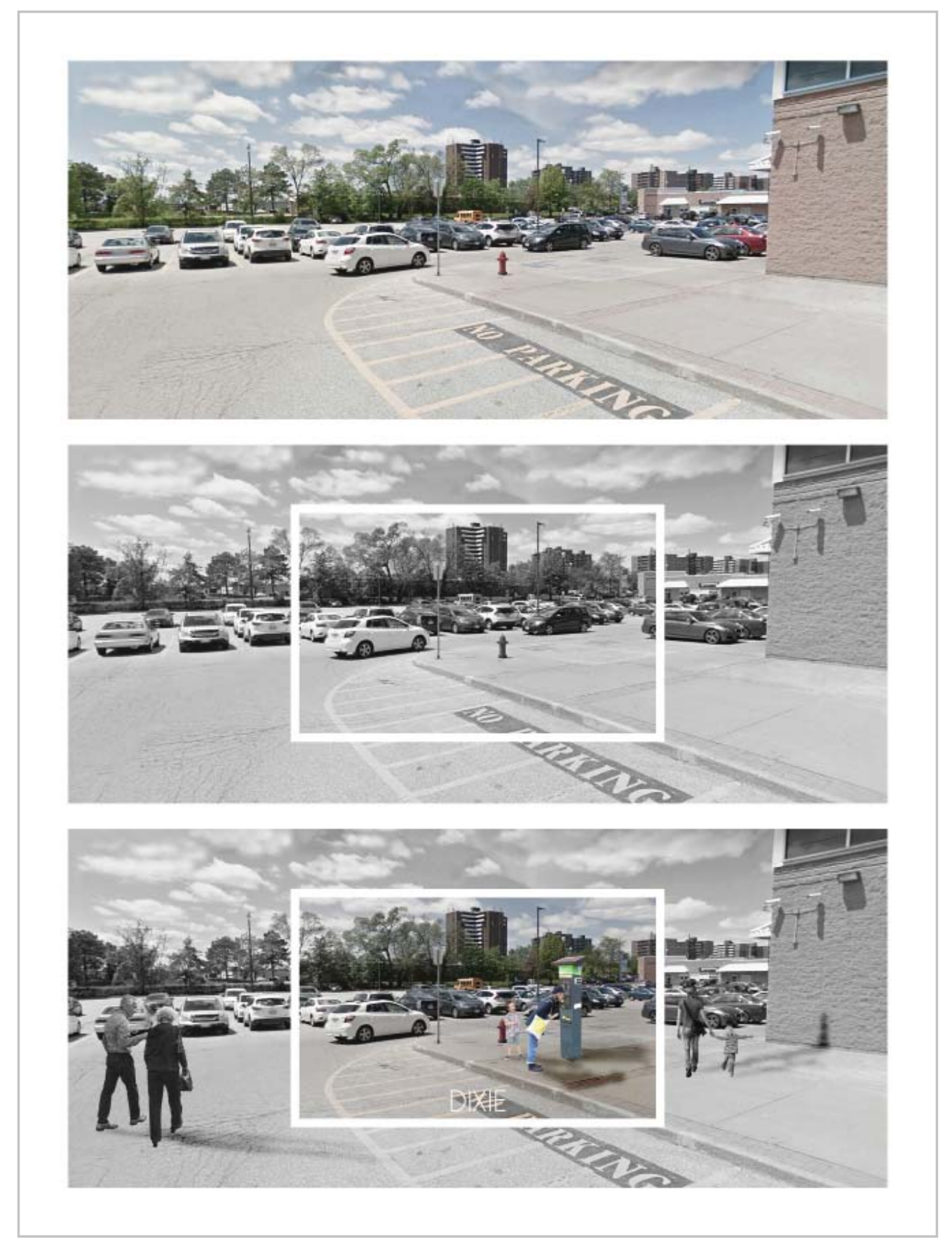

Figure 42: Full Scale Installation 


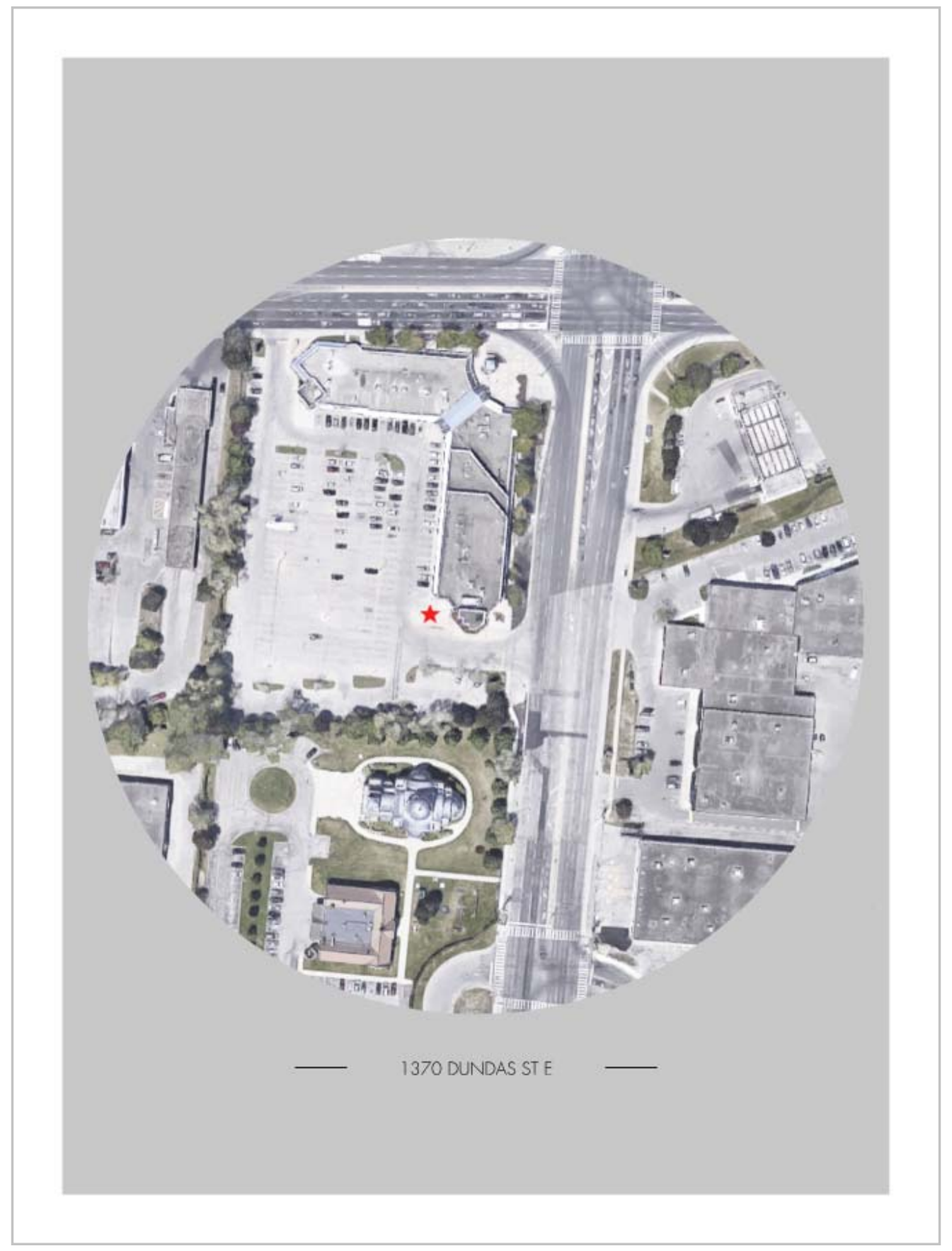

Figure 43: Installation Location 


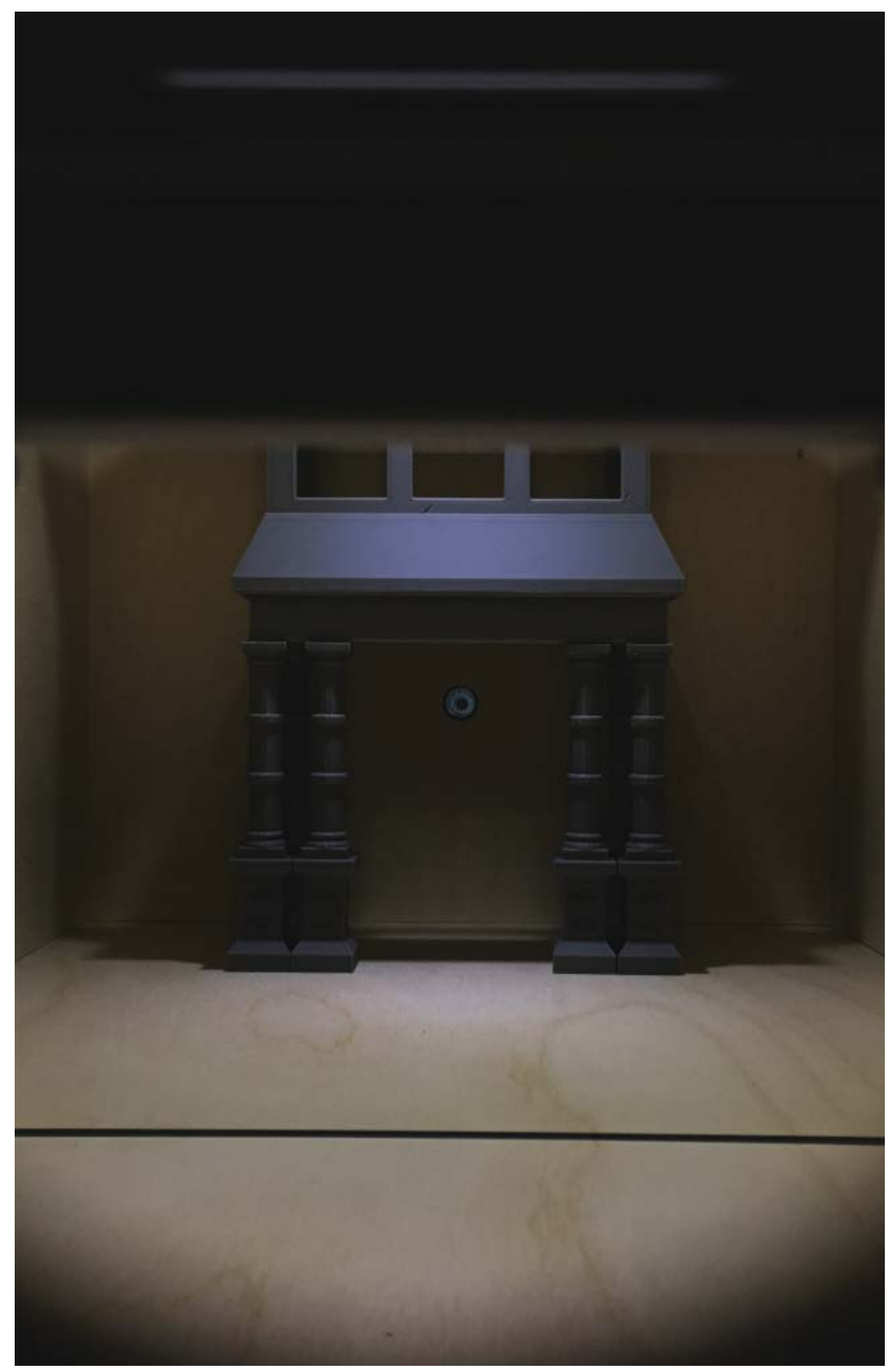

Figure 44: Memory Box 3 


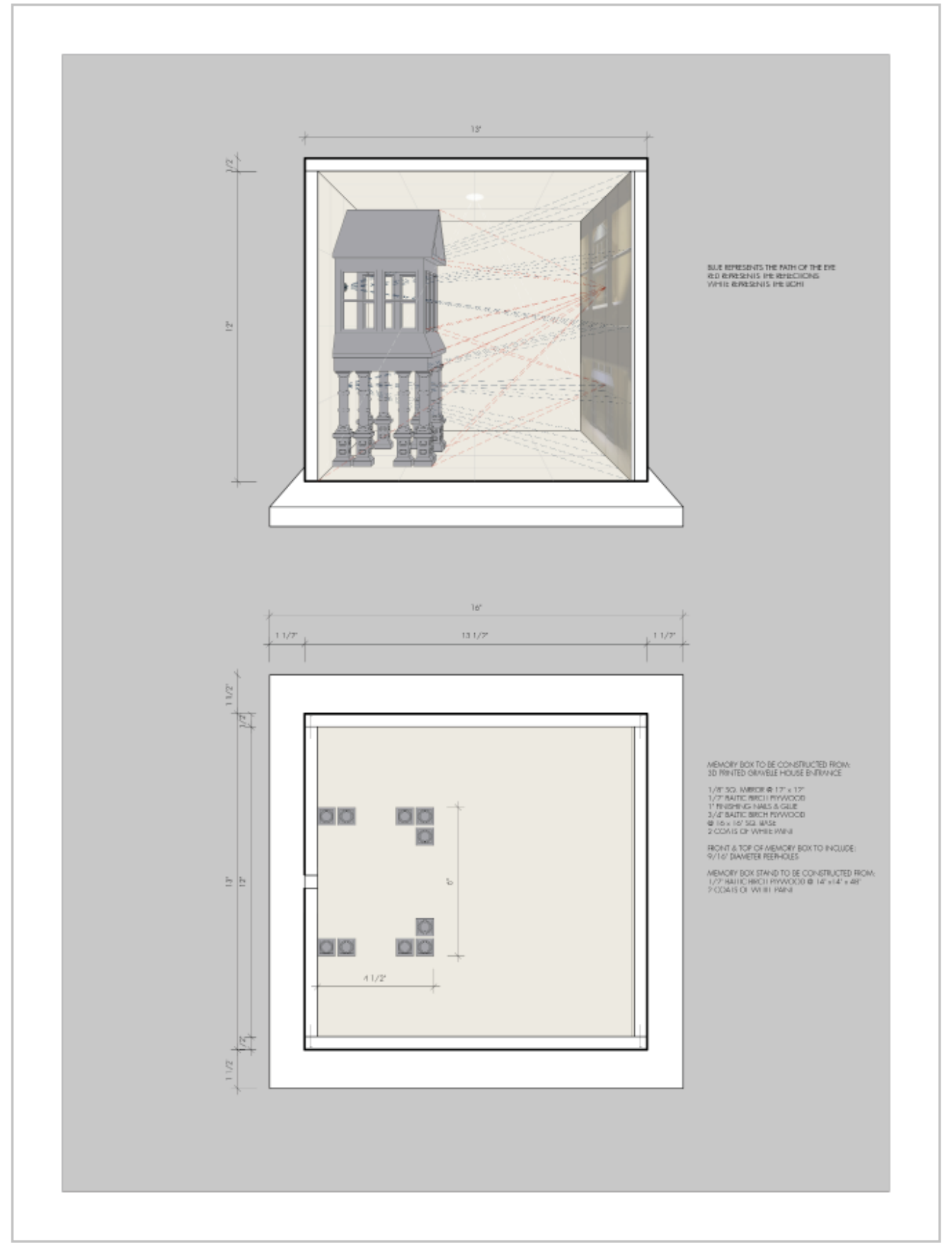

Figure 45: Memory Box 3 Construction 


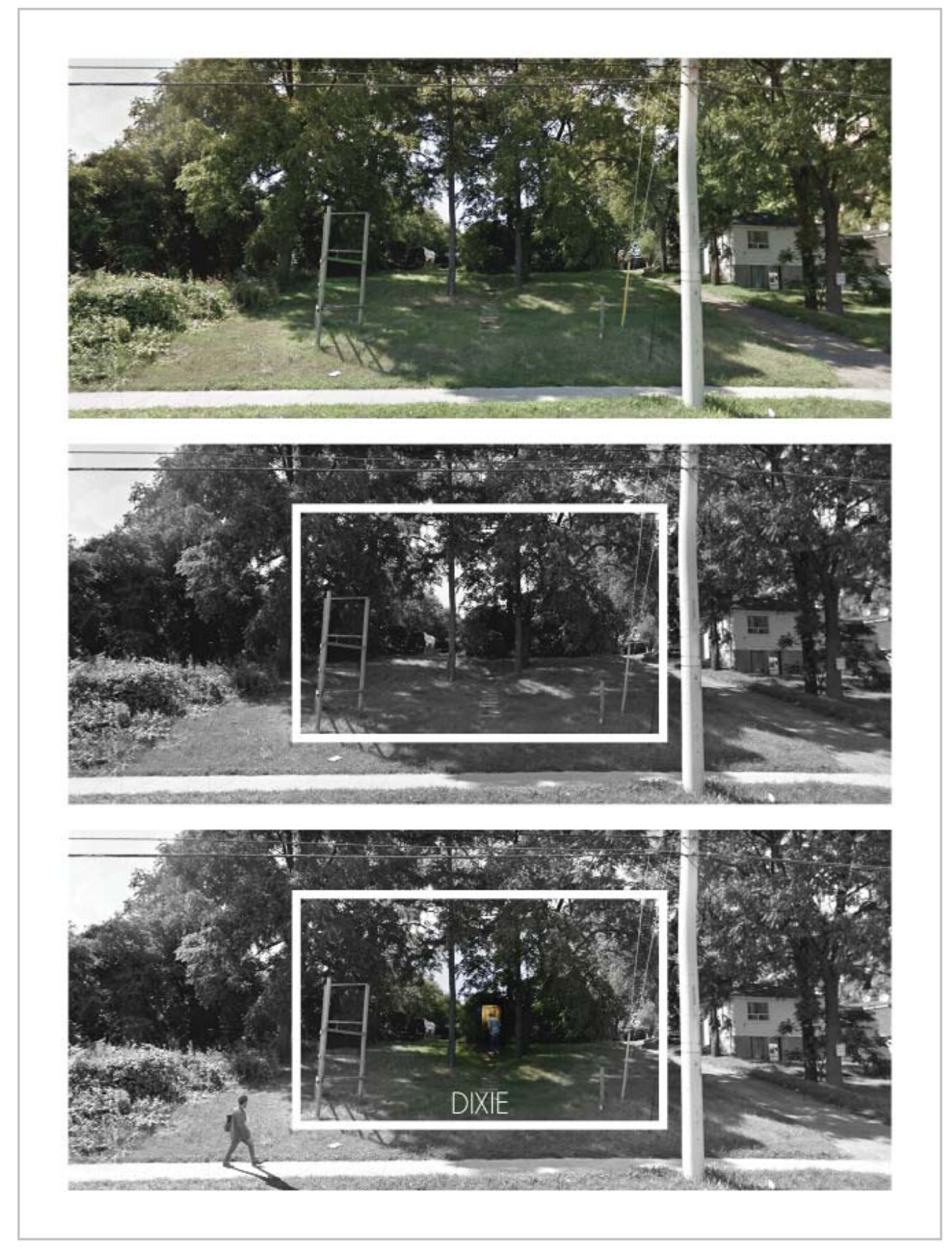

Figure 46: Full Scale Installation 


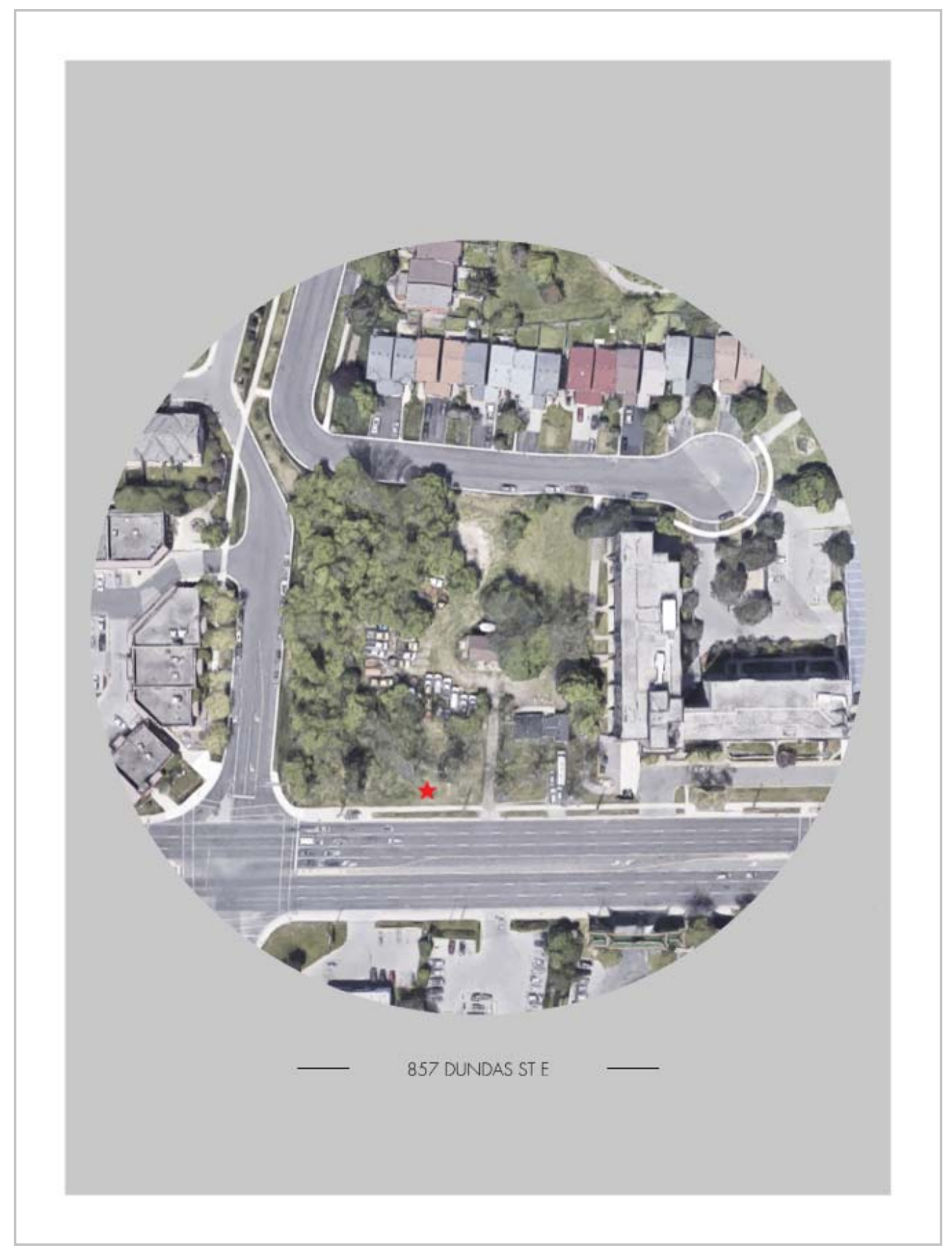

Figure 47: Installation Location 


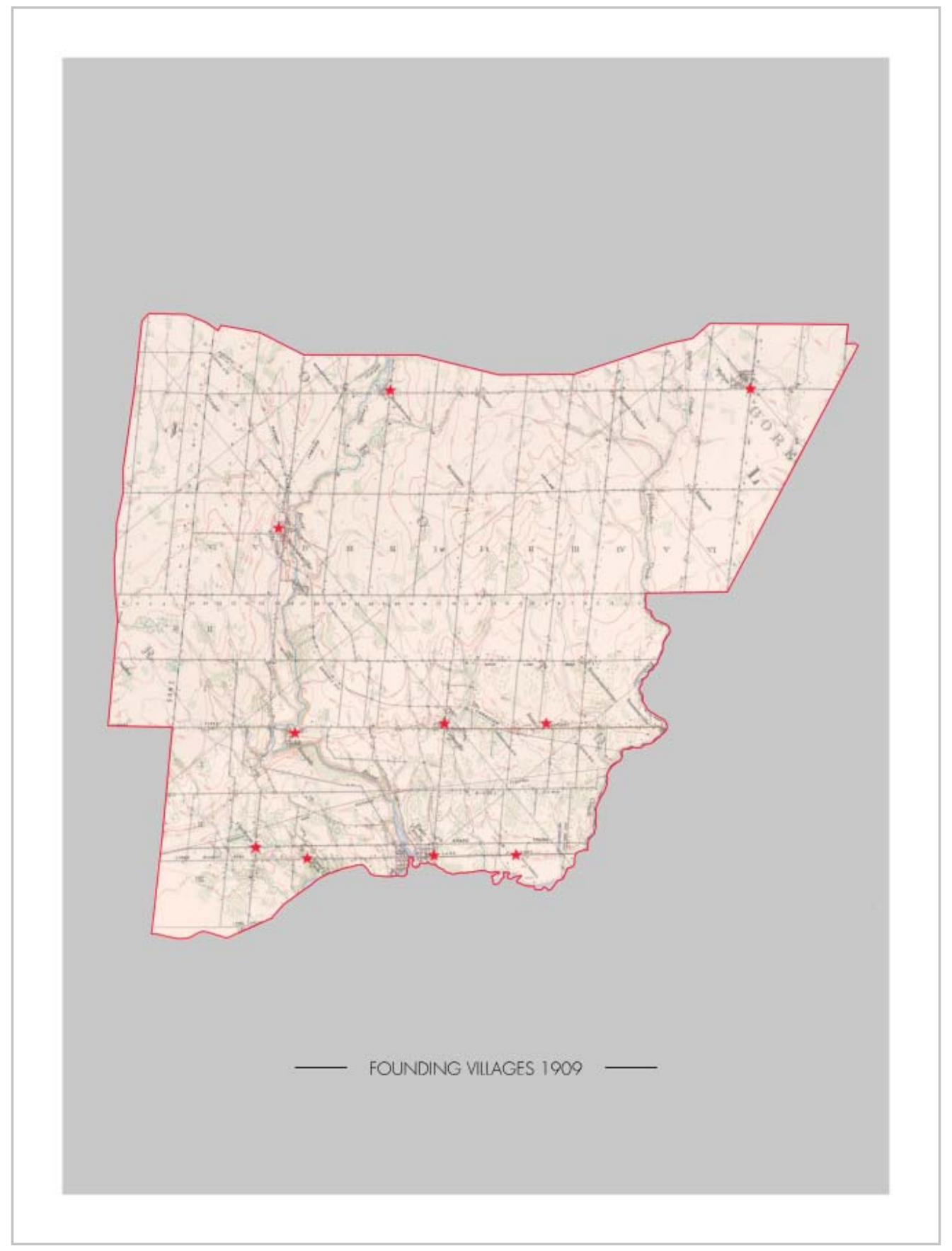

Figure 48: Founding Villages 1909 


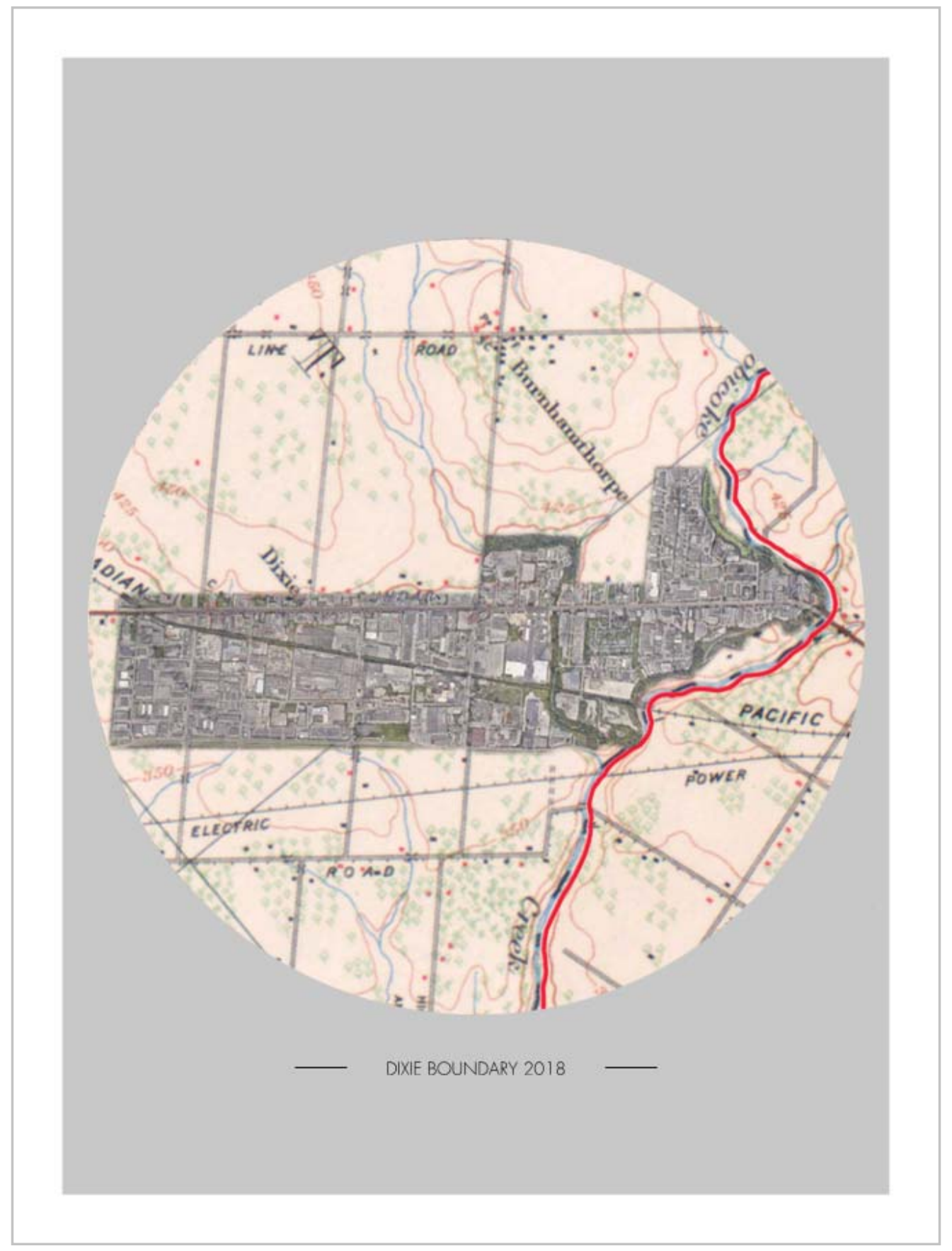

Figure 49: Dixie Boundary 2018 


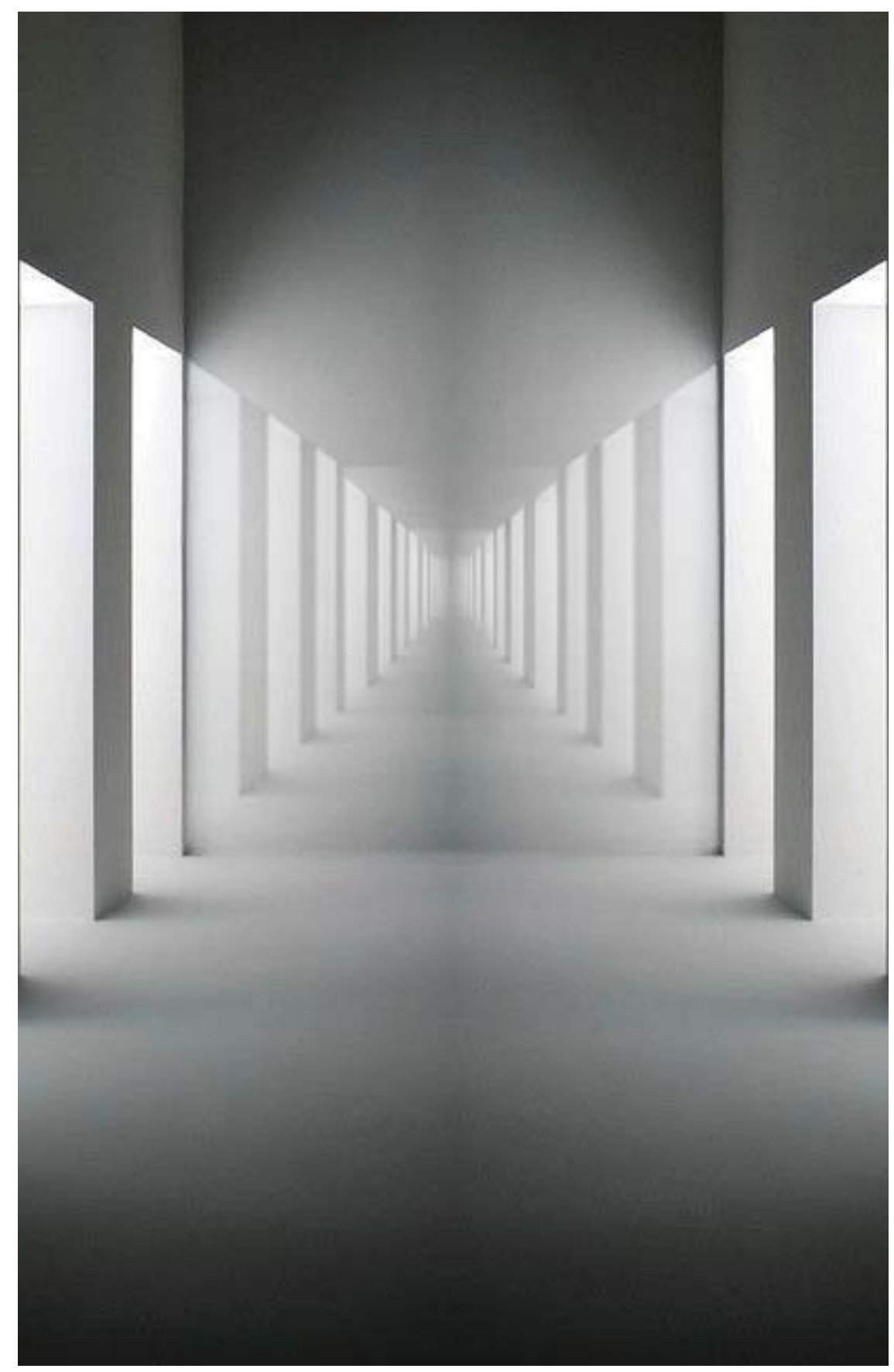

Figure 50: Concept of the Room 


\section{$\mathrm{R} \mathrm{O} \mathrm{O} \mathrm{M}$}

The final aspect of the thesis would focus on a way in which to present the project to the public, while describing the master narrative using the design of a room. This "room" is both a physical installation, and a manifestation of the mind. The design of this installation would manifest how the thesis reflects on the illusion of accessing the past by accessing space. Using vinyl tape to outline the room, tape would be marking the edges of the floor and ceiling during the final defense. The tape is there to manifest an invisible room, without the need of physically constructing it. The installation of the room provides a space to display the memory boxes and allow the viewers to engage with them. Method two involves a deeper use of the viewers' mind. Much like the memory boxes which deny physical access to individual memories, the room can only truly be understood and designed in our minds. The room represents the desire to house memories within a piece of architecture that could be used to trigger memories. While each person may visualize the room differently, I imagine the design to feature a space centered upon a boundless surrounding, where the 
user would enter the room using its main doorway. Upon entering the room, the user would see various thresholds which provide views into individual memories. The far wall opposite the entry would include a large mirror reflecting the thresholds to its side. The resulting reflection would feature an endless corridor, representing a limitless number of memories. As we are not limited by the number of memories we can have, the room should be understood as limitless. While the room is to be understood as limitless, the physical installation will only feature the three memory boxes, which I have described. The decision to only include three physical memory boxes was to further emphasize transmedia storytelling, as a way in which multiple mediums form a collective representation. 

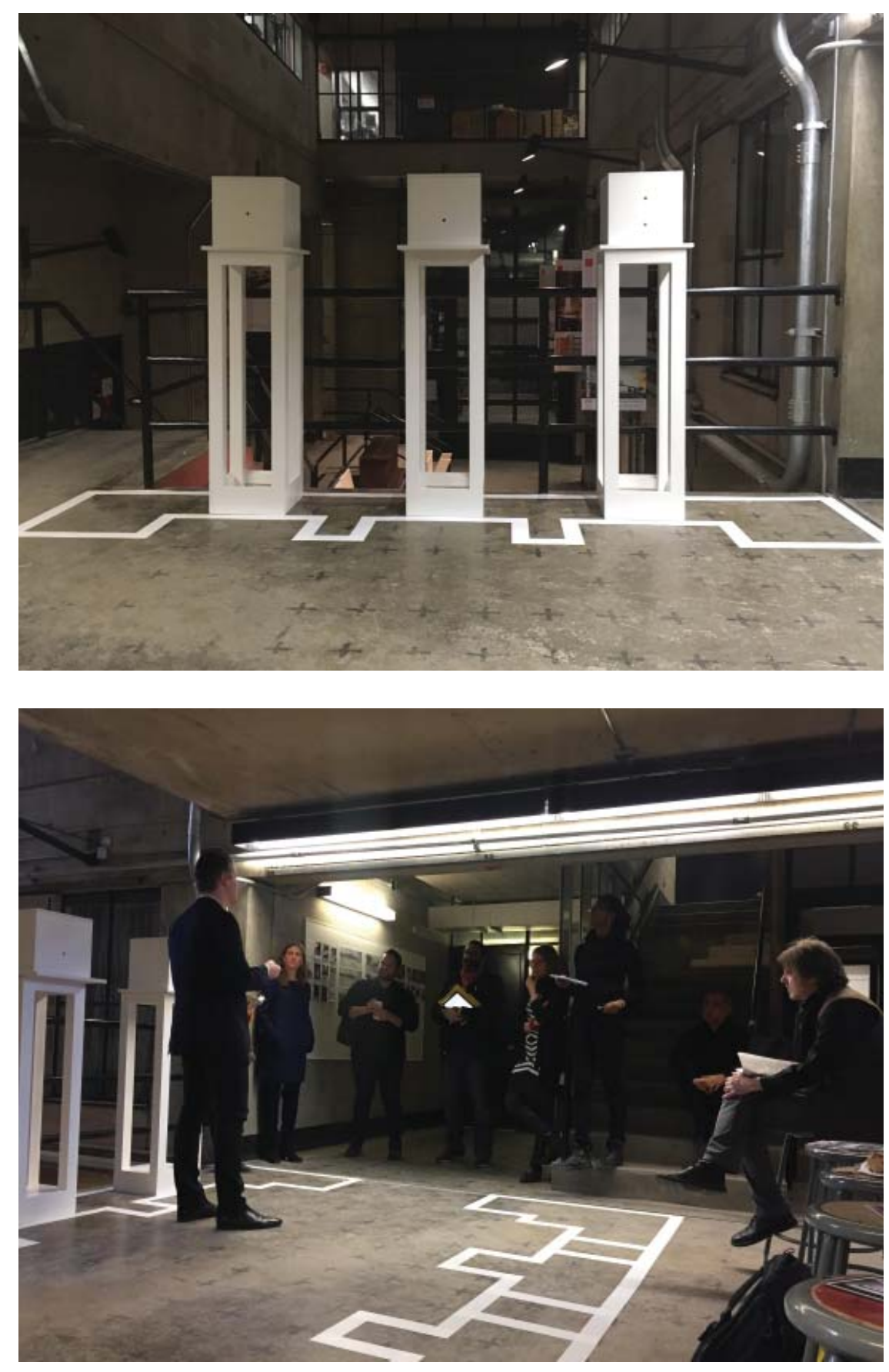

Figure 51: Thesis Defense 


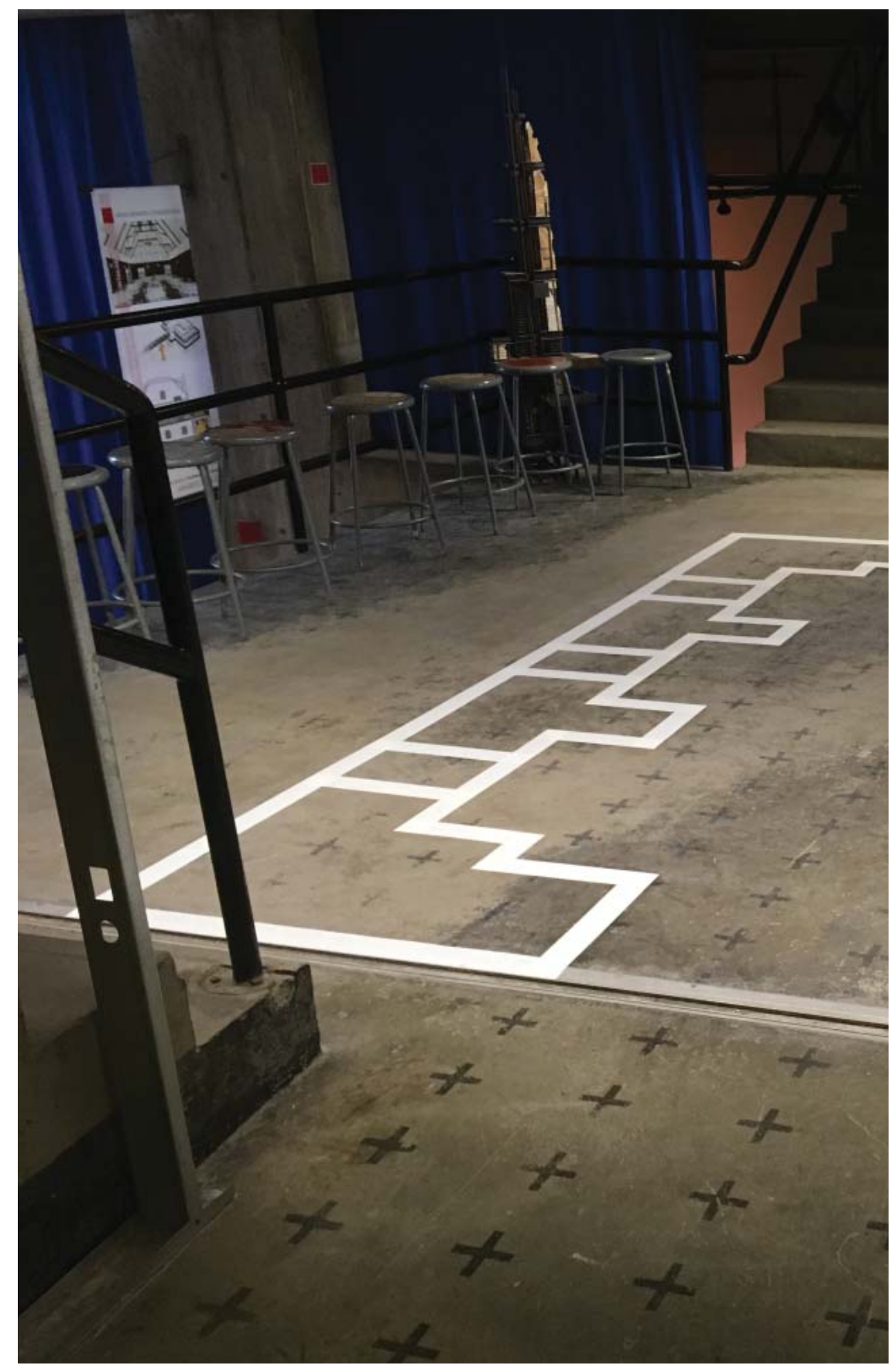

Figure 52: Room Installation 


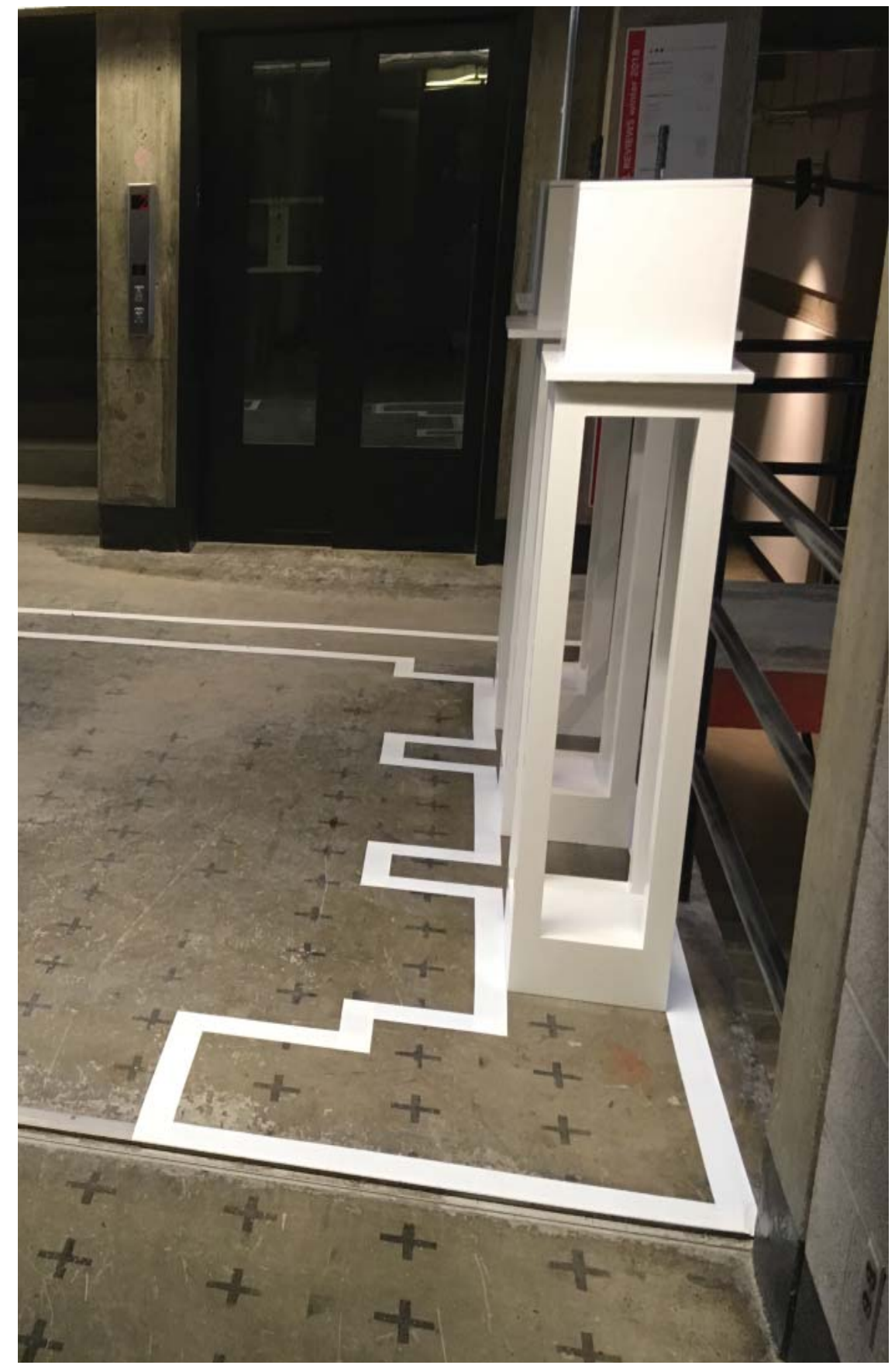

Figure 53: Room Installation 


\section{O N C L U S I O N}

This thesis began by exploring how memory plays an important part in the identity of cities and how our collective memories define a sense of place over time. Focused on the founding villages of Mississauga, Ontario, this thesis looked at the forgotten identities of its early settlements. Having worked with existing site conditions, and through the design of architectural installations, the intent was to activate memory triggers, which presented themselves in various forms, while engaging users with a memory of the towns' past. The design of the thesis would utilize transmedia storytelling as a method in which to represent individual elements and formats to provide a collective narrative.

Having undergone this process, the thesis provided an interesting perspective on the history behind Mississauga. As a former resident, the project gave me better insight surrounding the villages early settlements, and identities. While the thesis would bring into focus the town of Dixie, I imagine that the project could be expanded to further investigate the other founding villages, providing a larger narrative. However as many of the founding villages have also lost great portions of their characteristics, this reveals the complexity of collecting and producing memory triggers. Since much has been lost, or forgotten 
about, the notion of remembering does not seem to truly present itself in the current setting. In a way this thesis invites people to think about the importance of memories, and the identities "we" are leaving behind. 


\section{R E F E R E N C E S}

A Federal, Provincial and Territorial Collaboration. Standards and Guidelines for the Conservation of Historic Places in Canada: A Federal, Provincial and Territorial Collaboration. Ottawa: Parks Canada, 2010.

Bachelard, Gaston, and M. Jolas. 2014. The Poetics of Space. NY, NY: Penguin Books.

Bull, William Perkins. 1939. From MacDonell to McGuigan: The History of the Growth of the Roman Catholic Church in Upper Canada. Toronto: Perkins Bull Foundation.

"Dixie." 2018. Heritage Mississanga. Accessed April 1. https://www. heritagemississauga.com/page/Dixie.

"History." 2018. Heritage Mississanga - History. Heritage Mississauga. Accessed April 1. https://www.heritagemississauga.com/page/ History.

Horra, Dipna, Rachael Hamilton, Allison Macleod, and Jenny Munro. 2013. "Sounds of (Dis)Location: Practice-Base Studies in the Art of Unhomely Spaces." Essay. In Sounds of (Dis)Location, 175-201. Cambridge Scholars Publishing.

Jacobs, Jane M, and Stephen Cairns. 2017. Buildings Must Die - A Perverse View of Architecture. Mit Press Ltd.

Kan, Alan. 2018. "How Much Heritage Does Mississauga Have?" Insauga.com. Accessed April 1. https://www.insauga.com/how-muchheritage-does-mississauga-have. 


\section{R E F E R E N C E S}

Lam, Elsa. n.d. "Rails, Trails, Roads, and Lodgings: Networks of Mobility and the Touristic Development of the "Canadian Pacific Rockies," 1885-1930." The Site Magazine.

McCarthy, Cormac. 1993. All the Pretty Horses. Vol. One. The Border Trilogy. New York: Vintage Books.

"Memory." 2018. Oxford Dictionaries | English. Oxford Dictionaries. Accessed April 1. https://en.oxforddictionaries.com/definition/ memory.

Mississauga, Heritage. 2010. Journey to the Past: The Lost Villages of Mississanga. Mississauga, ON: Heritage Mississauga.

Norberg-Schulz, Christian. 1988. Architecture: Meaning and Place: Selected Essays. New York: Electa / Rizzoli.

Raftery, Anna-Marie. 1996. Passport to the Past: Heritage Tours. Mississauga, Ont.: The Mississauga Heritage Foundation.

Rossi, Aldo, and Peter Eisenman. 1982. The Architecture of the City. Cambridge.

Ruskin, John. 1849. “The Lamp of Memory.” Essay. In The Seven Lamps of Architecture, 203-6. London: John Ruskin.

Scott, Fred. 2008. On Altering Architecture. London: Routledge. 


\section{R E F E R E N C E S}

Vali, A P, and S Nasekhiyan. 2014. "The Concept and Sense of Place in Architecture from Phenomenological Approach." Indian Journal of Fundamental and Applied Life Sciences 4. http://www.cibtech.org/sp.ed/ jls/2014/04/JLS-446-S4-448-AMIRHOOSEIN-CONCEPT.pdf.

Viollet-le-Duc, Eugène. 1854. Dictionnaire Raisonne De L'Architecture. Vol. III. Paris: Viollet-le-Duc.

Wilkinson, Matthew. 2017. Heritage Mississauga Discussion. Personal.

Winton, Tracey Eve. 2016. "The Alternate Reality Game in Architectural Education: An Adventure in Transmedia Storytelling, Placemaking, History, Collaboration, Public Space, \& How Playing Fosters Learning." Rep. The Alternate Reality Game in Architectural Education: An Adventure in Transmedia Storytelling, Placemaking, History, Collaboration, Public Space, \& How Playing Fosters Learning. University of Waterloo.

Wolff, Rachel. 2009. "Marcel Duchamp's Secret Masterpiece." The Daily Beast. The Daily Beast Company. August 28. https://www. thedailybeast.com/marcel-duchamps-secret-masterpiece.

Wong, Liliane. 2017. Adaptive Reuse: Extending the Lives of Buildings. Basel: Birkhäuser. 


\section{E N D N O T E S}

1 A Federal, Provincial and Territorial Collaboration. Standards and Guidelines for the Conservation of Historic Places in Canada: A Federal, Provincial and Territorial Collaboration. Ottawa: Parks Canada, 2010.

2 Winton, Tracey Eve. 2016. "The Alternate Reality Game in Architectural Education: An Adventure in Transmedia Storytelling, Placemaking, History, Collaboration, Public Space, \& How Playing Fosters Learning."

3 "History." 2018. Heritage Mississanga - History. Heritage Mississauga. Accessed April 1. https://www. heritagemississauga.com/page/History.

4 Rossi, Aldo, and Peter Eisenman. 1982. The Architecture of the City. Cambridge.

5 Vali, A.P. and S. Nasekhiyan, 'The Concept and Sense of Place in Architecture from Phenomenological Approach, Indian Journal of Fundamental and Applied Life Sciences vol. 4, S4(2014), 3748.

6 Norberg-Schulz, Christian. 1988. Architecture: Meaning and Place: Selected Essays. New York: Electa / Rizzoli.

7 Raftery, Anna-Marie. 1996. Passport to the Past: Heritage Tours. Mississauga, Ont.: The Mississauga Heritage Foundation. 


\section{E N D N O T E S}

8 "Dixie." 2018. Heritage Mississanga. Accessed April 1. https:// www.heritagemississauga.com/page/Dixie.

9 "Memory." 2018. Oxford Dictionaries | English. Oxford Dictionaries. Accessed April 1. https://en.oxforddictionaries. $\mathrm{com} /$ definition/memory.

10 McCarthy, Cormac. 1993. All the Pretty Horses. Vol. One. The Border Trilogy. New York: Vintage Books.

11 Scott, Fred. 2008. On Altering Architecture. London: Routledge.

12 Viollet-le-Duc, Eugène. 1854. Dictionnaire Raisonne De L'Architecture. Vol. III. Paris: Viollet-le-Duc.

13 Ruskin, John. 1849. "The Lamp of Memory." Essay. In The Seven Lamps of Architecture, 203-6. London: John Ruskin.

14 Ibid, pg.37.

15 Wilkinson, Matthew. 2017. Heritage Mississauga Discussion. Interview by author. 